\title{
Mathematical Descriptions of a One- and Five-Year Old Child for Use in Dosimetry Calculations
}

\author{
J. M. L. Hwang \\ R. L. Shoup \\ G. G. Warner \\ J. W. Poston
}




\section{DISCLAIMER}

This report was prepared as an account of work sponsored by an agency of the United States Government. Neither the United States Government nor any agency Thereof, nor any of their employees, makes any warranty, express or implied, or assumes any legal liability or responsibility for the accuracy, completeness, or usefulness of any information, apparatus, product, or process disclosed, or represents that its use would not infringe privately owned rights. Reference herein to any specific commercial product, process, or service by trade name, trademark, manufacturer, or otherwise does not necessarily constitute or imply its endorsement, recommendation, or favoring by the United States Government or any agency thereof. The views and opinions of authors expressed herein do not necessarily state or reflect those of the United States Government or any agency thereof. 


\section{DISCLAIMER}

Portions of this document may be illegible in electronic image products. Images are produced from the best available original document. 


\section{Printed in the United States of America. Available from National Technical Information Service \\ U.S. Department of Commerce \\ 5285 Port Royal Road, Springfield, Virginia 22161 \\ Price: Printed Copy $\$ 5.50$; Microfiche $\$ 2.25$}

This report was prepared as an account of work sponsored by the United States Government. Neither the United States nor the Energy Research and Development Administration, nor any of their employees, nor any of their contractors, subcontractors, or their employees, makes any warranty, express or implied, or assumes any legal liability or responsibility for the accuracy, completeness or usefulness of any information, apparatus, product or process disclosed, or represents that its use would not infringe privately owned rights. 
ORNL/TM-5293

Contract No. W-7405-eng-26

HEALTH PHYSICS DIVISION

MATHEMATICAL DESCRIPTIONS OF A ONE- AND

FIVE-YEAR OLD CHILD FOR USE IN

DOSIMETRY CALCULATIONS

J. M. L. Hwang, R. L. Shoup, G. G. Warner

and J. W. Poston

MARCH 1976

Submitted by J. M. L. Hwang to the Graduate School of the University of Tennessee

in partial fulfillment of the requirements

for the degree of

Master of Science

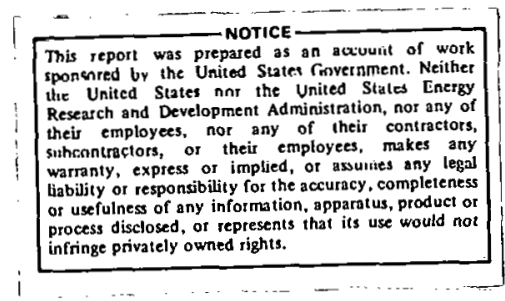

OAK RIDGE NATIONAL' LABORATORY

Oak Ridge, Tennessee 37830

operated by

IJNION CARBIDE CORPORATION

for the

ENERGY RESEARCH AND DEVELOPMENT ADMINISTRATION 


\section{THIS PAGE}

\section{WAS INTENTIONALLY \\ LEFT BLANK}




\section{ACKNOWLEDGMENTS}

The authors are indebted to Dr.W. S. Snyder for the ideas and assistance he gave in designing the organs representing the heart and the liver. Specfal acknowledgment goes to Dr. E. M. Smith who provided the biological data and helped with the calculation of the absorbed dose. The authors acknowledge also the encouragement of $\mathrm{Dr}$. S. J. Adelstein, Shields Warren Radiology Laboratory, during the course of this research.

One of us (JMLH) is grateful for the instruction and guidance given by Professors R. J. Lovell, M. F. Fair, and R. W. Lide of The University of Tennessee Department of Physics and Astronomy.

We wish to express our thanks to J. P. Hickey for his kind help in preparing all the figures. In particular, we wish to express our gratitude to Mrs. N. L. Barringer and Mrs. K. M. Branam for their patience and technical assistance in preparing this manuscript for publication.

This research was sponsored in part through an Interagency Agreement with the Bureau of Radiological Health, Food and Drug Administration. The authors wish to thank Dr. Marvin Rosenstein, Division of Electronic Products, BRH, for his support and encouragement during the course of this research.

This research was performed in the Health Physics Division of the Oak Ridge National Laboratory which is operated for the Energy Research and Development Administration by the Union Carbide Corporation. 
THIS PAGE

\section{WAS INTENTIONALLY \\ LEFT BLANK}




\section{ABSTRACT}

Estimating absorbed doses to children from external and internal radiation sources has become important to the nuclear industry and nuclear medicine. Previous methods for estimating absorbed doses to children were calculated from shrunken versions of the Snyder-Fisher phantom. However, the child is not merely an adult shrunk by a constant factor. The size and shapes of many organs are not those of the adult reduced by some factor, and this undoubtedly affects the dose to the various organs from a source in any one of them. To mitigate uncertainties in absorbed dose which may be introduced in using shrunken phantoms, two pediatric phantoms were developed.

Mathematical representations of a one-year old and a five-year old human have been designed. The phantoms consist of head, trunk and leg regions with a skeletal system and twenty-two internal organs, each. The mathematical descriptions of these phantoms have been coded Into Fortràn computer language for use with a Mnnte-Carlo photọn transport code. This computer code was used to calculate absorbed fractions of energy deposited in different target organs from a radionuclide deposited uniformly in a source organ.

Absorbed dose calculations were performed for two $99 \mathrm{mT}$ c labeled pharmaceuticals. Photon absorbed fraction estimates for the pediatric phantoms from Monte-Carlo calculations were combined with biological data to estimate dose distributions in one-year old and five-year old children. 


\section{THIS PAGE}

\section{WAS INTENTIONALLY LEFT BLANK}




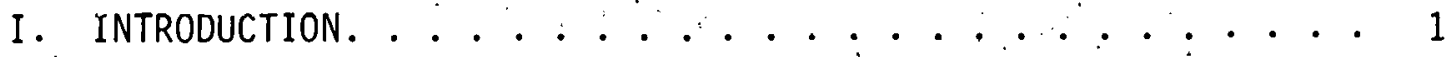

II. THEORY. ......................... 5

Interaction of Photons with Matter. ......... 5

Monte Carlo Technique . . . . . . . . . . 9

Absorbed Dose Calculations. : . . . . . . . . $\because . .12$

III. MATHEMATICAL PHANTOMS . . . . . . . . . . 15

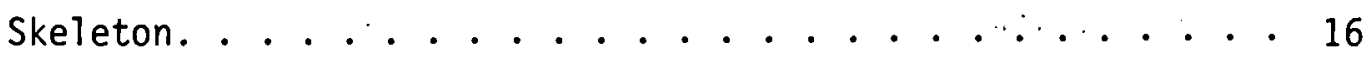

Bone Marrow . . . . . . . . . . . . . . $\because . .18$

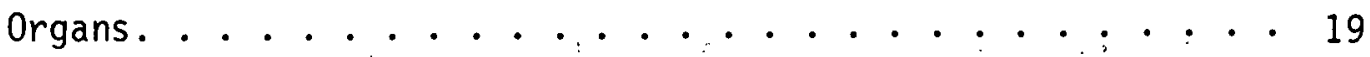

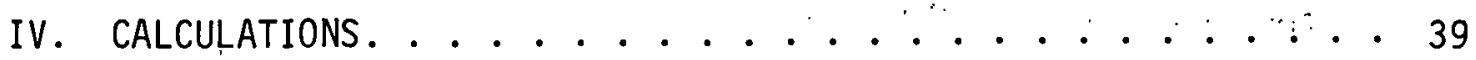

Monte-Carlo Code. . . . . . . . . . . . 39

Biological Data for Dose Calculations . . . . . . . 44

1. ${ }^{99 m}$ Tc Sulfur-Colloid. . . . . . ..$\therefore .44$

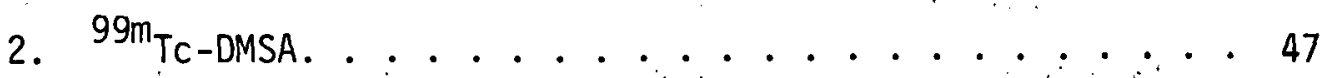

V. SUMMARY. ........................... 57

REFERENCES. . . . . . . . . . . . . . . . 59

APPENDIXES. . . . . . . . . . . . . . . . 65 


\section{LIST OF TABLES}

TABLE

PAGE

1. Summary - Physical Dimensions of the One-Year and Five-Year 0ld Phantoms. .............. 17

2. The Distribution of Active Bone Marrow in Children. . . . . 20

3. Masses of Red and Yellow Marrow and Bone in the OneYear 0ld Child Phantom. . . . . . . . . . . . . 21

4. Masses of Red and Yellow Marrow and Bone if the FiveYear old lhild Phantom. . . . . . . . . . . . . 222

5. Summary of Organs for the One-Year and Five-Year

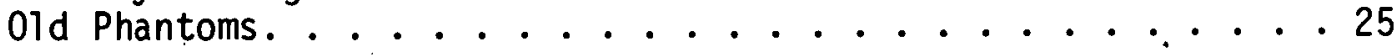

6. Sample Output from the Monte-Carlo Code for the OneYear-01d Phantom Using the Kdineys as a Source Organ. . . . . . 43

7. Absorbed Fractions for the Photon Spectrum of ${ }^{99 \mathrm{~m}} \mathrm{Tc}$ for the One-Year-0ld Phantom. . . . . . . . . . 50

8. Absorbed Fractions for the Photon Spectrum of ${ }^{99 \mathrm{~m}_{\mathrm{TC}}}$ for the Five-Year-01d Phantom . . . . . . . . . . . . 51

9. Absorbed Dose to Selected Organs in the One-Yeár 0ld Phantom per $\mu \mathrm{C} i$ of Administered Activity of

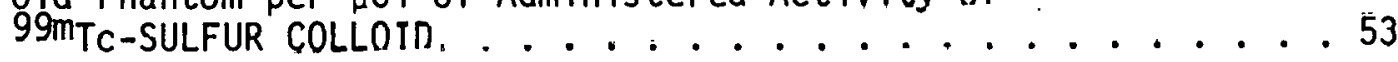

10. Absorbed Dose to Selected Organs in the Five-Year Old Phantom per $\mu \mathrm{C} i$ of Administered Activity of

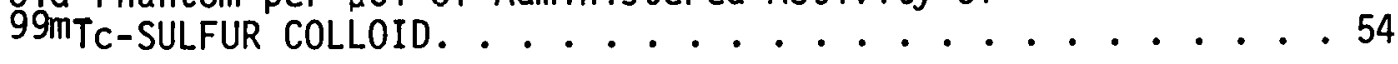

11. Absorbed Dose to Selected Organs in the One-Year Old Phantom per $\mu \mathrm{Ci}$ of Administered Activity of 99mTC-DMSA.

12. Absorbed Dose to Selected Organs in the Five-Year 81d Phantom per $\mu \mathrm{Ci}$ of Administered Activity of $9 \mathrm{~m}_{\mathrm{TC}-\mathrm{DMSA}} \ldots \ldots \ldots \ldots 6$ 


\section{LIST OF FIGURES}

FIGURE

PAGE

1. Anterior View of the Principal Organs in the Head and Trunk of the Phantoms Used for the One-Year 01d and

the Five-Year 01d. . . . ................... . . 24

2. X-Y Sectional Plots of the One-Year 01d Phantom Showing the Upper Leg and Hip Region . . . . . . . . . . . . . . . 27

3. $X-Y$ Sectional Plots of the One-Year 01d Phantom Showing the Lower Abdomen. . . . . . . . . . . . . . . . . . 28

4. X-Y Sectional Plots of the One-Year 01d Phantom Showing the Upper Abdomen. . . . . . . . . . . . . . ... . . . 29

5. X-Y Sectional Plots of the One-Year 01d Phantom Showing the Chest Region . . . . . . . . . . . . . . . . 30

6. $X-Y$ Sectional Plots of the One-Year 01d Phantom Showing the Shoulder and Head Regions: . . . . . . . . . . . . . 31

7. X-Z Sectional Plots of the One-Year 01d Phantom. . . . . . . 32

8. X-Y Sectional Plots of the Five-Year 01d Phantom Showing the Upper Leg and Hip Region . . . . . . . . . . . . . . . . 33

9. X-Y Sectional Plots of the Five-Year 01d Phantom Showing the Lower Abdomen. . . . . . . . . . . . . . . . . 34

10. X-Y Sectional Plots of the Five-Year 01d Phantom Showing the Upper Abdomen. . . . . . . . . . . . . . . . . 35

11. X-Y Sectional Plots of the Five-Year 01d Phantom Showing the Chest Region ...................... . 36

12. X-Y Sectional Plots of the Five-Year 01d Phantom Showing the Shou?der and Head Regions. . . . . . . . . . . . . 37

13. X-Z Sectional Plots of the Five-Year 01d Phantom . . . . . . 38

14. Isomeric Level Decay of $99 \mathrm{~m} T \mathrm{~T}$, Decay Data and Equilibrium Dose Constants. . . . . . . . . . . . . . . . . 52

A-I. The One-Year 01d Phantom . . . . . . . . . . . . . 66

A-II. Detailed View of Scapulae and Clavicles. . . . . . . . . 72 
A-III. Mathematical Models for the Bladder, Kidneys, Pancreas, Uterus, Spleen and Adrenals. . . . . . . . . . . 75

A-IV. Mathematical Models for the Heart, Liver, Brain and Lungs. . . . . . . . . . . . . . . . . . . 77

A-V. Mathematical Model for the Gastrointestinal Tract.. . . . 81

A-VI. Mathematical Models for the Thyruid, Testes, Ovaries, and Thymus................... . 84

A-VII. Sections of the Mathematical Thyroid at Various Heights for the Chlldren Phantoms. . . . . . . . . . . 86

B-I. The Five-Year 01d Phantom. . . . . . . . . . . 89 


\section{CHAPTER I}

\section{INTRODUCTION}

The first official recommendations of precautionary measures for ionizing radiations came in 1916 from the British Roentgen Society. Since that time, there have been general recommendations for radiation protection by various councils and commissions. "The International Congress of Radiology and the National Council on Radiation.Protection and Measurements (USA) have made: recommendations on the levels of maximum permissible exposure to ionizing radiation (ICRP, 1.965; ICRP, 1959; NBS, 1959). The application of these limits in radiation protection practices requires an accurate determination of absorbed doses. In nuclear medicine the determination of the radiological hazard to patients who are administered radiopharmaceuticals requires also an assessment of absorbed doses in organs from a radioactive material deposited in another organ.

In 1954, the International Commission on Radiological Protection (ICRP) recognized the need: for the standardization of some of the basic assumptions relative to the average $\operatorname{man}$, i.e., the mass and effective radii of the body organs, rates of:ingestion and inhalation, elimination rates, etc., and made the first attempt at defining Reference Man (formerly Standard Man): (ICRP, 1955). This first Reference Man consisted of little more than (1) the specification of the weights of some of the important organs and tissues, (2) specification of intakes of air, water, and a few elements, arid (3) some data on excretion. With increasing use of internally and externally applied radiation, it became necessary to expand the 
concept of Reference Man and to reevaluate the existing parameters. In December of 1963, Committee II of ICRP requested that the Commission establish a task group for the revision and extension of the Reference Man concept. During the formulation of this report members of the Task Group reported on the revision of Reference Man (Snyder, et al., 1966) and on the elemental composition of Reference Man (Tipton, et al., 1966). The Repurt of the ICRP Task Group on Reference Man has been published only rècently (ICRP, 1975).

The development of a reference. man and the subsequent incorporation of this design into computer codes used in absorbed dose calculations (Snyder, et al, 1969 and Snyder, et al., 1974A) has brought a certain sophistication to the area of dosc cstimation. In the past, many geometrical shapes had been used to simulate the human body. For example, Ellett, Callahan and Brownell (1964, 1965) and Reddy, Ellett, and Brownell (1967) used Monte Carlo techniques to determine the absorbed doses delivered by uniform low energy point source gamma-ray emitters in tissue equivalent phantoms. The phantoms included spheres, ellipsoids, and elliptical cylinders ranging in mass from 2.1 to $198 \mathrm{~kg}$. Other authors have used right cịcular cyllnders to simulate not only the huirian body (Jones, et al., 1971) but also the body of small. laboratory animals (Willhoit and Jones, 1970 and Jones, 1971).

With the increased growth of nuclear energy, estimates of absorbed dose to other population groups (e.g. children) were required. In addition, children are being exposed to many nuclear medicine procedures and accurate dose estimates are needed. Fisher 
and Snyder (1966) recognized this problem early and, in fact, reported on the design of six phantoms corresponding to ages 0 (newborn), 1-, 5-, 10-, 15-, and 20-years of age. The 20-year old phantom is the well-known Snyder-Fisher phantom (Fisher and Snyder, 1967) designed according to the data on Reference Man. The phantoms of ages younger than the adult were obtained by shrinking each of the three regions of the phantom (head, trunk and legs) by constant factors chosen to be representative of the particular age. All organs, etc. within each region were "shrunk" isotropically by the same factor and changes in organ shape, location, etc. were ignored. These phantoms have been used extensively in the evaluation of the exposure of children even though it was recognized that these phantoms represented children only to a first approximation (Hilyer and Snyder, 1973 and Poston, et al., 1974).

The physiological geometry of a child is differenc than that of an adult. For example: (1) the weight of the head with respect to total body weight is greater for a child than an adult, (2) the trunk of a child is more cylindrical than that of an adult trunk which is elliptical and (3) some internal organs, such as the thymus gland, are larger with respect to other major organs in the child (than in the adult). Such factors as these may lead to gross uncertainties in calculated dose estimates to children. Preliminary dosimetric studies (Warner, et al., 1974) indicate large differences exist for different age groups. For example, the absorbed dose to the total body can be higher in a child by a factor 10 or more for a particular source administered to a child and to an adult. 
4

The purpose of this research is to develop phantoms for children, 1-year and 5-years of age, and to use these phantoms as the basis for dosimetry studies similar to those of the adult. These mathematical phantoms will be suitable for use in Monte Carlo simulation of many exposure situations. However, only one application will be demonstrated, ie. the children phantoms will be used to simulate an exposure situation typical of that practiced in pediatric nuclear medicine. 


\section{CHAPTER II}

THEORY

Interaction of Photons with Matter

Photons are classified according to their origin, not their quantum energy. Gamma rays are produced in nuclear reactions, whereas $x$-rays are caused by the excitation or removal of orbital electrons or by the deceleration of electrons. The emission of gamma rays is a mechanism by which the energy of excitation of a nucleus can be removed. The excitation or removal of orbital electrons, which precedes the production of $x$-rays, may be accomplished in many ways, including the inelastic scattering of other electrons, the internalconversion phenomenon, and the electron-capture process. The energy released upon the return of the orbital electrons to the ground state appears as $x$-ray. photons, known as fluorescent radiation, or characteristic $x$-rays. The $x$-ray production which accompanies the deceleration of electrons is called bremsstrahlung.

When a photon interacts with matter it can be with an entire atom (photoelectric effect and Rayleigh scattering), or with an electron in an atom (Compton effect and pair production in the field of an electron), or with the atomic nucleus (pair production, etc.). The primary interactions of x-rays and gamma rays with matter involve the production of energetic secondary : charged particles; usually electrons. The biological effects of $x$-rays and gamma rays are in fact the effects of their secondary charged particles on the biological system. 
In photoelectric collisions the entire primary photon energy, hu, is absorbed by the struck atom. One electron, usually from the $K$ or $L$ shell, is then immediately ejected with kinetic energy, $T$, where.

$$
T=h \nu-B E
$$

and $B E$ is the binding energy of the electron. Momentum is conserved by the recoll of the entire residual atom. The energy $B E$ is emitted promptly by the residual atom as characteristic $x$-rays and Auger electrons from the filling of the vacancy in the inner shell. Because the entire atom participates in the interaction, the probability of the photoelectric interaction is described by an atomic cross section $\tau_{a} \mathrm{~cm}^{2} /$ atom. A crude expression is

$$
\tau_{a} \simeq \text { const } \frac{Z^{4}}{(h v)^{3}}
$$

- The angular distribution of photoelectrons per unit solid angle for the nonrelativistic case is given by

$$
d N=\frac{\sin ^{2} \theta}{(1-\beta \cos \theta)^{4}} d \Omega
$$

where $d N$ is the number of photoelectrons ejected in the small solid angle $d \Omega$ making an angle $\theta$ with the incoming photon and $\beta=\mathrm{v} / \mathrm{C}$ is the velocity of the photoelectron expressed as a function of the velocity of light.

The Compton effect is the change of photon wavelength or of frequency upon scattering electrons. For sufficiently high gamma-ray energies, these electrons can be considered as initially unbound and stationary. The application of the laws of conservation of energy and 
momentum to the collision of a primary photon with a free electron leads to the expression

$$
h_{v^{\prime}}=\frac{h_{v}}{1+(1-\cos \theta) h v / \mathrm{mc}^{2}}
$$

where $h \nu^{\prime}$ is the energy of the scattered photon and $\theta$ is the angle between its direction and that of the primary photon. The kinetic energy $E_{k i n}$ of the recuil electron is

$$
E_{k i n}=h v-h v^{-}=h v\left[\frac{(1-\cos \theta) h v / m c^{2}}{1+(1-\cos \theta) h v / m c^{2}}\right] .
$$

Since each electron enters individually into the scattering process, the partial absorption coefficient, $\sigma$, is proportional to $z$. The dependence of $\sigma$ on photon energy has been calculated quantummechanically by Klein and Nishina (Price, 1964). For $h_{\nu} \gg \mathrm{mc}^{2}$ the. expression for $\sigma$ is

$$
\sigma \simeq \frac{\mathrm{NZ}}{\mathrm{hv}}\left(\ln \frac{2 \mathrm{hv}}{\mathrm{mc^{2 }}}+\frac{1}{2}\right)
$$

which is essentially an inverse dependence on $h_{\nu}$. The Klein-Nishina calculation divides the absorption coefficient $\sigma$ into two parts, $\sigma_{s}$ and $v_{a}$. The energy in the scattered photons is taken into account by $\sigma$ 's and a represents the energy absorbed in the recoil electrons, only the latter represents a true energy absorption.

The third main type of interaction is called pair production in which a high-energy quantum interacts with the Coulomb field of an atomic nucleus. The annihilation of the photon produces a positronelectron pair. The interaction can be expressed by $h \nu \rightarrow e^{+}+e^{*}+2 T$, 
with a very small amount of energy going into the recoiling nucleus. A minimum incident photon energy, the threshold energy, of $h v=2 m_{0} c^{2}$ $=1.02 \mathrm{MeV}$ is required for pair production in the field. The atomic cross section, $\kappa_{a}$, for nuclear pair production can be written as $\kappa_{a}=N Z^{2}\left(h v-2 m_{0} c^{2}\right)$ in the vicinity of $1 \mathrm{MeV}$, and $\kappa_{a} \simeq N Z^{2} \ell n h_{v}$ at very high energies. Pair production is an important mode of interaction at photon energies greater lhan $2.5 \mathrm{MeV}$. The energy transferred "locally" from the gamma ray to the positron and the electron causes ionization or excitation which leads to molecular disruption and subseuqent chemical and biological changes.

Considered collectively, the photoelectric effect predominates at low energies; the Compton effect predominates at intermediate energies; and the pair production predominates at high energies. Interaction coefficients for these different processes are complex functions of photon energy and absorber material, and depend on the atomic composition but not upon the chemical or physical state of the absorber. In summary, the $Z$ and $E$ dependence for these three principal photon interactions can be described as follows:

$\begin{array}{lll} & \frac{Z \text {-dependence }}{} & \frac{\text { E-dependence }}{} \\ \text { photoelectric effect } & Z^{4} \mathrm{~cm}^{2} / \text { atom } & \frac{1}{E^{3} E<0.5 \mathrm{MeV}} \\ & & \frac{1}{E} E>0.5 \mathrm{MeV} \\ \text { Compton effect } & Z^{1} \mathrm{~cm}^{2} / \text { atom } & \frac{1}{E} \\ \text { pair production } & Z^{2} \mathrm{~cm}^{2} / \text { atom } & \ln E\end{array}$

(Attix, et al., 1968; Price, 1964; Lapp and Andrews, 1972; Whyte, 1959). 
Monte Carlo Technique.

Monte Carlo calculations provide a direct means of determining the gamma ray energy deposition in phantoms from photon emitters. Monte Carlo techniques are used to determine the average photon energy delivered to a given target region (absorbed fraction) or to a point region (specific absorbed fraction). Random sampling techniques are used to simulate the entire sequence of scattering and-absorption events that follow the emission of a source photon. Such $a$ : sequence is. known as a history and each history consists of a number of photon interactions.

Photon histories are determined using the mass-attenuation coefficients, $\mu_{p e}(e), \mu_{c}(E)$ and $\mu_{p p}(E)$, for the photoelectric, Compton and pair-production interactions, respectively. Because these are calculated from atomic attenuation coefficients and compositions, they have different values for regions with differing composition. For the first step of the procedure, an initial attenuation coefficient, $\mu_{0}$, is selected which is greater than or equal to those of any of the regions, i.e., skeletal, lung and the remainder of the phantom. A potential site for an interaction is chosen by the procedure of first. taking a distance traversed, defined as:

$$
d=-(\ln r) / \mu_{0}
$$

where $r$ is a number selected at random from a uniform distribution of numbers. The coordinates of a point at this distance (from the starting point) are tested to determine its location in the phantom; this region is designated as $i$. One then plays a game of chance with 
probability $\mu_{j} / \mu_{0}$ of acceptance of this as an interaction site where $\mu_{j}$ is the total mass attenuation coefficient for the region. If the outcome of the game is favorable, this site is accepted; if it is unfavorable, the photon is allowed to continue with the same direction and energy, but beginning at point $i$.

In addition to scattering, the photon has a finite probability of absorption which predominates at low energies. Thus very few photons will penetrate to large distances, and the statistics of the estimate will therefore be poor. To compensate partially for this, each photon is given a statistical weight that initially is set at unity. With each Compton scattering interaction, this weight is reduced to allow for the probability of survival, and the photon is allowed to continue. The reduction of weight is expressed by:

$$
w_{n}=w_{n-1} \frac{\mu_{c}\left(E_{n-1}\right)}{\mu\left(E_{n-1}\right)}
$$

in which $W_{n}$ is the weight carried by the photon after the $n^{\text {th }}$ collision and $\mu_{c}\left(E_{n-1}\right)$ and $\mu\left(E_{n-1}\right)$ are the coefficients for Compton scattering and the total coefficient before the $n^{\text {th }}$ collision, respectively. This reduction of the weight carried by the photons is equal to the expectation of a Compton scattering which the photon would have in the actual physical processes. The total flight history of the photon is terminated (1) if it escapes from the phantom, (2) if its energy falls below $4 \mathrm{keV}$ or (3) if its weight falls below $10^{-5}$; in the latter two cases, the energy is considered to be absorbed localíy. The energy deposition for the $n^{\text {th }}$ interaction is 


$$
\begin{aligned}
E_{n}^{*}=W_{n-1} & {\left[\frac{\mu_{p e}\left(E_{n-1}\right)}{\mu\left(E_{n-1}\right)} \cdot E_{n-1}+\frac{{ }_{c}\left(E_{n-1}\right)}{\mu\left(E_{n-1}\right)}\left(E_{n-1}-E_{n}\right)\right.} \\
& \left.+\frac{\mu_{p p}\left(E_{n-1}\right)}{\mu\left(E_{n-1}\right)}\left(E_{n-1}-2 m_{0} c^{2}\right)\right]
\end{aligned}
$$

in which $\mu_{p e}\left(E_{n-1}\right), \mu_{c}\left(E_{n-1}\right)$ and $\mu_{p p}\left(E_{n-1}\right)$ are the mass-attenuation coefficients for the photoelectric, Compton, and pair production processes before the collision at the site considered, respectively, and $m_{0} c^{2}$ is the rest mass energy of an electron. It should be noted that the total energy of the photon is absorbed locally when a photoelectric interaction occurs, and this is also the case for the kinetic energy of the electron and positron produced by pair production. The positron will be annihilated, and two photons of energy $m_{0} c^{2}(\simeq 0.511 \mathrm{MeV})$ will be emitted. The computer code is. designed to take account of these photons since a new photon of energy $0.511 \mathrm{MeV}$ with weight:

$$
2 w_{n-1} \mu_{p p}\left(E_{n-1}\right) / \mu\left(E_{n-1}\right)
$$

and random orientation is started at the site of the pair production and followed independently afterward.

No procedure has been used to take account of the finite range of the electrons and positrons produced. Generally, these ranges are small compared with the diameters of most organs, and the absorbed dose will not change abruptly with distance except at an interface where the composition and density change or at the boundary of the source organ. At such an interface the number of photon interactions 
per unit volume may change abruptly and the change in absorbed dose will be somewhat less abrupt due to the finite range of the secondary particles. However, no attempt is made to estimate boundary effects. An absorbed fraction is estimated for each organ considered as a whole.

Finally, bremsstrahlung may be considered as a further example of a secondary form of radiation which may have an extended range, and may be followed using Monte Carlo methods. But, this has not been done because first the probability of producing a photon with an energy approaching the kinetic energy of the electron is rather small-although greater than zero--and second, the total energy accounted for by bremsstrahlung is very small for these regions and materials (Snyder et al., 1969; Ellett, et al., 1968).

Direct simulation of the gamma-ray histories in which the histories are exact mathematical analogues of the physical events hids been used. Only photoelectric and Compton interactions are considered.

\section{Absorbed Dose Calculations}

Calculations of absorbed dose for both homogeneous and heterogeneous media, irradiated by various types of radiation, are developed around the concepts of the absorbed fraction arid specific absorbed fraction. Absorbed fractions and specific absorbed fractions were obtained from Monte Carlo calculations.

The photon absorbed fraction of photon energy in a target region, $V$, from a source region $r$, can be expressed as: 
where

$$
\phi_{i}(v+r)=\frac{m_{v} \bar{D}_{i}(v+r)}{\tilde{A}_{r} \Delta_{i}}
$$

$$
\begin{aligned}
\phi_{i}(v+r)= & \text { the absorbed fraction in } v \text { from } r, \\
m_{v}= & \text { the mass of the target volume, (in grams), } \\
D_{i}(v+r)= & \text { the mean absorbed dose in target volume from radiation } \\
& \text { of type } i \text { from the source region } r \text { in units of rad, } \\
\tilde{A}_{r}= & \text { the time integral of the source activity (cumulated } \\
& \text { activity) in units of } \mu C i-h r, \\
\Delta_{i}= & \text { the equilibrium absorbed dose constant (the emitted } \\
& \text { photon energy per disintegration) in units of g-rad/ } \\
& \mu C i-h r .
\end{aligned}
$$

For photons of energy $E_{i}(\mathrm{MeV})$ and fractional abundance $n_{i}$, the number of $\boldsymbol{i}$-type photuns per disintegration, $\Delta_{i}$, can be expressed as

$$
\Delta_{i}=2.13 n_{i} E_{i} \quad g-r a d / \mu C i-h r .
$$

The constant. 2.13 is equal to the product of:

$$
\begin{gathered}
1.602 \times 10^{-6}\left(\frac{\mathrm{erg}}{\mathrm{MeV}}\right) \times 10^{-2}\left(\frac{\mathrm{rad}}{\mathrm{erg} / \mathrm{g}}\right) \times 3.70 \times 10^{4}\left(\frac{\mathrm{dis} / \mathrm{sec}}{\mu \mathrm{Ci}}\right) \\
\times 3.60 \times 10^{3}\left(\frac{\mathrm{sec}}{\mathrm{hr}}\right)
\end{gathered}
$$

and has the units g-rad/( $\mu \mathrm{Ci}-\mathrm{hr})$ (MeV/dis).

A more general formulation is obtained by defining the specific absorbed fraction: 


$$
\Phi_{i}(v+r)=\frac{\phi_{i}(V+r)}{m_{v}} \quad g^{-1}
$$

- The absorbed fraction $\phi$, is relatively insensitive to size and shape of source and target when the energy is largely absorbed in a single target $(\phi \rightarrow 1)$. The specific absorbed fraction is relatively insensitive to size and shape of source and target when only a small fraction of the energy is absorbed in a single target $(\phi<<1)$.

The absorbed dose, $\bar{D}_{i}$, can be calculated from:

$$
\bar{D}_{i}(V+r)=\pi_{V} \sum_{i} \Delta_{i} \Phi_{j}(V+r)
$$

where $\tilde{A}_{V}$ is the cumulative activity (Loevinger and Berman, 1968). 
CHAPTER III

MATHEMATICAL PHANTOMS

Mathematical descriptions (phantoms) representing a one-year oldand a five-year old-child were designed in a manner similar to the adult phantom of Fisher and Snyder (1967): The phantoms consist of three principal sections: (1) an elliptical cylinder representing the arms, torso and hips; (2) two truncated cones representing the two legs and feet and attached to this is a small region with a plane front surface to contain an approximation to the testicles; and (3) an elliptical cylinder representing the neck region and the lower portion of the head which is topped by half an ellipsoid. The exterior of the one-year old phantom is shown in Figure A-I and that of the five-year old phantom is shown in Figure $B-I$ (see Appendixes $A$ and $B$ ).

Mathematical representations of a one-year old child of $10.4 \mathrm{~kg}$ weight and $76 \mathrm{~cm}$ height and a five-year old child of $20 \mathrm{~kg}$ weight and 112. $\mathrm{cm}$. height were formulated. The volumes for the whole bodie's of children represented by these phantoms were found through the use of available data of spccific gravity as a function of age. The specific gravity for the one-year old child was found to be 1.017 and that for the five-year old child was 1.019. The specific gravities for children tend to be lower than those for adults. Once the total volume of the body was established, the volume of each part, head, trunk, arms and legs, was partitioned. The volume percentages of the different parts of the total volume were different for each of the different ages. The head section was $25.5 \%$ of the total volume for a one-year old and $16.2 \%$ for a five year old. The trunk section was $50 \%$ 
of the total volume for a one-year old and $52.3 \%$ for a five-year old. The legs section was $15.5 \%$ of the total volume for a one-year old and $23 \%$ for a five-year old. The remaining volume was assigned to the arms, $9 \%$ for a one-year old and $8.5 \%$ for a five-year old. In designing the phantoms, the volumes for trunk and arms were composited and referred to as the volume of the trunk section. For all these sections circumferences were found in the anatomical references, (ICRP, 1975); all of the remaining gross dimensions were then determined. These data are summarized in Table 1.

\section{Skeleton}

The weight of the skeleton was one of the most difficult to determine due to the presence of bone marrow, fat and water. Many investigators have studied only dry, defatted bone or individual bones rather than the whole skeleton. Because it was so difficult to obtain an entire skeleton by dissection, data on the skeleton as a whole were not plentiful.

The total weight of the skeleton was taken as 1.6 kilograms for the one-year old phantom and 2.8 kilograms for the five-year old phantom (ICRP, 1975). The specific gravity of the skeleton was assumed to be 1.4 for the one-year old and the five-year old phantom. There was little information available on the weight or volume for each bone in the skeleton of children. Therefore, the relative volume of each bone was determined by certain proportionalities. This assumption can be expressed as

$$
\left(v_{C}\right)_{S} /\left(v_{A}\right)_{S}=\left(v_{C}\right)_{B} /\left(v_{A}\right)_{B}
$$


TABLE 1

SUMMARY - PHYSICAL DIMENSIONS OF THE ONE-YEAR

AND FIVE-YEAR OLD PHANTOMS

\begin{tabular}{|c|c|c|c|}
\hline & & One-Year & Five-Year \\
\hline Wt: & Total Mass (gms) & 10400 & 20000 \\
\hline S.G.: & Specific Gravity & 1.017 & 1.019 \\
\hline$V:$ & Total Volume $\left(\mathrm{cm}^{2}\right)$ & 10226 & 19621 \\
\hline$c_{1}:$ & Circumference of Trunk $(\mathrm{cm})$ & 49 & 61 \\
\hline$C_{2}:$ & Circumference of Head $(\mathrm{cm})$ & 46.6 & 49.4 \\
\hline$A_{1}:$ & $\begin{array}{l}\text { Major Axis (X-direction) } \\
\text { of the trunk }(\mathrm{cm})\end{array}$ & 8.6 & 11 \\
\hline $\mathrm{B}_{1}:$ & $\begin{array}{l}\text { Minor Axis (Y-direction) } \\
\text { of the trunk }(\mathrm{cm})\end{array}$ & 7 & 8.2 \\
\hline$A_{2}:$ & $\begin{array}{l}\text { Major Axis (Y-direction) } \\
\text { of the head }(\mathrm{cm})\end{array}$ & 8 & 8.8 \\
\hline $\mathrm{B}_{2}:$ & $\begin{array}{l}\text { Minor Axis (X-direction) } \\
\text { of the head }(\mathrm{cm})\end{array}$ & 6.8 & 6.8 \\
\hline$H_{1}:$ & Length of Trunk $(\mathrm{cm})$ & 32 & 42 \\
\hline $\mathrm{H}_{2}:$ & Length of Head $(\mathrm{cm})$ & 17.6 & 19.3 \\
\hline $\mathrm{H}_{3}:$ & Length of Legs $(\mathrm{cm})$ & 26.4 & 50.7 \\
\hline$H:$ & Total Height $(\mathrm{cm})$ & 76 & 112 \\
\hline$r_{1}:$ & Upper Radius of Legs $(\mathrm{cm})$ & 4.3 & 5.5 \\
\hline$r_{2}:$ & Lower Radius of Legs $(\mathrm{cm})$ & 1.7 & 1.7 \\
\hline$C:$ & $\begin{array}{l}\text { Vertical Semi-Axis of } \\
\text { the Ellipsoid of Head }(\mathrm{cm})\end{array}$ & 7 & 7.3 \\
\hline V: & Head $\left(\mathrm{cm}^{3}\right)$ & 2608 & 3180 \\
\hline$V:$ & Arms and Trunk $\left(\mathrm{cm}^{3}\right)$ & 6033 & 11933 \\
\hline V: & Legs $\left(\mathrm{cm}^{3}\right)$ & 1585 & 4514 \\
\hline
\end{tabular}


where $\left(V_{C}\right)_{S}$ is the total volume of the skeleton for the child, $\left(V_{A}\right)_{S}$ is the total volume of the skeleton for the adult, $\left(V_{C}\right)_{B}$ is the total volume of the whole body for the child, and $\left(V_{A}\right)_{B}$ is the total volume of the whole body for the adult. $\left(V_{A}\right)_{S},\left(V_{C}\right)_{B}$, and $\left(V_{A}\right)_{B}$ are known and $\left(v_{C}\right)_{S}$ can be found. The volume of the skeletal bones in each section was determined in the manner outlined above, i.e.,

$$
\begin{aligned}
& \left(v_{C}\right)_{\| S} /\left(V_{A}\right)_{H S}=\left(V_{C}\right)_{H} /\left(v_{A}\right)_{H} ; \\
& \left(v_{C}\right)_{T S} /\left(V_{A}\right)_{T S}=\left(v_{C}\right)_{T} /\left(V_{A}\right)_{T} \ldots . \text { etc. }
\end{aligned}
$$

HS represents the bones in the head section; TS represents the bones in the trunk section. After the volume of the bones in each section was found, the volumes of individual bones in each section were found by applying this proportional method again. The weights, the volumes, and the equations describing the bones for each phantom are given in Appendix $A$ for the one-year old and in Appendix $B$ for the five-year old.

\section{Bone Marrow}

Two types of bone marrow may be distinguished in the adult, namely, red and yellow. Red bone marrow is hematopoetically active. Yellow marrow does not have any hematopoietic activity, being composed mostly of fat. In the new born, all of the bone marrow is red. There is a gradual reduction in the percentage of cellularity of red marrow with age and its replacement by fatty marrow. By the age of twenty, no red marrow generally exists in extremities other than the proximal epiphysis of the femurs and the humerii. The distribution of active 
marrow in the adult is in the skull, clavicles, scapulae, sternum, ribs, spine, pelvis and proximal extremities.

The percentage of the red and yellow bone marrow in the individual bones of the one-year old child and the five-year old child was determined by Shleien (1973). These data are shown in Table 2.

Information on active bone marrow distribution throughout the skeleton is sparse for children. Therefore, in arriving at bone marrow distribution for the children phantoms it is assumed that: (a) while the volume of active bone marrow increased with age, the percentage distribution of the total marrow with respect to skeletal weight remained constant; and (b) the percentage distribution of marrow in individual bones in children is the same as the percentage distribution in adults. The mean weight of the whole bone marrow for the one-year old child was assumed to be 150 grams and for the fiveyear old was 450 grams. There was a small quantity of yellow marrow in the shafts of the tibias and femurs of a one-year old child and for purposes of this model this yellow marrow was neglected. The weight of the red bonc marrow used in the nne-year old phantom was 150 grams and that used in the five-year old phantom was 400 grams. The weights of the two marrow types for the one-year old and five-year old phantoms are given in Tables 3 and 4 . These quantities were assigned to the corresponding regions of bone and were assumed to be distributed uniformly in these regions.

Organs

Mathematical descriptions of the organs were formulated after consideration of the descriptive and schematic material from several 
TABLE 2

THE DISTRIBUTION OF ACTIVE BONE MARROW IN CHILDREN

\begin{tabular}{|c|c|c|c|c|c|}
\hline \multicolumn{4}{|c|}{ One-Year } & \multicolumn{2}{|c|}{$F \cdot$ ve-Year } \\
\hline Site & $\begin{array}{l}\text { Distribution of } \\
\text { Red Bone Marrow } \\
\text { in Skeleton }\end{array}$ & $\begin{array}{l}\text { Red Marr } \\
\text { of Total } \\
\text { Yellow) }\end{array}$ & $\begin{array}{l}\text { ow Fracticn } \\
\text { Marrow (Red \& } \\
\text { in the Bone }\end{array}$ & $\begin{array}{l}\text { Distribution of } \\
\text { Red Bone Marrow } \\
\text { in Skeleton }\end{array}$ & $\begin{array}{l}\text { Red Marrow Fraction } \\
\text { of Total Marrow (Red } 8 \\
\text { Yellow) in the Bone }\end{array}$ \\
\hline $\begin{array}{l}\text { Arms } \\
\text { Upper } \\
\text { Lower. }\end{array}$ & $\begin{array}{l}4.08 \\
1.38 \\
2.70\end{array}$ & : & $\begin{array}{l}1 \\
1 \\
1\end{array}$ & $\begin{array}{l}4.08 \\
1.38 \\
2.70\end{array}$ & $\begin{array}{l}0.8 \\
0.8 \\
0.8\end{array}$ \\
\hline Clavicles & 1.12 & $\cdot$ & 1 & 1.12 & 0.9 \\
\hline $\begin{array}{l}\text { Legs } \\
\text { Upper } \\
\text { Lower }\end{array}$ & $\begin{array}{l}8.81 \\
4.54 \\
4.27\end{array}$ & & $\begin{array}{l}1 \\
1 \\
1\end{array}$ & $\begin{array}{l}8.81 \\
4.54 \\
4.27\end{array}$ & $\begin{array}{l}0.8 \\
0.8 \\
0.8\end{array}$ \\
\hline Pelvis & 34.44 & & 1 & 34.44 & 0.9 \\
\hline Ribs & 13.00 & & 1 & 13.00 & $0.85^{\circ}$ \\
\hline Scapulae & 3.48 & & 1 & 3.48 & 0.9 . \\
\hline $\begin{array}{l}\text { Skul1 } \\
\text { Cranium } \\
\text { Mandible }\end{array}$ & $\begin{array}{l}7.00 \\
6.37 \\
0.63\end{array}$ & $\cdot$ & $\begin{array}{l}1 \\
1 \\
1\end{array}$ & $\begin{array}{l}7.00 \\
6.37 \\
0.63\end{array}$ & $\begin{array}{l}0.9 \\
0.9 \\
0.9\end{array}$ \\
\hline $\begin{array}{l}\text { Spine } \\
\text { Upper } \\
\text { Middle } \\
\text { Lower }\end{array}$ & $\begin{array}{r}28.04 \\
3.14 \\
14.00 \\
10.90\end{array}$ & . & $\begin{array}{l}1 \\
1 \\
1 \\
1\end{array}$ & $\begin{array}{r}28.04 \\
3.14 \\
14.00 \\
10.90\end{array}$ & $\begin{array}{l}0.95 \\
0.95 \\
0.95 \\
0.95\end{array}$ \\
\hline
\end{tabular}

(Shleien, 1973) 
TABLE 3

MASSES OF RED AND YELLOW MARROW AND BONE

IN THE ONE-YEAR OLD CHILD PHANTOM

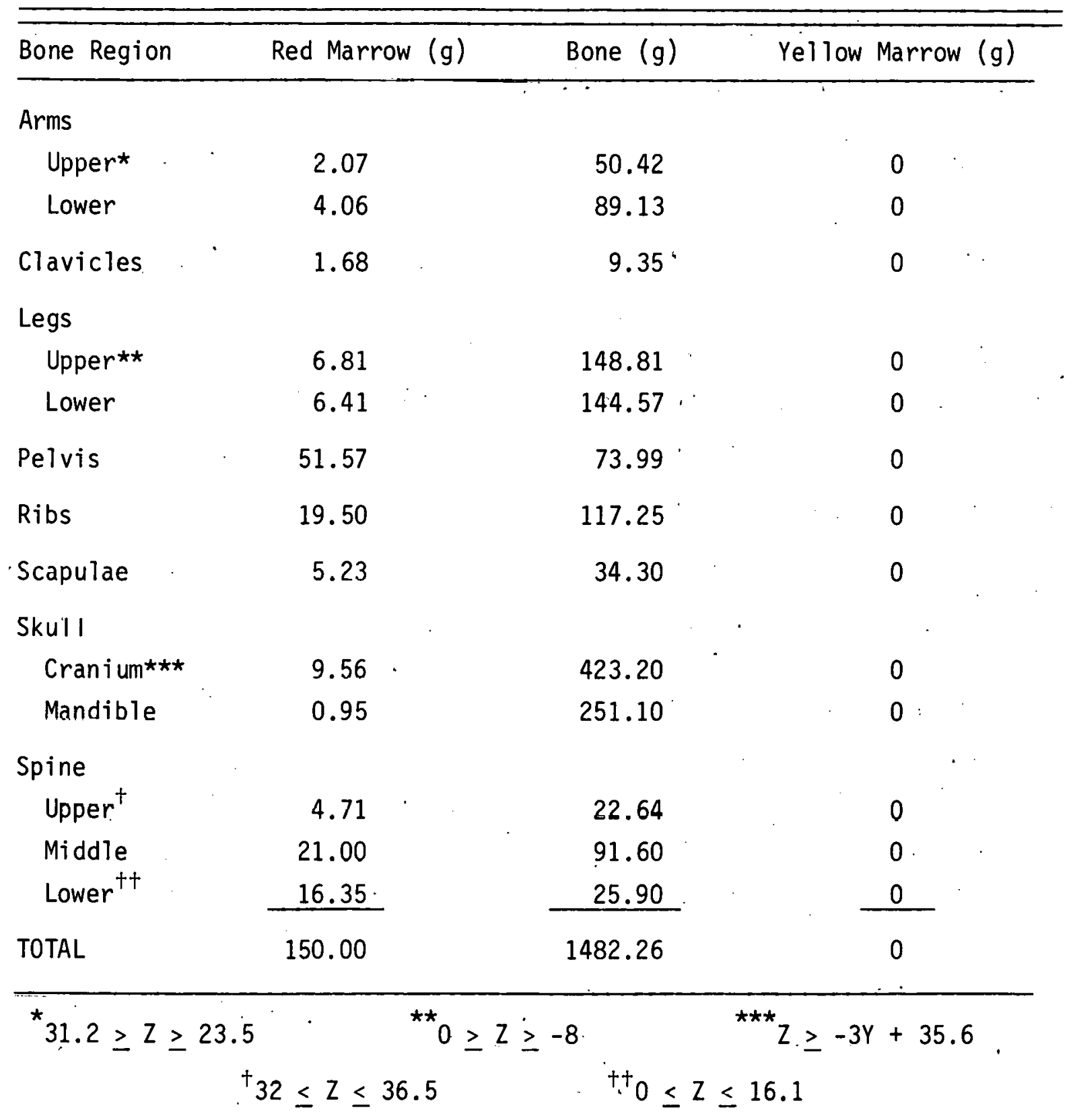


TABLE 4

MASSES OF RED AND YELLOW MARROW AND BONE

IN THE FIVE-YEAR OLD CHILD PHANTOM

\begin{tabular}{|c|c|c|c|c|c|}
\hline Bone Region & Red Marrow & $(g)$. & Bone $(g)$ & Yellow Marrow. & $(g)$. \\
\hline \multicolumn{6}{|l|}{$\overline{\text { Arms }}$} \\
\hline Upper* & 5.52 & & 84.5 & 1.38 & . \\
\hline Lower & 10.84 & . & 148.72 & 2.71 & \\
\hline Clavicles & 4.48 & & 17.22 & 0.50 & \\
\hline \multicolumn{6}{|l|}{ Legs } \\
\hline Upper** & 18.16 & . & 395.13 & 4.54 & . \\
\hline Lower & 17.08 & & . 384.00 & 4.27 & $\cdots$ \\
\hline Pelvis & 137.80 & & 91.10 & 15.31 & \\
\hline Ribs & 52.00 & & 236.74 & 9.17 & \\
\hline Scapulae & 13.96 & & 61.45 & 1.55 & \\
\hline \multicolumn{6}{|l|}{ Skull } \\
\hline Craniumt** & 26.80 & & 449.75 & 2.98 & , \\
\hline Mandible & 2.52 & & 276.47 & 0.28 & \\
\hline \multicolumn{6}{|l|}{ Spine } \\
\hline Upper $^{\dagger}$ & 12.56 & & 44.35 & 0.66 & \\
\hline Middle & 56.00 & 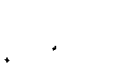 & 159.83 & 2.95 & \\
\hline Lower ${ }^{\dagger \dagger}$ & 4.3. $6 n$ & & 38.09 & 2.30 & . \\
\hline TOTAL & 401.32 & & 2388.15 & 48.60 & \\
\hline$\star$ & & $\star_{0}$ & 14.5 & ${ }^{\star \star \star} Z \geq-3 Y+$ & 46.7 \\
\hline & ${ }^{+} 42 \leq z$ & 47.5 & $t_{0}$ & $\leq 21.1$ & \\
\hline
\end{tabular}


general anatomy references. The representations of the organs by the mathematical equations (given in Appendix A and Appendix B) are only approximate. The goal in constructing these mathematical organs was to obtain the approximate size and shape of an average organ through the use of a few simple mathematical equations. If the size and shape approximate those of the real organ, the dose estimate should be correspondingly accurate. To minimize running time and the cost, the formulas used should be as simple as possible. The tissue region of the phantom had an average density of $1.05 \mathrm{~g} / \mathrm{cm}$. For the lungs a density of $0.3 \mathrm{gm} / \mathrm{cm}$ was used. The volume of each organ was determined from these mathematical descriptions. When there are left and right organs, the equations for only one, the left, are given in the Appendixes. The equations for the other may be obtained by replacing $X$ by $-X$ in the inequalities. The principal internal organs are shown in Figure A-III, A-IV, A-V, A-VI, and A-VII (see Appendix A), which represent the general shape of each organ. Figure 1 shows an anterior view of some of the larger organs and their positions in the phantoms. A brief summary of organ weights and volumes can be found in Table 5.

In order to check the proper positioning of the organs, organ shapes, etc. the mathematical descriptions for these phantoms were coded and checked with a computer plotting program. Results of this program showed that the skeleton and the organs are positioned correctly within the interior of the phantom, i.e. internal organs and bones do not intersect each other. 


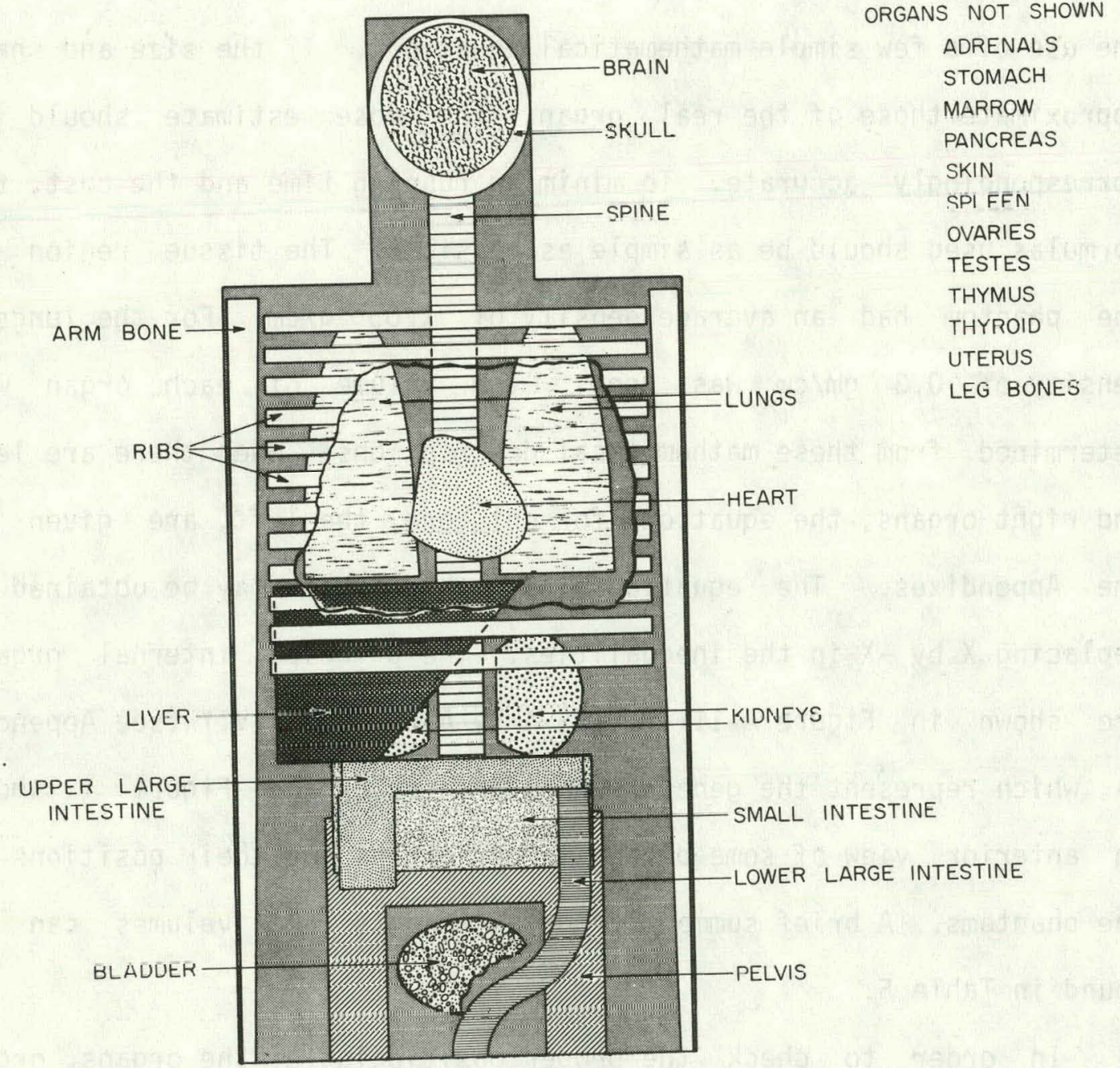

ORNL-DWG 66-8212 A

ORGANS NOT SHOWN

ADRENALS

PANCREAS

SKIN

SPI FFN

TESTES

THYMUS

LEG BONES

FIGURE 1. ANTERIOR VIEW OF THE PRINCIPAL ORGANS IN THE HEAD AND TRUNK OF THE PHANTOMS USED FOR THE ONE-YEAR OLD AND THE FIVE-YEAR OLD. 
TABLE: 5

- SUMMARY OF ORGANS FOR THE ONE-YEAR AND FIVE-YEAR OLD PHANTOMS

\begin{tabular}{lcccr}
\hline \multicolumn{1}{c}{ Organs } & $\begin{array}{r}\text { One-Year } \\
\text { Mass }\end{array}$ & $\begin{array}{c}\text { Five-Year } \\
(\mathrm{g})\end{array}$ & $\begin{array}{c}\text { One-Year } \\
\text { Volume }\end{array}$ & $\begin{array}{c}\text { Five-Year } \\
\left(\mathrm{cm}^{3}\right)\end{array}$ \\
\hline Adrenals & 4.04 & 6.12 & 3.94 & 5.97 \\
Bladder & 8 & 14 & 12.04 & 17.96 \\
Brain & 1005.5 & 1179.3 & 977.2 & 1146.1 \\
G.I. Tract & 27.27 & 52.18 & 25.99 & 49.69 \\
$\quad$ Stomach & 75.90 & 175.95 & 76.92 & 178.32 \\
S.I. ${ }^{*}$ & 26.35 & 46.46 & 25.26 & 44.55 \\
U.L.I. & 21.45 & 40.02 & 20.56 & 38.37 \\
L.L.I. & 48.17 & 91.16 & 46.78 & 88.52 \\
Heart & 68.00 & 115.51 & 64.95 & 110.22 \\
Kidneys & 128.82 & 255.10 & 429.40 & 850.32 \\
Lungs & 303.64 & 608.14 & 289.54 & 575.89 \\
Liver & 0.65 & 1.90 & 0.62 & 1.81 \\
Ovaries & 8.99 & 18.93 & 8.58 & 18.07 \\
Pancreas & 27.30 & 49.62 & 25.71 & 46.72 \\
Spleen & 1612.50 & 2785.15 & 1151.79 & 1989.39 \\
Skeleton & 150.0 & 400.0 & & \\
$\quad$ Red Bone Marrow & 0 & 48.0 & & \\
Yellow Bone Marrow & 21.88 & 30.61 & 21.32 & 29.84 \\
Thymus & 2.38 & 4.85 & 2.26 & 4.62 \\
Thyroid & 1.47 & 1.60 & 1.41 & 1.53 \\
Testes & 1.53 & 2.60 & 1.45 & 2.47 \\
Uterus & & & & \\
\hline
\end{tabular}

*Includes Sma11, Intestine Contents 
The plot routine simply scans diagonally back and forth in a specified plane of a phantom using the mathematically encoded geometries of the organs. When the routine locates an interface between two different organs or media, it plots a point at that position. Examples generated by this plot routine are presented in Figures 2-13. This program has been instrumental in avoiding organ overlap and in developing organ shapes, sizes, and orientations. 

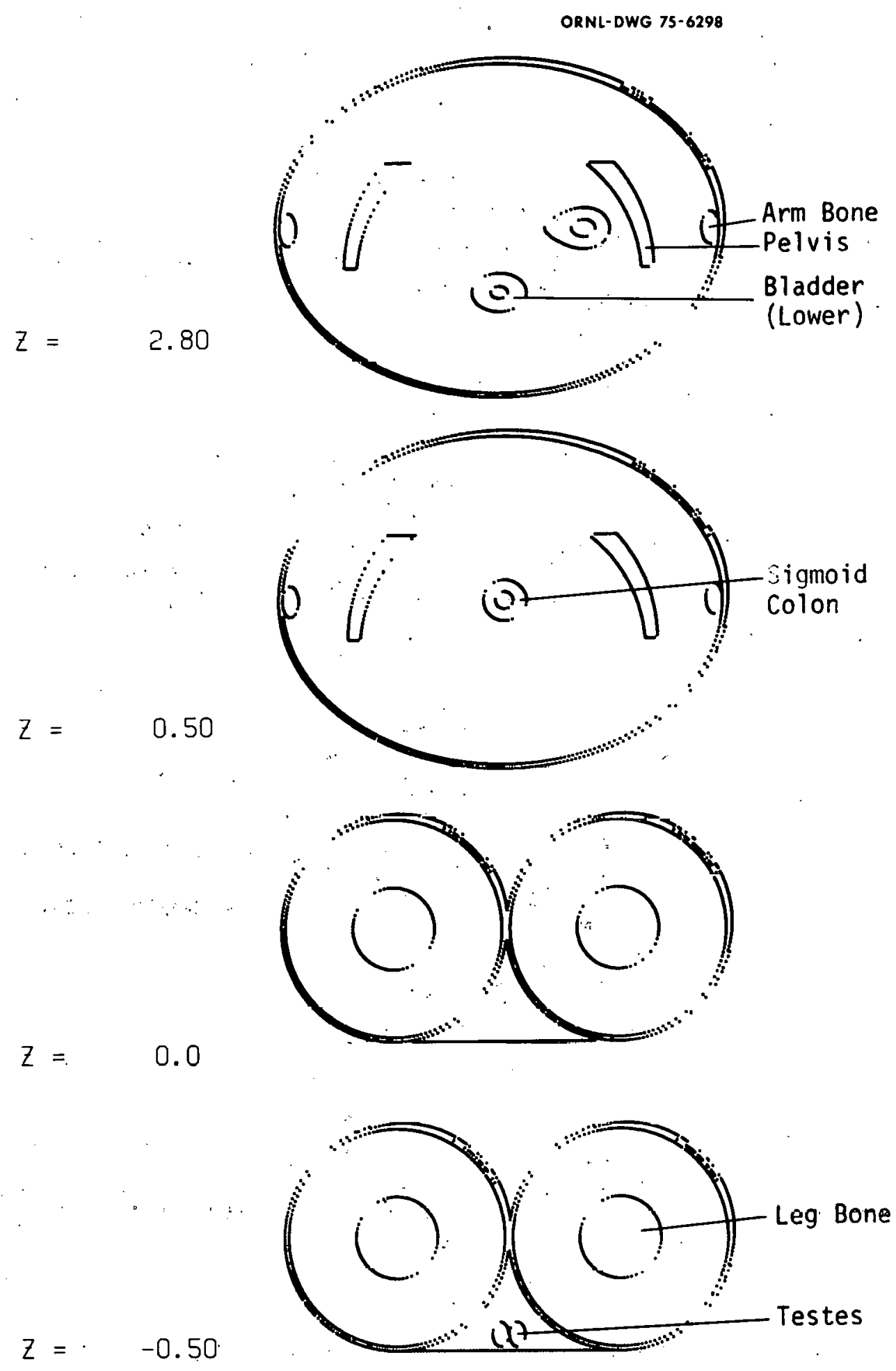

FIGURE 2. X-Y SECTIONAL PLOTS OF THE ONE-YEAR OLD PHANTOM SHOWING THE UPPER LEG AND HIP REGION. 


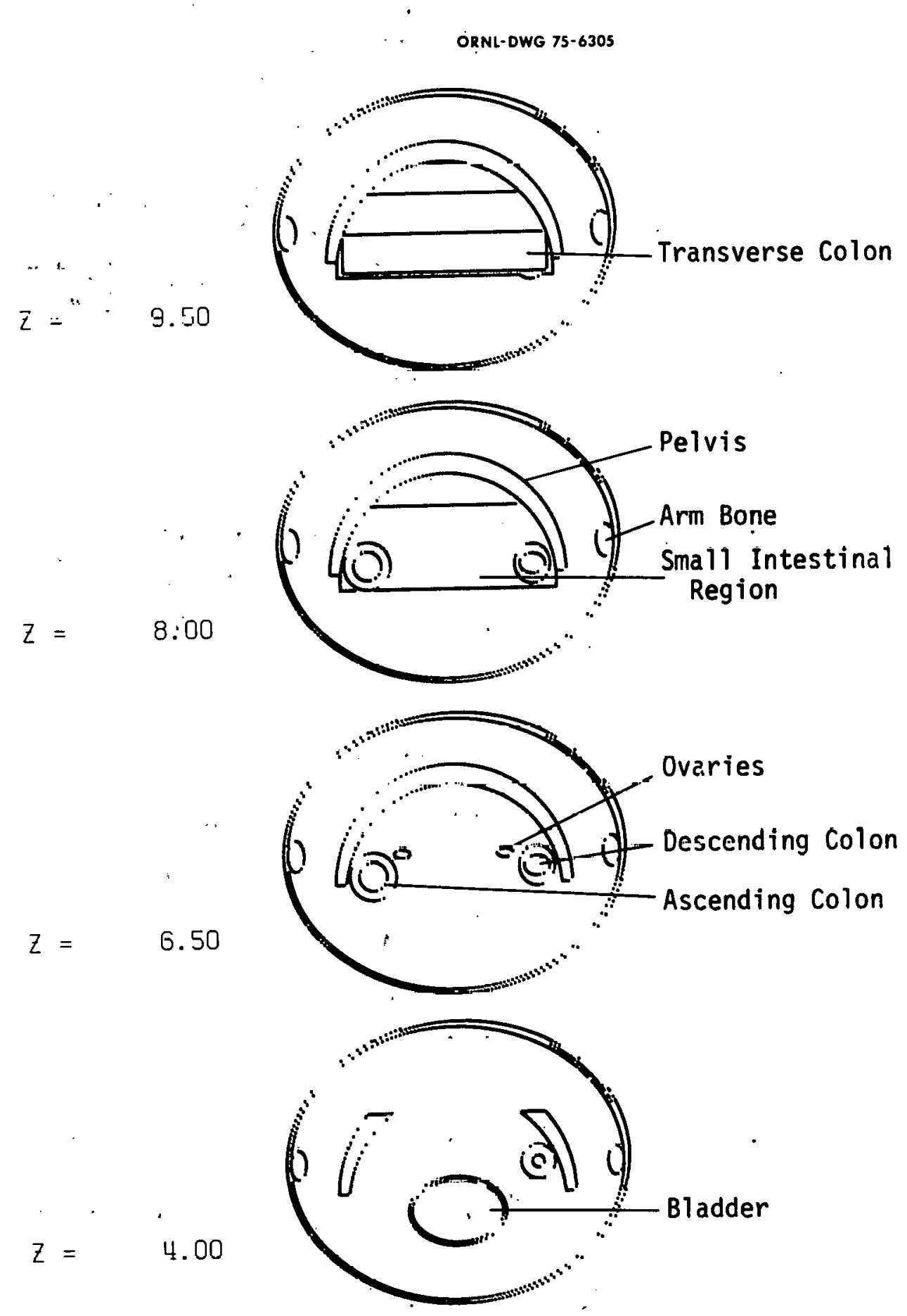

FIGURE 3. X-Y SECTIONAL PLOTS OF THE ONE-YEAR OLD PHANTOM SHOWING THE LOWER ABDOMEN. 

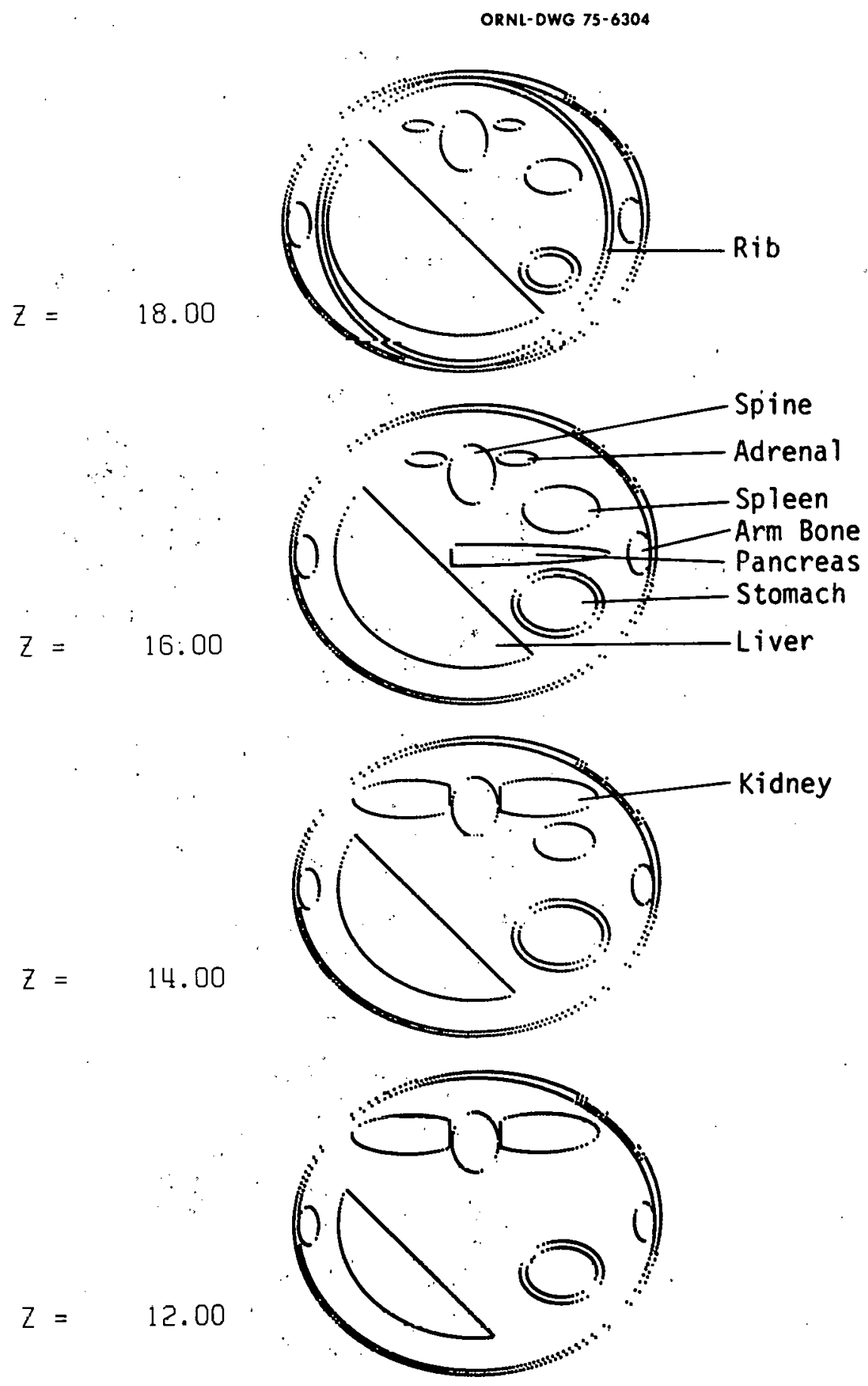

FIGURE 4. X-Y SECTIONAL PLOTS OF THE ONE-YEAR OLD PHANTOM. SHOWING THE UPPER ABDOMEN. 

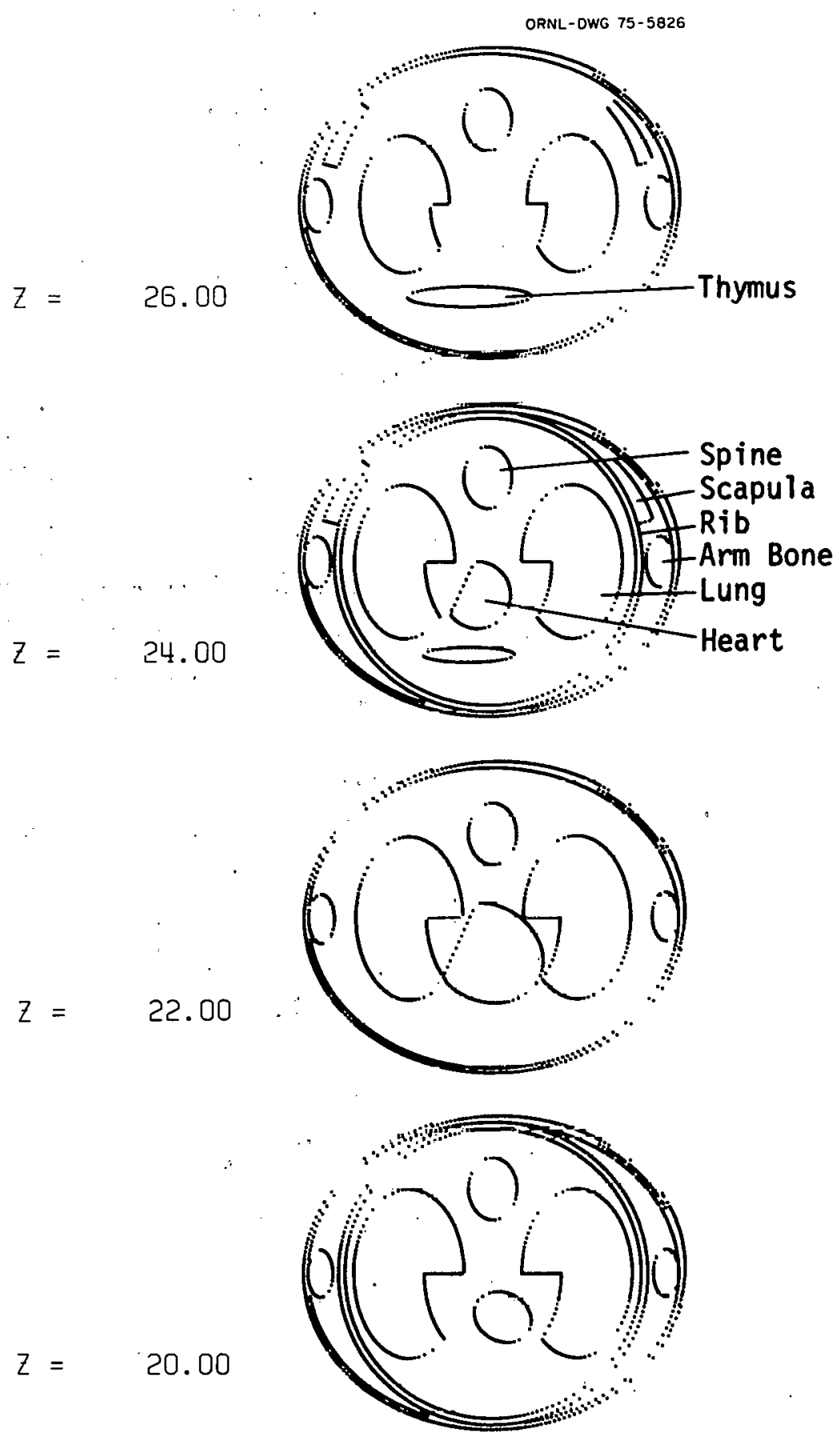

FIGURE 5. $X-Y$ SECTIONAL PLOTS OF THE ONE-YEAR OLD PHANTOM SHOWING THE CHEST REGION. 


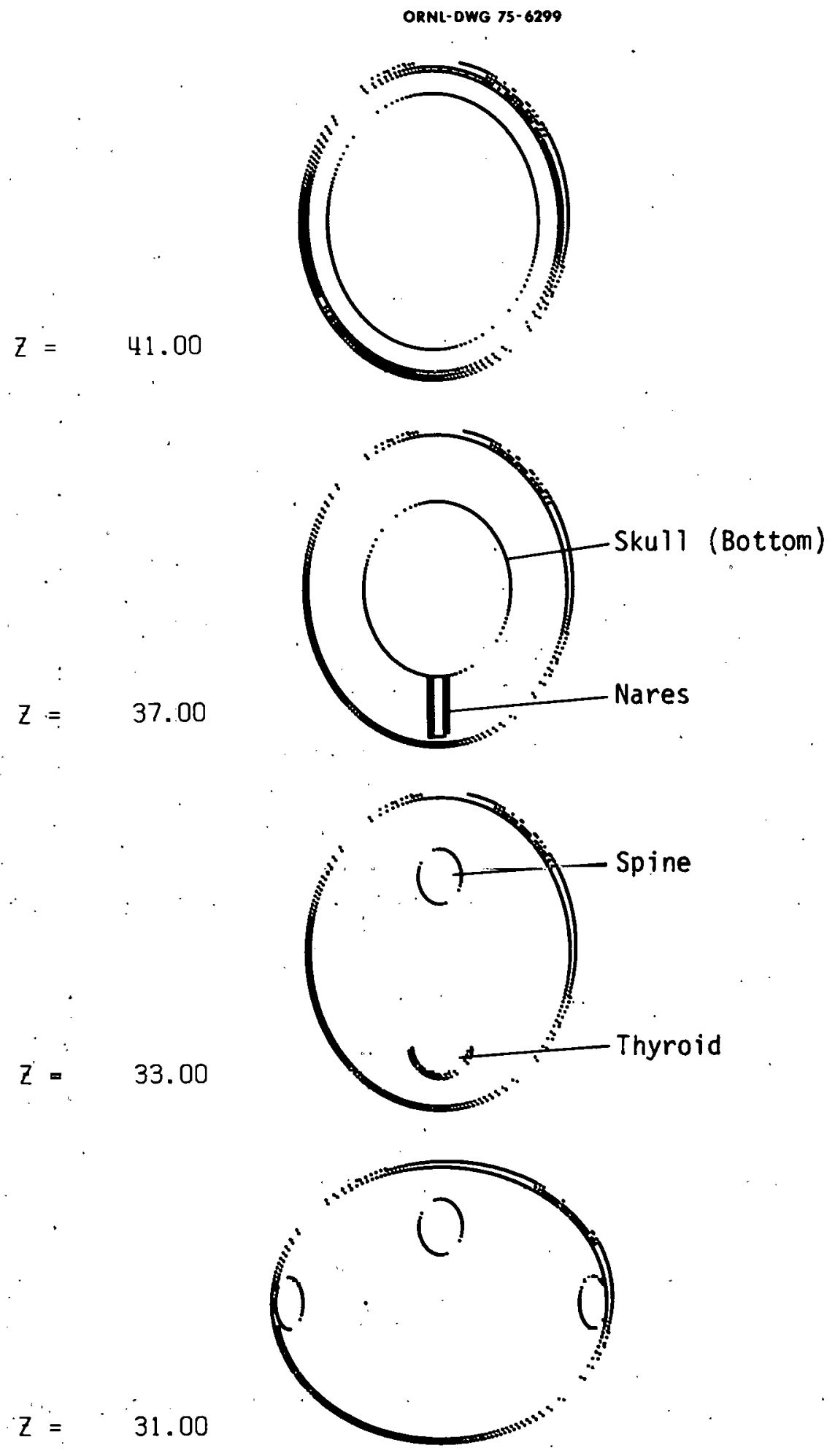

FIGURE 6. X-Y SECTIONAL PLOTS OF THE ONE-YEAR OLD PHANTOM SHOWING THE SHOULDER AND HEAD REGIONS. 


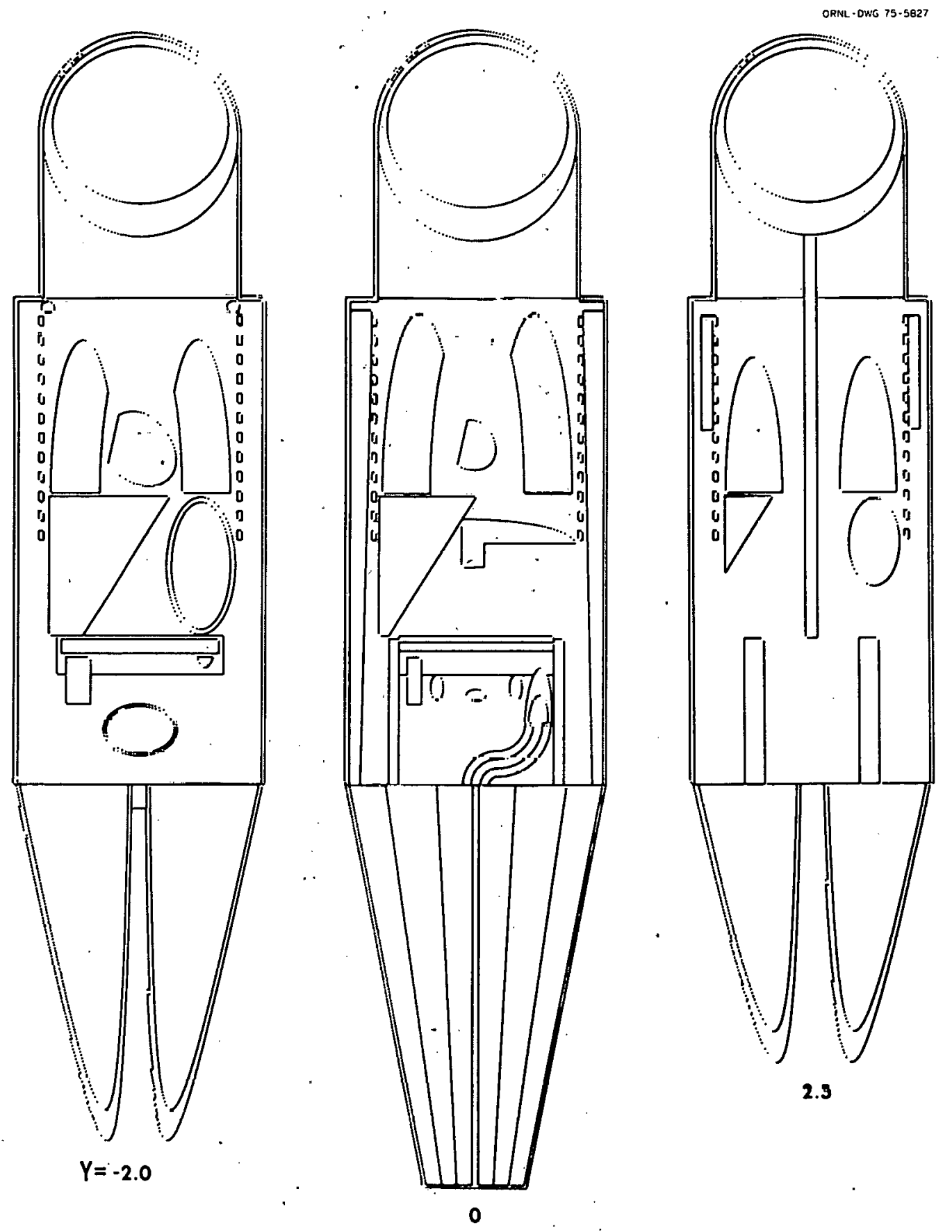

FIGURE 7. $X-Z$ SECTIONAL PLOTS OF THE ONE-YEAR OLD PHANTOM. 

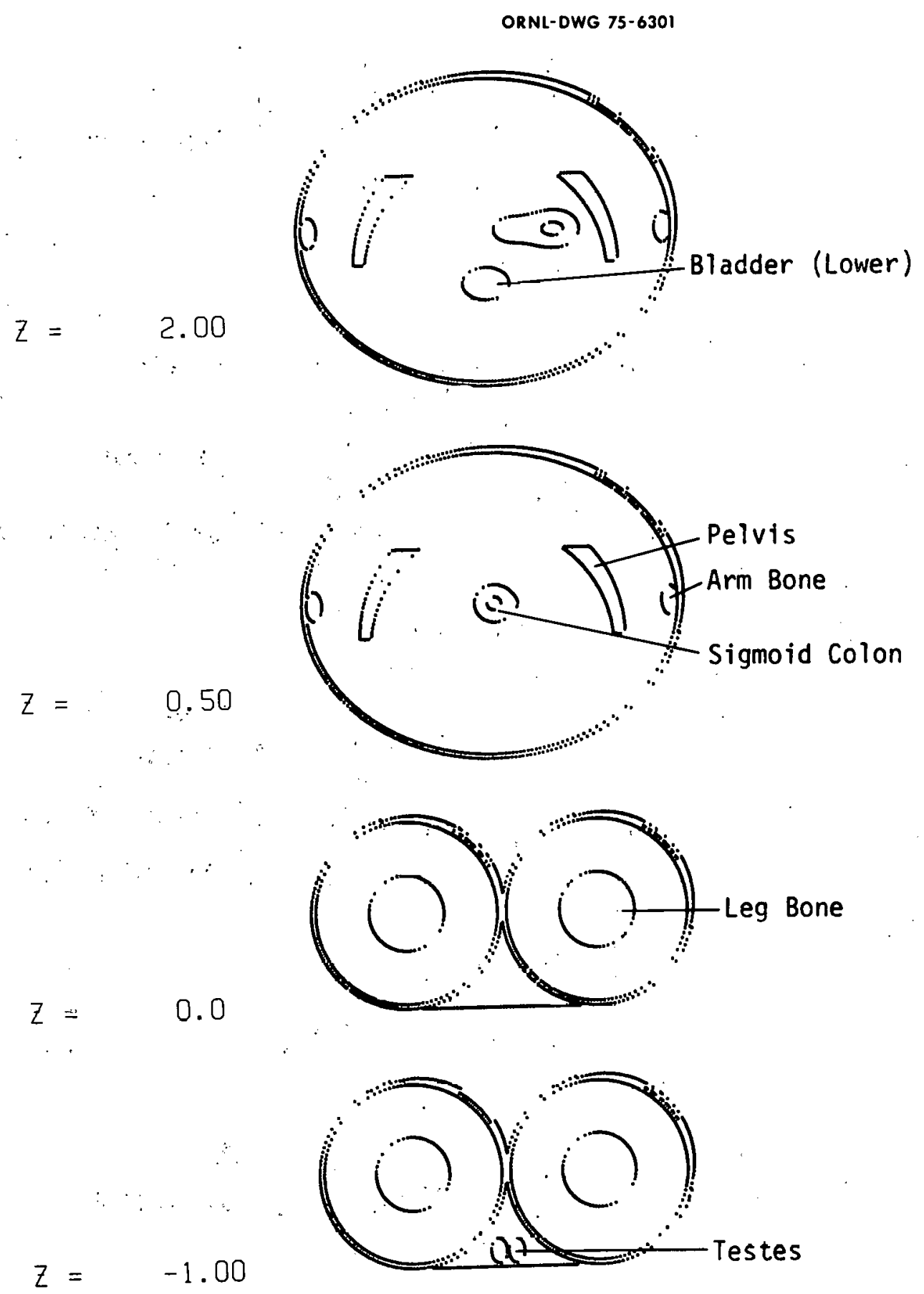

FIGURE 8. X-Y SECTIONAL PLOTS OF THE FIVE-YEAR OLD' PHANTOM SHOWING THE UPPER LEG AND HIP REGION. 


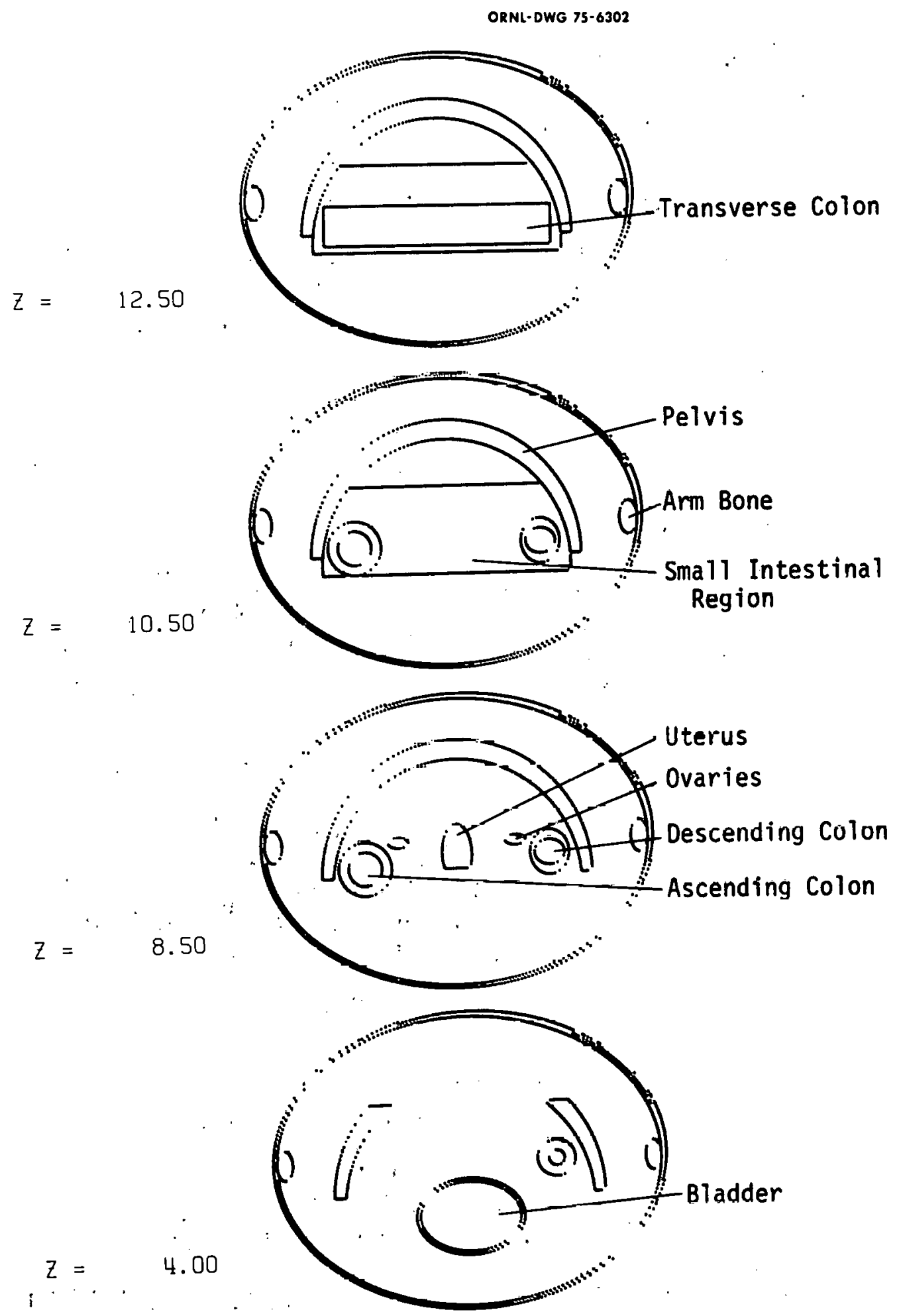

FIGURE 9. X-Y SECTIONAL PLOTS OF THE FIVE-YEAR OLD PHANTOM SHOWING THE LOWER ABDOMEN. 


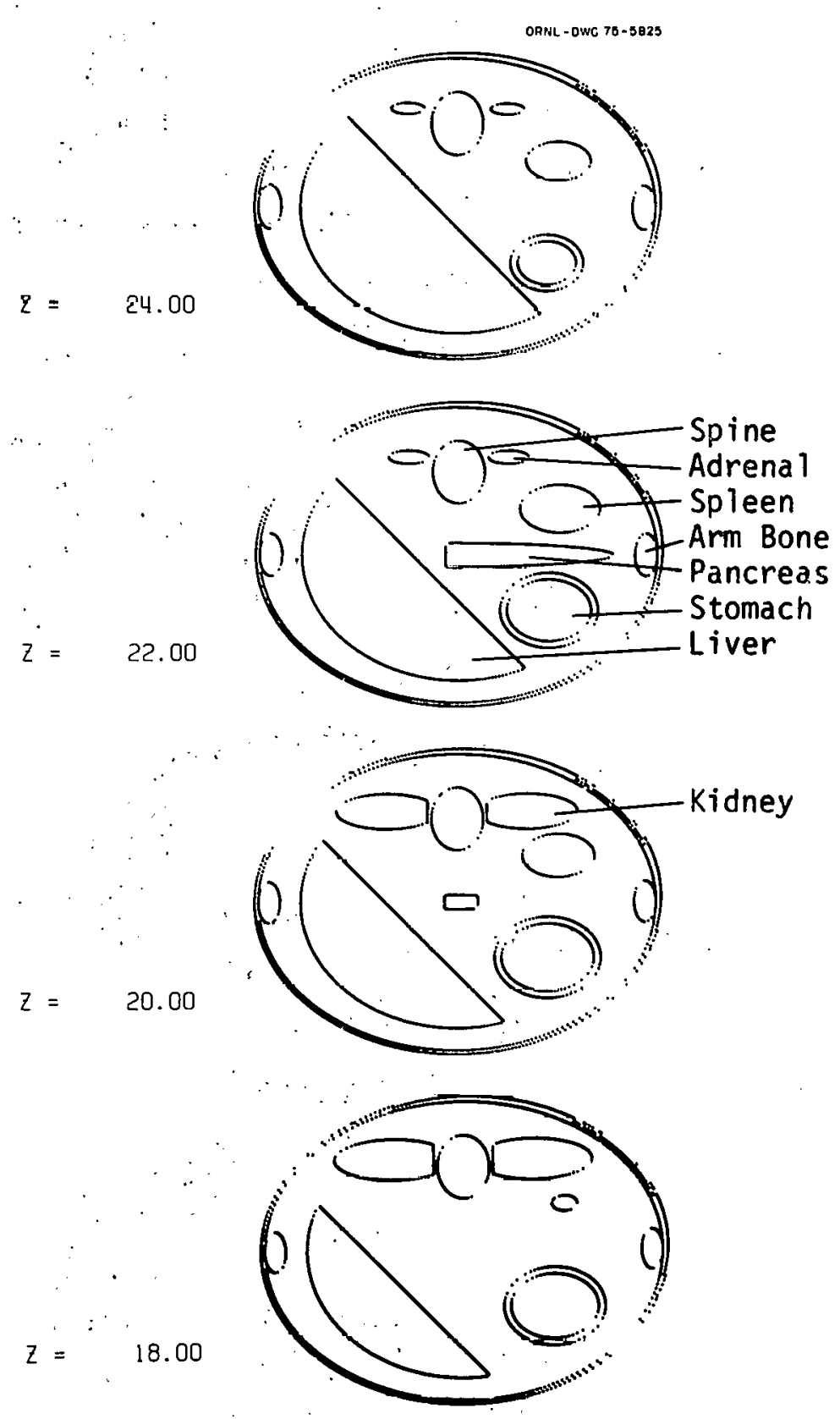

FIGURE 10. X-Y SECTIONAL PLOTS OF THE FIVE-YEAR OLD PHANTOM SHOWING: THE UPPER ABDOMEN. 


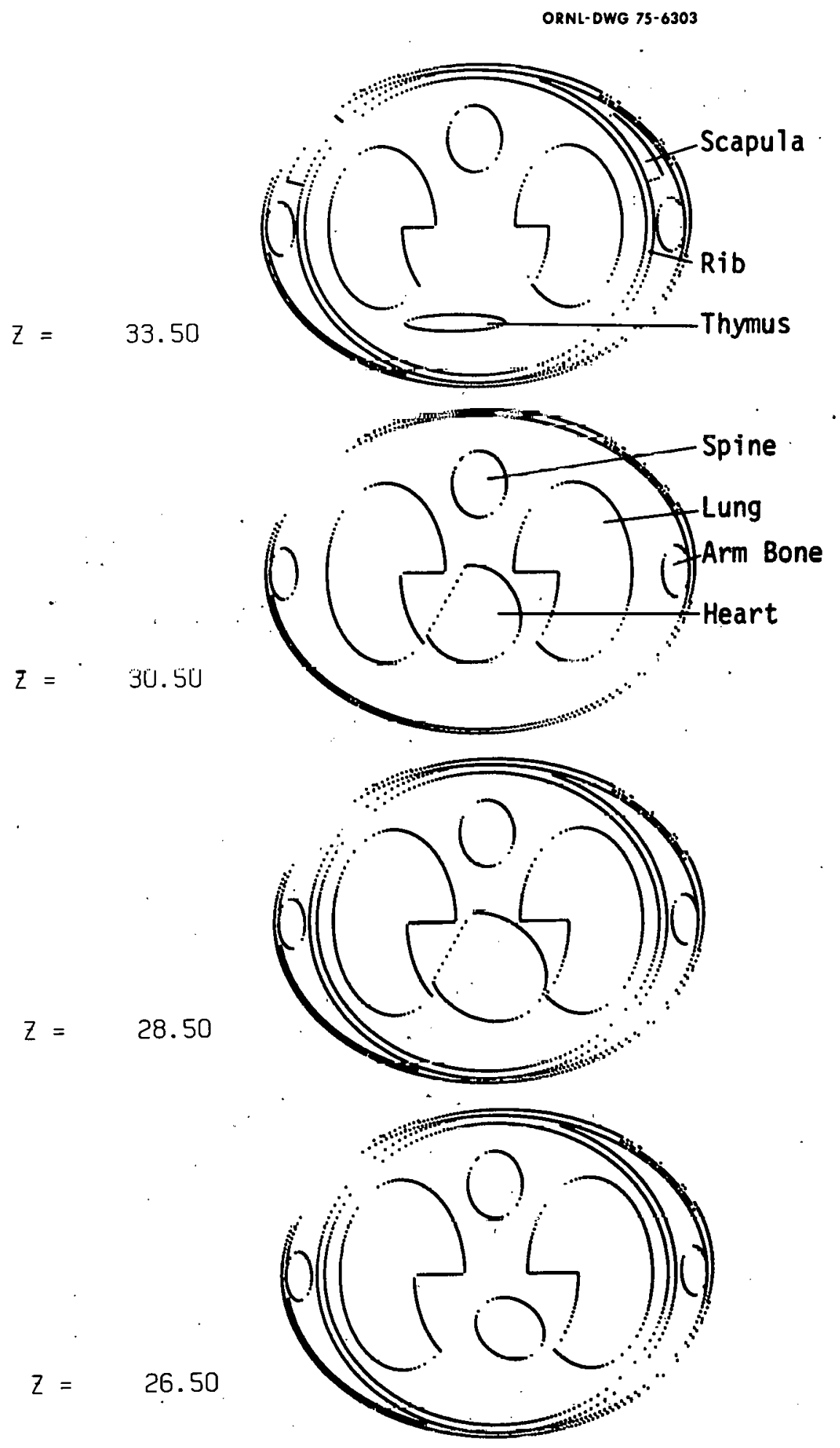

FIGURE 11. X-Y SECTIONAL PLOTS OF THE FIVE-YEAR OLD PHANTOM SHOWING THE CHEST REGION. 


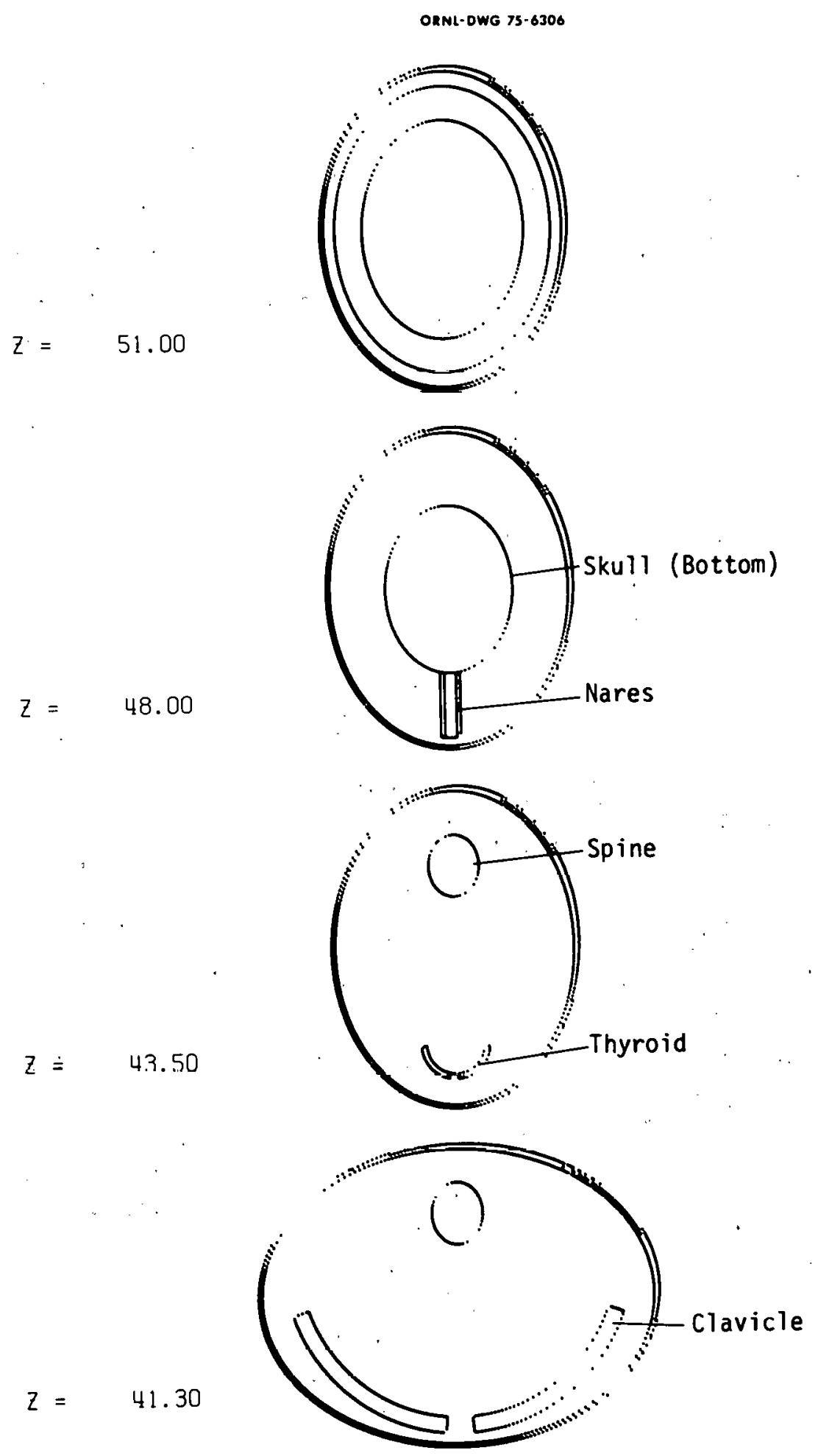

FIGURE 12. X-Y SECTIONAL PLOTS OF THE FIVE-YEAR OLD PHANTOM SHOWING THE SHOULDER AND HEAD REGIONS. 


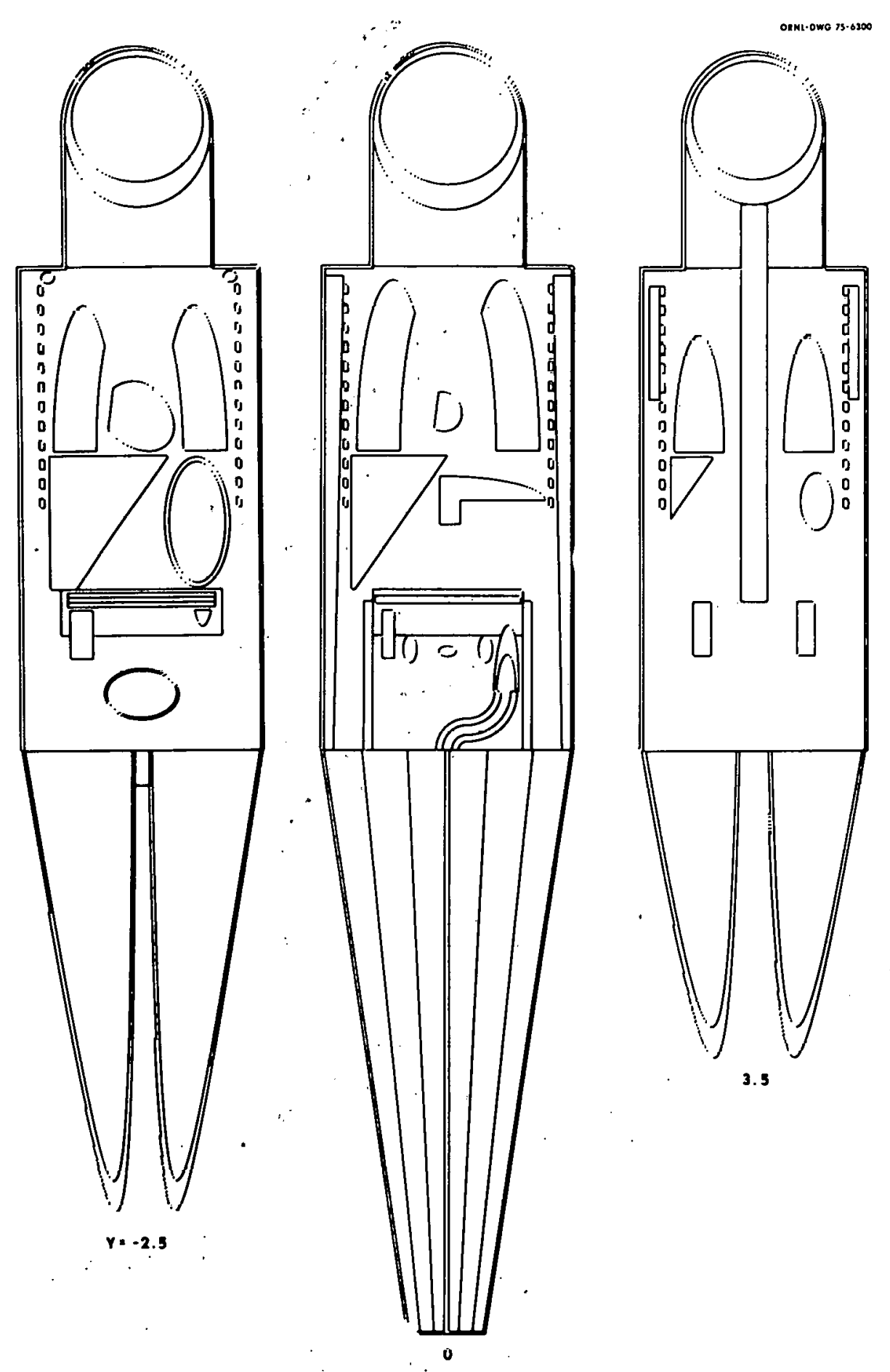

FIGURE 13. $X-Z$ SECTIONAL PLOTS OF THE FIVE-YEAR OLD PHANTOM. 
CHAPTER IV

CALCULATIONS

Monte-Carlo Code

A photon transport code had been written to compute random histories which originate in one source organ and to estimate the fraction of a photon's initial energy absorbed in each of the target organs. This code, a Monte-Carlo computer program, was written to estimate the distribution of absorbed energies in target organs for a variety of gamma-ray exposure situations. A radioactive source was specified through a computer subroutine. A magnetic tape was prepared from tables of the photoelectric and pair-production cross sections. These data were combined with computed values of the Compton cross section to produce, on the tape, the following tables:

(1) total cross section for all media under study,

(2) ratio of scattering to total cross section for all media,

(3) ratio of pair-production to total cross section for all medla

An indexing procedure was required for finding the values of Tables 1 , 2 , and 3 for a particular energy during the calculation.

The subroutine describing the source was written to describe the specific exposure situation, i.e., a radionuclide. This routine described the distribution, energy, and energy spectrum of the photons from a given source. Each photon was given eight of the nine parameters which characterize it; and they are changed as a result of subsequent events in its history. The eight initial parameters which 
the source must start with included: (1) three starting coordinates relative to the phantom coordinate system, (2) three starting direction cosines relative to these axes, (3) the initial energy, and (4) the initial statistical weight. The statistical weight is related to the probability of existence of the photon. An initial weight of 1.0 was given to each photon and was reduced following each interaction by multiplying the initial weight by the ratio of the cross section for Compton scattering to the total cross section (see Equation 8). In this way, photons were never absorbed, thus improving the statistics of dose estimate. A ninth characteristic parameter of a photon was defined by the mean path length which was a function of the reciprocal of the total macroscopic cross ection. The mean path length for a particular energy was made constant regardless of the medium.

Energy deposition at an interaction site $n$ by a photor coming from the previous interaction site $n-1$ is calculated by Equation 9. After an interaction, the photon had a new energy and new direction both of which were governed by the well-known Klein-Nishina scattering formula:

$$
d \sigma_{s}=\frac{e^{4}}{m^{2} c^{4}}\left(\frac{h \nu^{-}}{h \nu}\right)^{2}\left(\frac{h \nu}{h \nu^{\prime}}+\frac{h \nu^{-}}{h \nu}-\sin ^{2} \theta\right) d \Omega
$$

This formula gives the cross section per electron, $d \sigma_{s}$, for the scattering of a photon of energy $h \nu$ into the element of solid angle $d \Omega$ at the angle $\theta$ (with the energy $h \nu^{-}$). Patr production is allowed when the photon energies were above $1.02 \mathrm{MeV}$. The characteristics of the parent photons were stored temporarily while a history of the daughter 
photon was followed with direction chosen isotropically and energy of $0.511 \mathrm{MeV}$. This photon had twice the weight of the parent so as to represent the production of a photon pair. This history was followed until terminated by one of the test criteria. Then the parent photon history was continued because as stated before, no photons were absorbed.

When the histories of all source photons had been compiled and the accumulated energies were recorded, standard deviations, coefficients of variation, and absorbed fractions for each subregion were computed (Warner, et al., 1968).

Standard deviations and absorbed fractions were calculated from deposited energy in the different organs and tissues of the phantom. Let $E_{n i}$ be the energy deposited in the region under consideration on the $n^{\text {th }}$ interaction of the $i^{\text {th }}$ source photon. This energy might be zero, as it was in the frequently occurring case when the $n^{\text {th }}$ interaction didn't occur within the region. The total energy deposited by the $i^{\text {th }}$ photon in the region would be

$$
E^{*}=\sum_{n=1}^{m_{j}} E_{n i}^{*}
$$

in which $m_{f}$ is the number of interactions in the region occurring in the ${ }^{\text {th }}$ history before termination. The estimate of the average energy deposited per photon in the region is then

$$
\bar{E}=\frac{1}{M} \sum_{i=1}^{M} E_{i}^{*}
$$


in which $M$ source photons were followed. (Dose is obtained by multiplying the energy deposition by the appropriate constant $1.6 \mathrm{x}$ $\left.10^{-8} \mathrm{rads} / \mathrm{MeV}.\right)$

The standard deviation of the mean, $\sigma$, was calculated using the formula

$$
\sigma^{2}=\frac{1}{M(M-1)} \sum_{i=1}^{M}\left(E_{i}^{*}-E\right)^{2} .
$$

Absorbed fraction of the $i^{\text {th }}$ history can be expressed as

$$
\phi_{i}=\frac{E_{i}^{*}}{E_{0}}
$$

where $E_{0}$ is, the initial photon energy emitted by the source. The absorbed fraction in a target. organ is expressed as:

$$
\phi=\sum_{i=1}^{M} \phi_{i}=\sum_{i=1}^{M} \frac{E_{i}^{*}}{E_{i}}
$$

Since the absorbed fraction differs from $E$ by a constant factor, the coefficient of variation, C.V., was given by

$$
\text { C.V. }=\frac{100 \sigma}{\tau}
$$

(Snyder, et al., 1974).

The computer code had been programmed for 60,000 photons to estimate gamma-ray dose in the various organs from a source of $99 m \mathrm{~T}$ c uniformly distributed in the bladder contents, kidneys, liver, spleen, red bone marrow and the total body respectively. An example output from the Monte-Carlo code for the one-year old phantom using the kidneys as a source organ is shown in Table 6. 
TABLE 6. SAMPLE OUTPUT FROM THE MONTE-CARLO CODE FOR THE ONE-YEAR-OLD PHANTOM USING THE KIDNEYS AS A SOURCE ORGAN.

\begin{tabular}{|c|c|c|c|c|c|c|c|c|c|c|}
\hline \multicolumn{2}{|c|}{ Organ } & \multirow{2}{*}{$\frac{\text { Rads/Fhoton }}{5.195 E-14}$} & \multirow{2}{*}{$\frac{\text { Std. Dev. }}{2.385 E-16}$} & \multirow{2}{*}{$\frac{\text { Coef. Var. }}{4.591 E-03}$} & \multirow{2}{*}{$\frac{\text { Collitions }}{15 \mathrm{C} 658}$} & \multirow{2}{*}{$\frac{\text { Mass }}{1.040 E 04}$} & \multirow{2}{*}{$\frac{E(G-R a d s)}{5.401 E-10}$} & \multirow{2}{*}{$\frac{\text { Var. of } E}{6.149 E-24}$} & \multirow{2}{*}{$\begin{array}{l}\text { Absd. Frac. } \\
2.618 E-01\end{array}$} & \multirow{2}{*}{$\begin{array}{l}\text { Photon: } \\
40238\end{array}$} \\
\hline 1. & Total Body & & & & & & & & & \\
\hline 2. & Legs & $3.604 E-15$ & $1.591 E-16$ & $4.414 E-0 ?$ & 1899 & $1.672 E \quad 03$ & $6.027 E-12$ & $7.075 E-26$ & $2.921 E-03$ & 820 \\
\hline 3. & Trunk & $9.016 \mathrm{E}-14$ & $4.163 E-16$ & $4.617 \mathrm{E}-03$ & $14 i 230$ & 5.875E 03 & $5.297 E-10$ & $5.983 E-24$ & $2.568 \mathrm{E}-01$ & 40063 \\
\hline 4. & Head & $1.529 \mathrm{E}-15$ & $8.833 E-17$ & $5.775 E-02$ & 1529 & $2.849 \mathrm{E} \quad 03$. & $4.357 E-12$ & $6.333 E-26$ & $2.112 E-03$ & 483 \\
\hline \multirow[t]{6}{*}{5.} & Total Tissue & $5.039 E-14$ & $2.913 E-16$ & $5.782 E-03$ & 89369 & $6.115 E \quad 03$ & $3.081 E-10$ & $3.174 E-24$ & $1.493 E-01$ & 31863 \\
\hline & . & . & . & . & . & . & . & . & . & . \\
\hline & . & . & . & . & . & . & . & . & . & . \\
\hline & . & . & . & . & . & . & . & $\cdot$. & . & . \\
\hline & . & $:$ & . & . & . & . & . & . & . & . \\
\hline & . & . & , & . & . & . & . & . & . & . \\
\hline 100. & S.I. + Conts. & $1.050 E-13$ & $3.402 E-15$ & $3.239 \mathrm{E}-02$ & 2334 & $7.590 E \quad 01$ & $7.972 E-12$ & $6.666 E-26$ & $3.864 E-03$ & 1598 \\
\hline 101. & RM Lo. L. Arm & $5.732 E-14$ & $3.274 \bar{E}-15$ & $5.711 \mathrm{E}-02$ & 581 & $2.030 E 00$ & $1.164 E-13$ & $4.416 E-29$ & $5.640 E-05$ & 434 \\
\hline 102. & RM LO. R. Arm & $6.223 E-14$ & $3.472 E-15$ & $5.580 \mathrm{E}-02$ & 655 & $2.030 E \quad 00$ & $1.263 \mathrm{E}-13$ & $4.968 E-29$ & $6.123 E-05$ & 471 \\
\hline 103. & RM LO. L. Leg & $6.685 E-16$ & $2.675 E-16$ & $4.002 E-01$ & 18 & $3.205 E 00$ & $2.143 E-15$ & 7. $352 E-31$ & $1.038 \mathrm{E}-06$ & 8 \\
\hline 104. & RM Lo. R. Lec & $1.138 \mathrm{E}-15$ & $3.855 E-16$ & $3.388 E-01$ & 25 & $3.205 E 00$ & $3.646 \mathrm{E}-15$ & 1. $526 \mathrm{E}-30$ & $1.767 E-06$ & 15 \\
\hline
\end{tabular}


Biological Data for Dose Calculations

Methods for the calculation of absorbed dose for biologicallydistributed radionuclides have evolved over the years. Some of the procedures contain simplifying assumptions for the radionuclides and the biological models of interest. The word "model" was used to designate the set of assumed spatial, structural and kinetic conditions for which dose calculations were to be made. The everincreasing number and types of radionuclides in medical application and the growing interest in detailed biological models prompted the re-evaluation of the various computational procedures and also the physical and biological data required for the calculation.

Some widely used radiopharmaceuticals in pediatric nuclear medicine are $99 \mathrm{mTc}$ labeled. Examples of two commonly administered drugs are 99mTC Sulfur-colloid and 99mTC-DMSA which concentrate in the liver and the renal cortices, respectively. Binlogical data for these pharmaceuticals were provided with the assistance of Dr. $E, M$. Smith and are given below.

1. $99 \mathrm{mTS}$ Sulfur-colloid

(a) Distribution of the sulfur-colloid is the following:

Organ Fraction of Admin. Activity

Liver 0.85

Spleen

0.07

Red Marrow

0.05

Total Body

0.03 
(b) Assumptions used in calculation of the cummulated activity, A:

(1) Administered activity is instantaneously taken up by the organs and uniformly distributed in the organs.

(2) The biological clearance of the material is much larger than the physical half-life of $99 \mathrm{mTc}$, i.e. $T_{\text {eff }}=T_{\frac{1}{2}}$ phy.

(3) The fraction (0.03) distributed in the total body is assumed to be uniformly distributed in all tissues. This assumption will introduce an error of less than $5 \%$ with total body dose.

(c) Calculation of cumulated activity, $\tilde{A}(\mu C i-h) . \quad \tilde{A}$ is the cumulated activity given by

$$
\tilde{A}=\int_{t_{1}}^{t_{2}} A(t) d t \ldots \mu C i
$$

It is convenient to define a distribution function $Q(t)$ as the amount of the administered radionuclide in the organ at time $t$, then the activity is given by

$$
A(t)=q(t) e^{-\lambda t} \quad \mu C i
$$

where $\lambda$ is the physical decay constant of the radionuclide. If now $q(t)$ can be resolved into exponential components with an accuracy adequate for absorbed dose calculations, then

$$
q(t)=\sum_{j} q_{j} e^{-\lambda j t} \quad \mu C j
$$

where the coefficient $q_{j}$ is the value of the $j^{\text {th }}$ exponential component at time $t=0$ and $\lambda_{j}$ is the biological decay constant of the $j^{\text {th }}$ exponential constant. Carrying out the integration of 


$$
\tilde{A}=\int_{t_{1}}^{t_{2}} A(t) d t
$$

from $t_{1}=0$ to $t_{2}=t$

$$
\tilde{A}(t)=A_{0} \sum_{j} \frac{q_{j}}{\lambda+\lambda_{j}}\left[1-e^{-\left(\lambda+\lambda_{j}\right) t}\right]_{\mu C i-h}
$$

and

$$
\ddot{A}_{h}(\infty)=A_{0} \sum_{j} \frac{\eta_{h j}}{\lambda+\lambda_{j}} \quad \mu C i-h
$$

where $\tilde{A}_{h}(\infty)$ is the cumulated activity in the source region $r_{h}$ over an infinite period $(\mu \mathrm{Ci}-h), q_{h j}$ is the fractional value of the $j^{\text {th }}$. exponential component of the administered substance as the labeled radiopharmaceutical that appears in the source region $r_{h}$ and $A_{0}$ is the administered activity in $\mu$ C.i. For $99 \mathrm{mTC}$, the half-life, $T_{\frac{1}{1}}$, is six hours and the decay constant, $\lambda$

$$
\lambda=\frac{\log 2}{T_{3 / 2}}=\frac{0.693}{6}=0.1155 \mathrm{~h}^{-1}
$$

(1) Liver

$$
\tilde{A}_{L}(\infty)=(1 \times 0.85) / 0.1155=7.36 \mu C i-h / \mu C i \text { admin } .
$$

(2) Spleen

$$
\tilde{A}_{S P L}(\infty)=(1 \times 0.07) / 0.1155=0.606 \mu C i-h / \mu C i \text { admin. }
$$

(3) Red Marrow

$$
\tilde{A}_{R M}(\infty)=(1 \times 0.05) / 0.1155=0.433 \mu C i-h / \mu C i \text { admin. }
$$


(4) Total Body

$$
\begin{aligned}
& \tilde{A}_{T B}(\infty)=(1 \times 0.03) / 0.1155=0.260 \mu C i-h / \mu C i \text { admin. } \\
& \text { 2. 99mTC-DMSA (2, 3-dimercaptosuccinic acid })
\end{aligned}
$$

(a) Distributions of $99 \mathrm{mTC}-\mathrm{DMSA}$ and assumptions in calculating A.

(1) $60 \%$ of the administered activity localized instantaneously in the renal cortices with $T_{\frac{1}{2} B}$ much larger than $T_{\frac{1}{2}}$ phy ; i.e., $T_{\text {eff }}=T_{\text {phy }}$. Ratio of the cortical tissue in the adult to total renal tissue is $186 / 300=0.62$.

(2) $33 \%$ of the administered activity distributed itself instantaneously and uniformly throughout the total body with a $T_{\frac{1}{2} B} \gg T_{\text {phy }}$; i.e., $T_{\text {eff }}=T_{\text {phy }}$.

(3) $5 \%$ of the administered activity localized instantaneously in the liver and spleen (proportional to organ mass) with a $T_{\frac{1}{2} B} \gg T_{\text {phy }}$; i.e., $T_{\text {eff }}=T_{\text {phy }}$.

(4) $2 \%$ of the administered activity was cleared by the kidneys, the effective residence time of the activity in the bladder was one hour. Physical decay was not considered. (The value of $2 \%$ excretion was taken to err the low side, thus increasing the estimate of tissue radiation dose from retained activity).

(5) There was no free $99 \mathrm{mT} \mathrm{Tc}$ and all of the $99 \mathrm{mTC}$ actively. followed the kinetics of the renal agent.

(b) Calculation of $\mathrm{A}(\mu \mathrm{C} i-h)$.

(1) Renal Cortices

$$
\tilde{A}_{R C}=A_{o} \frac{q_{R C}}{\lambda_{\text {eff }}}=\frac{1 \times 0.6}{0.1155}=5.19 \mu C i-h / \mu C i \text { admin. }
$$


(2) Total Body

$$
\tilde{A}_{T B}=A_{0} \frac{q_{T B}}{\lambda_{\text {eff }}}=\frac{1 \times 0.33}{0.1155}=2.86 \mu \mathrm{Ci}-\mathrm{h} / \mu \mathrm{Ci} \text { admin. }
$$

(3) Bladder

$$
\tilde{A}_{B L A D}=A_{O} a_{B L A D} t=1 \times 0.22 \times 1=0.22 \mu C i-h / \mu C i \text { admin. }
$$

(4) Liver and Spleen

$$
\tilde{A}_{L \& S}=\frac{A_{0} q_{L \& S}}{\lambda_{\text {eff }}}=\frac{1 \times 0.05}{0.1155}=0.43 \mu \mathrm{Ci}-\mathrm{h} / \mu \mathrm{Ci} \text { admin. }
$$

\section{Absorbed Dose Calculations}

The calculation of absorbed dose depends on both the properties of the radiation source and the biological model. The absorbed dose, $\bar{D}$, can be expressed by

$$
\bar{D}(v+r)=\tilde{A}_{r} / m_{v} \times \sum_{i} \Delta_{i} \phi_{f}(v+r) \text { rads }
$$

where the $\widetilde{A}^{\prime} s$ are given in the previous section, $m_{v}$ is the mass of the target organ and $\Delta_{i}$ is the equilibrium dose constant for the source radionuclide and is expressed in terms of $\mathrm{g}-\mathrm{rad} / \mu \mathrm{Cl}-\mathrm{hr}$.

The calculation of the $\phi_{j}{ }^{\prime} s$, the absorbed fraction, for ${ }^{9} \mathrm{gm}_{\mathrm{Tc}}$ is described in the section on the Monte-Carlo Code. A set of $\phi_{j}$ 's is calculated for each source organ which may exist. From the two radiopharmaceutical examples discussed in the section on Biological Data, six source organs are identified: bladder contents, kidneys, liver, spleen, red bone marrow and total body. A composite of the 
photon absorbed fractions of $99 \mathrm{~m} \mathrm{Tc}$ for these source organs for the one year old and the five year old phantoms are shown in Tables 7 and 8 , respectively.

For ${ }^{99 m} \mathrm{Tc}$ labeled pharmaceuticals, the equilibrium dose constant used for calculating absorbed dose is the sum of the $\Delta_{i}$ 's for penetrating radiations, i.e., gamma-rays and $x$-rays. This is illustrated in Figure 14.

The masses of individual target organs, $m_{v}$, can be found in Table 5 (see page 25).

These data, cumulated activity, organ masses, equilibrium dose constant and absorbed fractions are combined to calculate the absorbed dose to different target organs in the one-year old and the five-year old phantoms. The following target organs were selected as being important for the radiopharmaceutical studied in children: bladder wal1, gonads, kidneys, liver, ovaries, red bone marrow, spleen, testes, thymus, and thyroid as well as the total body dose. Tables 9 and 10 show the absorbed dose for $99 \mathrm{~m}_{\mathrm{Tc}}$ sulfur-colloid calculated for the one-year old and five-year old phantoms, rcspectively; and absorbed dose calculations are illustrated in Tables 11 and 12 for 99mTC. DMSA. 
TABLE 7. ABSORBED FRACTIONS FOR THE PHOTON SPECTRUM CIF $99^{\mathrm{m}} \mathrm{TC}$ FOR THE ONE-YEAR-OLD PHANTOM*

\begin{tabular}{|c|c|c|c|c|c|c|c|}
\hline \multirow{2}{*}{$\begin{array}{l}\text { Target } \\
\text { Organs }\end{array}$} & \multicolumn{7}{|c|}{ Source Organs } \\
\hline & & Blad. Cont. & Kidneys & Liver & Spleen & Tatal Body & Red Marrow \\
\hline $\begin{array}{l}\text { Adrenals } \\
\text { Bladder Wail1 } \\
\text { Brain } \\
\text { G.I. (Stomach) } \\
\text { G.I. (SI) } \\
\text { G.I. (ULI Wa11) } \\
\text { G.I. (LLI Wa11) } \\
\text { Heart } \\
\text { Kidneys } \\
\text { Liver } \\
\text { Lungs } \\
\text { Ovaries } \\
\text { Pancreas } \\
\text { Skeleton } \\
\text { Red Marrow } \\
\text { Yel. Tow Marrow } \\
\text { Skin } \\
\text { Spleen } \\
\text { Testes } \\
\text { Thymus } \\
\text { Thyroid } \\
\text { Uterus } \\
\text { Total Body }\end{array}$ & & $\begin{array}{l}1.278 \mathrm{E}-05 \\
7.622 \mathrm{E}-03 \\
6.112 \mathrm{E}-05 \\
4.151 \mathrm{E}-04 \\
5.849 \mathrm{E}-03 \\
2.082 \mathrm{E}-03 \\
3.110 \mathrm{E}-03 \\
1.682 \mathrm{E}-04 \\
8.877 \mathrm{E}-04 \\
4.185 \mathrm{E}-02 \\
3.157 \mathrm{E}-04 \\
5.415 \mathrm{E}-05 \\
8.780 \mathrm{E}-05 \\
2.224 \mathrm{E}-02 \\
5.215 \mathrm{E}-03 \\
0.0 \\
6.803 \mathrm{E}-03 \\
2.881 \mathrm{E}-04 \\
1.734 \mathrm{E}-04 \\
3.089 \mathrm{E}-05 \\
0.0 \\
4.859 \mathrm{E}-04 \\
3.023 \mathrm{E}-01\end{array}$ & $\begin{array}{l}5.057 \mathrm{E}-04 \\
1.062 \mathrm{E}-04 \\
2.330 \mathrm{E}-04 \\
7.886 \mathrm{E}-04 \\
3.864 \mathrm{E}-03 \\
8.516 \mathrm{E}-04 \\
4.197 \mathrm{E}-04 \\
7.415 \mathrm{E}-04 \\
4.879 \mathrm{E}-02 \\
1.129 \mathrm{E}-02 \\
1.777 \mathrm{E}-03 \\
2.051 \mathrm{E}-05 \\
5.695 \mathrm{E}-04 \\
2.895 \mathrm{E}-02 \\
8.270 \mathrm{E}-03 \\
0.0 \\
7.112 \mathrm{E}-03 \\
3.437 \mathrm{E}-03 \\
1.368 \mathrm{E}-05 \\
1.214 \mathrm{E}-04 \\
4.278 \mathrm{E}-06 \\
3.623 \mathrm{E}-05 \\
2.618 \mathrm{E}-01\end{array}$ & $\begin{array}{l}1.745 E-04 \\
1.362 E-04 \\
3.603 E-04 \\
1.318 E-03 \\
3.599 E-03 \\
1.761 E-03 \\
2.383 E-04 \\
2.330 E-03 \\
2.683 E-03 \\
9.003 E-02 \\
3.743 E-03 \\
1.737 E-05 \\
7.216 E-04 \\
2.154 E-02 \\
4.393 E-03 \\
0.0 \\
6.526 E-03 \\
8.116 E-04 \\
8.420 E-06 \\
3.445 E-04 \\
1.565 E-05 \\
2.762 E-05 \\
2.853 E-01\end{array}$ & $\begin{array}{l}5.019 \mathrm{E}-04 \\
4.962 \mathrm{E}-05 \\
6.076 \mathrm{E}-04 \\
2.811 \mathrm{E}-03 \\
2.232 \mathrm{E}-03 \\
6.394 \mathrm{E}-04 \\
3.394 \mathrm{E}-04 \\
1.966 \mathrm{E}-03 \\
7.994 \mathrm{E}-03 \\
9.978 \mathrm{E}-03 \\
5.255 \mathrm{E}-03 \\
5.125 \mathrm{E}-06 \\
1.828 \mathrm{E}-03 \\
2.961 \mathrm{E}-02 \\
6.015 \mathrm{E}-03 \\
0.0 \\
6.197 \mathrm{E}-03 \\
4.500 \mathrm{E}-02 \\
1.381 \mathrm{E}-06 \\
2.740 \mathrm{E}-04 \\
8.620 \mathrm{E}-06 \\
2.499 \mathrm{E}-05 \\
2.929 \mathrm{E}-01\end{array}$ & $\begin{array}{l}1.148 \mathrm{E}-04 \\
2.069 \mathrm{E}-04 \\
2.229 \mathrm{E}-02 \\
7.119 \mathrm{E}-04 \\
2.136 \mathrm{E}-03 \\
\mathbf{5} .532 \mathrm{E}-04 \\
5.277 \mathrm{E}-04 \\
1.377 \mathrm{E}-03 \\
1.652 \mathrm{E}-03 \\
7.841 \mathrm{E}-03 \\
2.897 \mathrm{E}-03 \\
1.697 \mathrm{E}-05 \\
2.199 \mathrm{E}-03 \\
4.525 \mathrm{E}-02 \\
4.863 \mathrm{E}-03 \\
0.0 \\
8.566 \mathrm{E}-03 \\
6.950 \mathrm{E}-04 \\
4.413 \mathrm{E}-05 \\
5.403 \mathrm{E}-04 \\
6.926 \mathrm{E}-05 \\
4.865 \mathrm{E}-05 \\
2.362 \mathrm{E}-01\end{array}$ & $\begin{array}{l}5.047 \mathrm{E}-05 \\
4.091 \mathrm{E}-04 \\
5.231 \mathrm{E}-05 \\
6.654 \mathrm{E}-04 \\
9.164 \mathrm{E}-03 \\
2.644 \mathrm{E}-03 \\
2.614 \mathrm{E}-03 \\
2.052 \mathrm{E}-04 \\
2.819 \mathrm{E}-03 \\
5.298 \mathrm{E}-03 \\
4.954 \mathrm{E}-04 \\
9.060 \mathrm{E}-05 \\
1.542 \mathrm{E}-04 \\
7.861 \mathrm{E}-02 \\
2.806 \mathrm{E}-02 \\
0.0 \\
6.785 \mathrm{E}-03 \\
5.181 \mathrm{E}-04 \\
3.959 \mathrm{E}-05 \\
2.657 \mathrm{E}-05 \\
0.0 \\
1.214 \mathrm{E}-04 \\
2.915 \mathrm{E}-01\end{array}$ \\
\hline
\end{tabular}

*Note: When using these data the weighted value of the equilibrium dose constant, i.e. $\frac{\sum n_{j} \Delta_{i} \text {, }}{\sum n_{j}}$
should be used. For technicium-99m the value is $0.242 \mathrm{~g}-\mathrm{rad} / \mu \mathrm{C}$-hr. 
TABLE 8. ABSORBED FRACTIONS FOR THE PHOTON SPECTRUM OF $99 \mathrm{~m}_{\mathrm{TC}}$ FOR THE FIVE-YEAR-OLD PHANTOM*

\begin{tabular}{|c|c|c|c|c|c|c|}
\hline \multirow{2}{*}{$\begin{array}{l}\text { Target } \\
\text { Organs }\end{array}$} & \multicolumn{5}{|c|}{ Source Organs } & \multirow[b]{2}{*}{ Red Marrow } \\
\hline & Blad. Cont. & Kidney's & Liver & Spleen & Total Body & \\
\hline $\begin{array}{l}\text { Adrenals } \\
\text { Bladder Wall } \\
\text { Brain } \\
\text { G.I. (Stomach) } \\
\text { G.I. (SI) } \\
\text { G.I. (ULI Wall) } \\
\text { G.I. (LLI Wal1) } \\
\text { Heart } \\
\text { Kidneys } \\
\text { Liver } \\
\text { Lungs } \\
\text { Ovaries } \\
\text { Pancreas } \\
\text { Skeleton } \\
\text { Red Marrow } \\
\text { Yellow Marrow } \\
\text { Skin } \\
\text { Spleen } \\
\text { Tes tes } \\
\text { Thymus } \\
\text { Thyroid } \\
\text { Uterus } \\
\text { Total Body }\end{array}$ & $\begin{array}{l}1.613 \mathrm{E}-05 \\
6.280 \mathrm{E}-02 \\
9.070 \mathrm{E}-06 \\
4.378 \mathrm{E}-04 \\
7.566 \mathrm{E}-03 \\
1.752 \mathrm{E}-03 \\
3.353 \mathrm{E}-03 \\
1.320 \mathrm{E}-04 \\
5.986 \mathrm{E}-04 \\
3.154 \mathrm{E}-03 \\
2.624 \mathrm{E}-04 \\
1.235 \mathrm{E}-04 \\
8.614 \mathrm{E}-05 \\
2.527 \mathrm{E}-02 \\
8.567 \mathrm{E}-03 \\
9.783 \mathrm{E}-04 \\
6.329 \mathrm{E}-03 \\
1.983 \mathrm{E}-04 \\
1.014 \mathrm{E}-04 \\
4.622 \mathrm{E}-05 \\
5.515 \mathrm{E}-10 \\
3.430 \mathrm{E}-04 \\
3.673 \mathrm{E}-01\end{array}$ & $\begin{array}{l}4.982 \mathrm{E}-04 \\
4.026 \mathrm{E}-04 \\
1.824 \mathrm{E}-04 \\
1.240 \mathrm{E}-03 \\
5.502 \mathrm{E}-03 \\
1.122 \mathrm{E}-03 \\
3.102 \mathrm{E}-04 \\
1.091 \mathrm{E}-03 \\
5.716 \mathrm{E}-02 \\
1.430 \mathrm{E}-02 \\
2.206 \mathrm{E}-03 \\
2.756 \mathrm{E}-05 \\
8.274 \mathrm{E}-04 \\
3.658 \mathrm{E}-02 \\
1.405 \mathrm{E}-02 \\
1.128 \mathrm{E}-03 \\
6.575 \mathrm{E}-03 \\
4.025 \mathrm{E}-03 \\
5.052 \mathrm{E}-06 \\
9.301 \mathrm{E}-05 \\
1.683 \mathrm{E}-07 \\
3.087 \mathrm{E}-05 \\
3.207 \mathrm{E}-01\end{array}$ & $\begin{array}{l}1.373 E-04 \\
4.836 E-04 \\
1.642 E-04 \\
1.561 E-03 \\
5.032 E-03 \\
1.744 E-03 \\
2.250 E-04 \\
3.163 E-03 \\
2.773 E-03 \\
1.133 E-01 \\
4.238 E-03 \\
2.581 E-05 \\
1.003 E-03 \\
2.555 E-02 \\
6.976 E-03 \\
7.355 E-04 \\
6.278 E-03 \\
8.002 E-04 \\
1.232 E-06 \\
2.358 E-04 \\
4.315 E-06 \\
3.532 E-05 \\
3.380 E-01\end{array}$ & $\begin{array}{l}5.063 \mathrm{E}-03 \\
2.334 \mathrm{E}-04 \\
3.529 \mathrm{E}-04 \\
3.321 \mathrm{E}-03 \\
3.017 \mathrm{E}-03 \\
7.365 \mathrm{E}-03 \\
2.724 \mathrm{E}-04 \\
2.365 \mathrm{E}-03 \\
9.457 \mathrm{E}-03 \\
1.098 \mathrm{E}-02 \\
6.150 \mathrm{E}-03 \\
1.376 \mathrm{E}-05 \\
2.935 \mathrm{E}-03 \\
3.517 \mathrm{E}-02 \\
9.465 \mathrm{E}-03 \\
8.875 \mathrm{E}-04 \\
6.108 \mathrm{E}-03 \\
5.464 \mathrm{E}-02 \\
8.396 \mathrm{E}-07 \\
1.792 \mathrm{E}-04 \\
5.468 \mathrm{E}-06 \\
3.075 \mathrm{E}-05 \\
3.496 \mathrm{E}-01\end{array}$ & $\begin{array}{l}4.104 \mathrm{E}-05 \\
1.057 \mathrm{E}-03 \\
1.503 \mathrm{E}-02 \\
9.215 \mathrm{E}-04 \\
3.443 \mathrm{E}-03 \\
8.693 \mathrm{E}-04 \\
6.700 \mathrm{E}-04 \\
1.656 \mathrm{E}-03 \\
1.729 \mathrm{E}-03 \\
9.276 \mathrm{E}-03 \\
3.695 \mathrm{E}-03 \\
2.210 \mathrm{E}-05 \\
3.966 \mathrm{E}-04 \\
4.907 \mathrm{E}-02 \\
8.270 \mathrm{E}-03 \\
9.211 \mathrm{E}-04 \\
8.909 \mathrm{E}-03 \\
7.258 \mathrm{E}-04 \\
2.875 \mathrm{E}-05 \\
4.416 \mathrm{E}-04 \\
5.909 \mathrm{E}-05 \\
6.139 \mathrm{E}-05 \\
2.715 \mathrm{E}-01\end{array}$ & $\begin{array}{l}2.341 \mathrm{E}-05 \\
2.063 \mathrm{E}-03 \\
1.803 \mathrm{E}-05 \\
5.237 \mathrm{E}-04 \\
1.259 \mathrm{E}-02 \\
2.658 \mathrm{E}-03 \\
2.763 \mathrm{E}-03 \\
1.883 \mathrm{E}-04 \\
2.039 \mathrm{E}-03 \\
4.647 \mathrm{E}-03 . \\
3.925 \mathrm{E}-04 \\
1.097 \mathrm{E}-04 \\
1.514 \mathrm{E}-04 \\
9.183 \mathrm{E}-02 \\
4.539 \mathrm{E}-02 \\
4.980 \mathrm{E}-03 \\
6.106 \mathrm{E}-03 \\
3.588 \mathrm{E}-04 \\
2.291 \mathrm{E}-05 \\
2.904 \mathrm{E}-05 \\
3.178 \mathrm{E}-09 \\
1.718 \mathrm{E}-04 \\
3.514 \mathrm{E}-04\end{array}$ \\
\hline
\end{tabular}

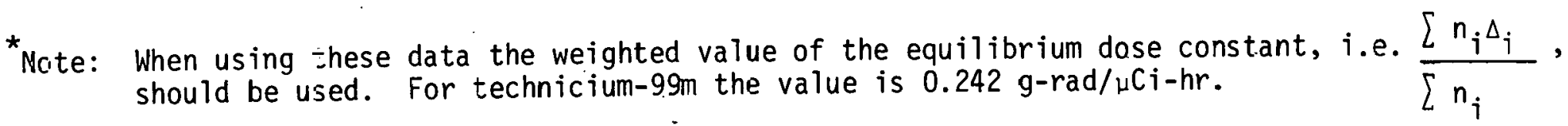




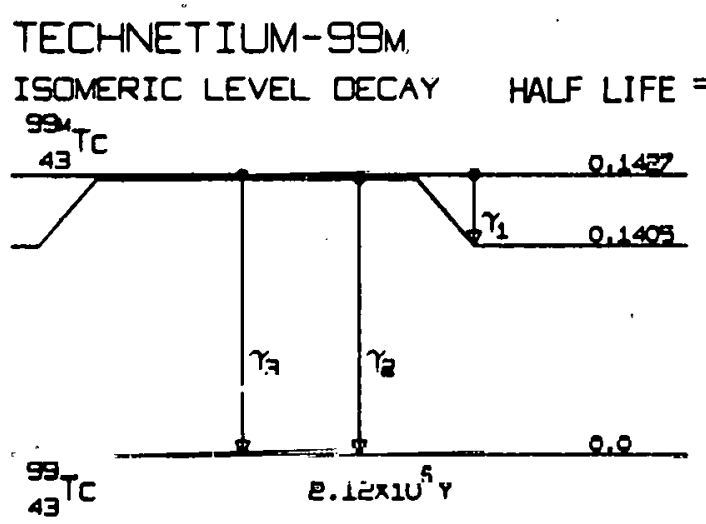

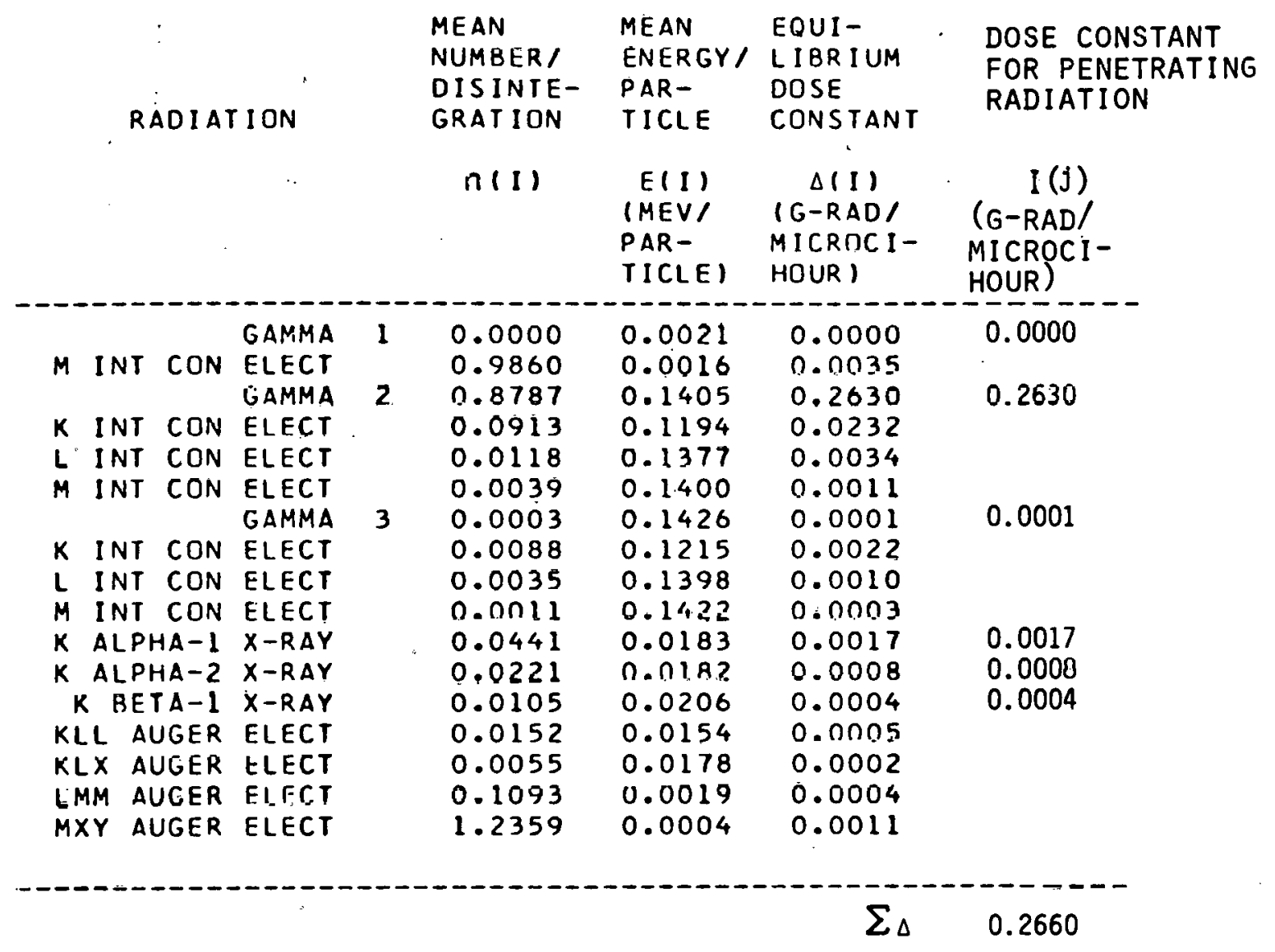

FIGURE 14. ISOMERIC LEVEL DECAY OF 99mTC, DECAY DATA AND EQUILIBRIUM DOSE CONSTANTS. 
TABLE 9. ABSORBED DOSE TO SELECTED ORGANS IN THE ONE-YEAR OLD PHANTOM PER $\mu \mathrm{C} i$ OF ADMINISTERED ACTIVITY OF $99 \mathrm{~m}_{\text {TC }}$-SULFUR COLLDID

\begin{tabular}{|c|c|c|c|c|c|c|}
\hline \multirow{2}{*}{$\begin{array}{l}\text { Target } \\
\text { Cirgans }\end{array}$} & & \multicolumn{4}{|c|}{ Source Organs } & \multirow{2}{*}{$\begin{array}{l}\text { Total Dose to the } \\
\text { Target Organs (rads } / \mu \mathrm{C} i)\end{array}$} \\
\hline & & Liver & Spleen & Red Marrow & Tota? Body & \\
\hline Liver & & $5.806 \mathrm{E}-04$ & $5.298 E-06$ & $2.010 \mathrm{E}-06$ & $1.786 \mathrm{E}-06$ & $5.897 \mathrm{E}-04$ \\
\hline Ovaries & & $2.571 E-05$ & $1.270 \mathrm{E}-06$ & $1.604 \mathrm{E}-05$ & $1.804 \mathrm{E}-06$ & $4.582 E-05$ \\
\hline Red Marrow & & $5.734 E-05$ & $6.464 E-06$ & $2.155 \mathrm{E}-05$ & $2.242 \mathrm{E}-06$ & $8.760 E-05$ \\
\hline Spleen & & $5.820 E-05$ & $2.657 \mathrm{E}-04$ & $2.186 E-06$ & $1.761 E-06$ & $3.278 E-04$ \\
\hline Testes & & $1.130 \mathrm{E}-05$ & $1.526 \mathrm{E}-07$ & $3.125 \mathrm{E}-06$ & $2.092 \mathrm{E}-06$ & $1.667 \mathrm{E}-05$ \\
\hline Thymius & & $3.082 E-05$ & $2.019 E-06$ & $1.399 E-07$ & $1.708 E-06$ & $3.469 E-05$ \\
\hline Thyroid & & $1.289 E-05$ & $5.846 E-07$ & 0.0 & $2.015 E-06$ & $1.549 \mathrm{E}-05$ \\
\hline Toital Body & & $5.371 \mathrm{E}-05$ & $4.540 E-06$ & $3.228 E-06$ & $1.571 E-06$ & $6.305 E-05$ \\
\hline
\end{tabular}


TABLE 10. ABSORBED DOSE TO SELECTED ORGANS IN THE FIVE-YEAR OLD PHANTOM PER $\mu C \mathrm{j}$ OF ADMINISTERED ACTIVITY OF $99 \mathrm{~m}_{\mathrm{T}} \mathrm{c}$-SULFUR COLLOID

\begin{tabular}{|c|c|c|c|c|c|}
\hline \multirow{2}{*}{$\begin{array}{l}\text { Target } \\
\text { Organs }\end{array}$} & \multicolumn{4}{|c|}{ Source Organ } & \multirow{2}{*}{$\begin{array}{c}\text { Total Dose to the } \\
\text { Target Organs (rads/ } / \mu \mathrm{C} i)\end{array}$} \\
\hline & Liver & Spleen & Red Marrow & Total Body & \\
\hline Liver & $3.548 \mathrm{E}-04$ & $2.911 E-06$ & 3.802E-07 & $1.055 \mathrm{E}-06^{\circ}$ & $3.696 \mathrm{E}-04$ \\
\hline Ovaries & $2.665 E-05$ & $1.170 \mathrm{E}-06$ & $5.664 E-06$ & $8.061 E-07$ & $3.529 E-05$ \\
\hline Red Marrow & $3.403 E-05$ & $3.802 E-06$ & L. $303 \mathrm{E}-05$ & $1.425 E-06$ & $5.230 \mathrm{E}-05$ \\
\hline Spleen & $3.157 E-05$ & $1.775 E-04$ & $8.328 E-07$ & $1.012 \mathrm{E}-06$ & $2.109 \mathrm{E}-04$ \\
\hline Testes & $1.506 \mathrm{E}-06$ & $8.453 E-08$ & $1.648 E-06$ & $1.242 \mathrm{E}-06$ & $4.481 E-06$ \\
\hline Thymus & $1.508 \mathrm{E}-05$ & $9.437 \mathrm{E}-07$ & i. $.093 E-07$ & $9.977 \mathrm{E}-07$ & $1.713 \mathrm{E}-05$ \\
\hline Thyroid & $1.740 E-06$ & $1.816 \mathrm{E}-07$ & 7.541E-11 & $8.419 E-07$ & $2.764 \mathrm{E}-06$ \\
\hline Total Body & $3.347 E-05$ & $2.850 \mathrm{E}-06$ & ċ.047E-06 & $1.229 \mathrm{E}-06$ & $3.960 \mathrm{E}-05$ \\
\hline
\end{tabular}


TABLE 11. ABSORBE[ DOSE TO SELECTED ORGANS IN THE ONE-YEAR OLD PHANTOM PER $\mu \mathrm{C} i$ OF ADMINISTERED ACTIVITY OF $99 \mathrm{mTC}$-DMSA

\begin{tabular}{|c|c|c|c|c|c|}
\hline \multirow{2}{*}{$\begin{array}{l}\text { Target } \\
\text { Organs }\end{array}$} & \multicolumn{4}{|c|}{ Source Organs } & \multirow{2}{*}{$\begin{array}{l}\text { Total Dose to the } \\
\text { Target Organs (rads } / \mu \mathrm{C} i \text { ) }\end{array}$} \\
\hline & Kidneys & Total Body & Bladder & Liver \& Spleen & \\
\hline Bladder & $2.004 E-05$ & $2.180 E-05$ & $5.543 E-06$ & $1.445 \mathrm{E}-05$ & $6.183 E-05$ \\
\hline Kidneys & $9.905 E-04$ & $1.848 \mathrm{E}-05$ & $6.945 E-08$ & $5.261 E-06$ & $1.014 \mathrm{E}-03$ \\
\hline Liver & $5.134 E-05$ & $1.965 \mathrm{E}-0$. & $7.333 E-08$ & $3.162 E-05$ & $1.027 \mathrm{E}-04$ \\
\hline Ovaries & $4.353 E-05$ & $1.985 \mathrm{E}-05$ & $4.429 E-07$ & $2.894 E-06$ & $6.672 E-05$ \\
\hline Red Marrow & $7.611 \mathrm{E}-05$ & $2.466 \mathrm{E}-0.05$ & $1.849 E-07$ & $3.466 \mathrm{E}-06$ & $1.044 \mathrm{E}-04$ \\
\hline Spleen & 1. $738 \mathrm{E}-04$ & $1.937 E-05$ & $5.614 \mathrm{E}-08$ & $1.849 \mathrm{E}-05$ & $2.117 E-04$ \\
\hline Testes & $1.294 \mathrm{E}-05$ & $2.301 E-05$ & $6.323 E-07$ & $6.182 E-07$ & $3.720 E-05$ \\
\hline Thymus & $7.660 \mathrm{E}-06$ & $1.878 E-05$ & $7.511 E-09$ & $1.779 \mathrm{E}-06$ & $2.822 E-05$ \\
\hline Thyroid & $2.485 \mathrm{E}-06$ & $2.217 E-05$ & 0.0 & $7.290 E-07$ & $2.538 \mathrm{E}-05$ \\
\hline Total Body & $3.475 E-05$ & $1.728 \mathrm{E}-0.5$ & $1.546 \mathrm{E}-07$ & $3.159 E-06$ & $5.534 \mathrm{E}-05$ \\
\hline
\end{tabular}


TABLE 12. ABSORZEED DOSE TO SELECiED ORGANS IN THE FIVE-YEAR DLC PHANTOM PER $\mu:$ : OF ADMINISTERED ACTIVITY OF $99 \mathrm{~m}_{\text {TC-DMSA }}$

\begin{tabular}{|c|c|c|c|c|c|}
\hline \multirow{2}{*}{$\begin{array}{l}\text { Target } \\
\text { Organs }\end{array}$} & \multicolumn{4}{|c|}{ Source Organs } & \multirow{2}{*}{$\begin{array}{l}\text { Total Dose to the } \\
\text { Target Organs ( } \mathrm{rads} / \mu \mathrm{C} i)\end{array}$} \\
\hline & Kidneys & Total Body & Bladder & Liver \& Spleen & \\
\hline Bladder & $3.917 E-05$ & $5.663 \mathrm{E}-05$ & c. $353 \mathrm{E}-05$ & $3.755 E-06$ & $1.230 \mathrm{E}-04$ \\
\hline Kidneys & $6.832 \mathrm{E}-04$ & $1.139 \mathrm{E}-05$ & $2.757 \mathrm{E}-08$ & $3.208 \mathrm{E}-06$ & $6.978 E-04$ \\
\hline Liver & $3.246 \mathrm{E}-05$ & $1.160 \mathrm{E}-0.5$ & $2.759 \mathrm{E}-08$ & $1.997 E-05$ & $6.406 E-05$ \\
\hline Ovaries & $2.007 E-05$ & $8.868 \mathrm{E}-06$ & $3.465 E-07$ & $1.506 \mathrm{E}-06$ & $3.079 \mathrm{E}-05$ \\
\hline Red Marrow & $4.833 \mathrm{E}-05$ & $1.568 \mathrm{E}-05$ & $1.136 \mathrm{E}-07$ & $2.038 \mathrm{E}-06$ & E.616E-05 \\
\hline Spleen & $1.12 \mathrm{GE}-04$ & $1.113 \mathrm{E}-05$ & $2.126 \mathrm{E}-08$ & $1.050 \mathrm{E}-05$ & $1.336 \mathrm{E}-04$ \\
\hline Testes & $4.356 \mathrm{E}-06$ & $1.366 \mathrm{E}-05$ & $3.369 \mathrm{E}-07$ & $8.606 \mathrm{E}-08$ & $1.844 \mathrm{E}-05$ \\
\hline Thymus & $4.195 E-06$ & $1.096 \mathrm{E}-05$ & $8.033 \mathrm{E}-10$ & $8.664 E-07$ & $1.602 E-05$ \\
\hline Thyroid & $4.787 \mathrm{E}-08$ & $9.261 \mathrm{E}-06$ & $6.044 \mathrm{E}-13$ & $1.036 \mathrm{E}-07$ & $9.412 \mathrm{E}-06$ \\
\hline Total Body & 2.239E-05 & $1.045 \mathrm{E}-05$ & $9.884 \mathrm{E}-08$ & $1.960 \mathrm{E}-06$ & $3.490 \mathrm{E}-05$ \\
\hline
\end{tabular}




\section{CHAPTER V}

\section{SUMMARY}

Mathematical representations of one-year old and five-year old children were developed using anatomical references as a basis for gross phantom geometries and organ sizes, shapes and weights. These mathematical phantoms were encoded into Fortran computer language such that they could be used in the Monte-Carlo photon transport code in existence at ORNL. This transport code and the Snyder-Fisher phantom were the basis of dosimetric studies on adults.

Absorbed dose calculations were performed for two $99 m_{T}$ c labeled pharmaceuticals using the one-year old and five-year old phantoms. The radioistope ${ }^{99 m}$ Tc was chosen for use in these calculations since this isotope has wide use in pediatric nuclear medicine (Adelstein, 1975 and Smith, 1975)

The development of pediatric phantoms. which can be used to estimate absorbed dose has become important. Children are being exposed to many nuclear medicine procedures, and dose estimates are needed in the muclear industry, for children represent an important group in the U.S. population. Previous estimates of absorbed dose in children were calculated by using shrunken versions of the snyderFisher phantom. This adult phantom was reduced by factors chosen to represent a particular age. But a child is not merely an adult shrunk by a constant factor. Some organs are in different proportion in children than in the adult, e.g., the thymus gland is larger in children in proportion to the rest of the organs than in the adult. 
These pediatric phantoms will play an increasingly important role in calculating absorbed doses to children from both internal and external radiation sources and will help eliminate uncertainties introduced when shrunken adult phantoms are used in estimating dose. 


\section{REFERENCES}




\section{REFEREINCES}

Adelstein, S. J., Personal Communication to J. W. Poston, 1975.

Altman, P. L. and D. S. Dittmer, "Growth Including Reproduction and Morphological Development," Biological Handbook, Fed. Am. Soc. Expt1. Biol., Washington, (1962).

Attix, F. H., W. C. Roesch, and E. Tochlin, in Radiation Dosimetry (Academic Press, 1968), pp. 94-154.

Berger, M. J., MIRD Pamphlet No. 2, J. Nucl. Med. 9, Supp1. No. 1, $15(1968)$.

Boyd, [., "The Specific Gravity nf the Human Body," Human Biol. $\underline{5}$, pp. 646-672, (1933).

Coppoletta, J. M. and S. B. Wolbach, "Body Length and Organ Weights of Infants and Children," Am. J. Pathol. 9, pp. 55-70, (1933).

Dil lman, L. T., MIRD Pamphlet No. 4, J. Nuc1. Med. 10, Supp1. No. 2 (1969).

Ellett, W. H., A. B. Callahan, and G. L. Brownell, Brit. J. Radiol. 37, $45(1964)$.

Ellett, W. H., A. B. Callahan, and G. L. Brownell, Brit. J. Radiol. 38 , $541(1965)$.

Ellett, W. H., G. L. Brownel1, and A. R. Reddy, Phys. Med. Biol. 13, 219 (1968).

Ellett, W. H., Phys. Med. Biol. 14, 615 (1969).

Ellis, R. E., Phys. Med. Biol. 5, 225 (1961).

[mery, J. and A. Mitha1, "The Weight of the Lungs," The Anatomy of the Lungs ( $W$. Heineman Medical Books Ltd. and Spartics Internationā Medical Publications, Loveham, Suffolk, U.K., 1969), pp. 203-206, edited by J. Emery.

Engel, S., The Child's Lung Developmental Anatomy, Physiology and Pathology, (Edward Arnold and Co., London, 1947).

Fisher, H. L., Jr. and W. S. Snyder, Oak Ridge National Laboratory Report ORNL-4007, 211 (1966).

Fisher, H. L., Jr. and W. S. Snyder, Oak Ridge National Laboratory Report ORNL-4168, 245 (1967). 
Fair, M. F., Personal Communication, 1974.

Garry, S. M., P. S. Stansbury, and J. W. Poston, Oak Ridge National Laboratory Report ORNL-TM-4411, (1974).

Hayes, R. L. and M. Brucer, Intern. J. Appl. Rad. Isotopes g, 111 (1960).

Hilyer, M. J. C., W. S. Snyder, and G. G. Warner, Oak Ridge National Laboratory Report ORNL-4811, 91 (1972).

Hilyer, M. J. and W. S. Snyder, "Estimates of Dose from Xenon-133 to Infants and Children for Immersion in an Infinite Cloud and for Medical Uses," Seventh Midyear Topical Symposium of the Health Physics Society San Juan, Puerto Rico, December 11-14, 1972, DHEW Publication (FDA) 73-8029, pp. 131-140 (1973).

Ingalls, N. W., Am. J. Anat. 48 , pp. 45-98 (1931).

Jones, T. D., Health Physics 21,553-562 (1971).

Jones, T. D., W. S. Snyder and J. A. Auxier, Health Physics 21, 253-272 (1971).

Krogman, W. M. in The Human Skeleton in Forensic Medicine (Charles C. Thomas, publisher, 1962) pp. 122-131.

Lapp, R. E. and H. L. Andrews in Nuclear Radiation Physics, (PrenticeHa11, Inc., Englewood Cliffs, N. J.) pp. 236-245 (1972).

Loevinger, R. and M. Berman, MIRD Pamphlet No. 1, J. Nucl. Med. $\underline{9}$, Suppl. No. 1, 7 (1968).

Mueller, K. H., A. Trias, and R. D. Ray, J. Bone Joint Surgery $4 \underline{8}$ A, pp. 140-148 (1966).

National Bureau of Standards Handbook 69 (1959).

Poston, J. W., W. S. Snyder, and G. G. Warner, "Age Factors for Dose Rates from an Infinite Cloud of a Photon Emitter," Proceedings of the Eighth Midyear Topical Symposium of the Health Physics Society, Knoxville, Tennessee, October 21-24, 1974, CONF-741018, (1974).

Price, W. J., in Nuclear Radiation Detection (McGraw-Hill Book Company, 1964) pp. 20-28.

Recommendations of the International Commission on Radiological Protection, Report of International Sub-Committee. II on Permissible Dose for Internal Radfation - 1954, Brit. J. Radiol. Suppi. $\underline{6}$ (1955). 
Recommendations of the International Commission on Radiological Protection, ICRP Publication 9 (Pergamon Press, 0xford, 1965).

Reddy, A. R., W. H. Ellet, and G. C. Brownell, Brit. J. Radiol. 40, 512 (1967).

Report of the ICRP Committee 2 on Permissible Dose for Internal Radiation (1959), Health Physics $\underline{3}$ (1960).

Scammon, R. E., "The Vevelopmental Anatomy of the Chest and the Thnracic Oryans," The Normal Chest of the Adult and the Child, (w1171ams and Wilkins, Co., Baltimore, 1927 ) Chap. XI, pp. 300-335, edited by J. A. Myers.

Scammon, R. E., "The Measurement of the Body in Childhood," The Measurement of Man (University of Minnesota Press, Minneapol is, 1930), pp. $173-215$, edited by J. A. Harris, C. M. Jackson, D. G. Paterson, and R. E. Scammon.

Shleien, B., "A View of Determinations of Radiation Dose to the Active Bone Marrow from Diagnostic X-ray Examination," 1973, DHEW Publication (FDA) 74-8007.

Smith, E. M., Personal Communication to J. W. Poston (1975).

Snyder, W. S., M. J. Cook, and I. H. Tipton, Dak Ridge National Laboratory Report ORNL-4007, 213 (1966).

Snyder, W. S., M. R. Ford, and G. G. Warner, Oak Ridge National Laboratory Report ORNL-4316, 274 (1968).

Snyder, W. S., M. R. Ford, G. G. Warner, and H. L. Fisher, Jr., MIRD Pamphlet No. 5, J. Nucl. Med. 10, Suppl. No. 3 (1969).

Snyder, W. S. and M.J. Cook, Oak Ridge National Laboratory Report ORNL4720, 116 (1971).

Snyder, W. S., M. R. Ford, and G. G. Warner, Oak Ridge National Laboratory Report ORNL-4822, 86 (1972).

Snyder, W. S., M. J. Cook, E. S. Nasset, L. Karhausen, G. P. Howells, and I. H. Tipton, Report of the Task Group on Reference Man, ICRP Publication No. 2.3, (1975).

Snyder, W. S., M. R. Ford, G. G. Warner and S. B. Watson, "A Tabulation of Dose Equivalent per Microcurie-Day for Source and Target Organs of an Adult for Various Radionuclides," Oak Ridge National Laboratory Report ORNL-5000 (1974a). 
Snyder, W. S., M. R. Ford, and G. G. Warner, Oak Ridge National Laboratory Report ORNL-4979, 5 (1974b).

Stansbury, P. S. and J. W. Poston, Oak Ridge National Laboratory Report ORNL-4979, 73 (1974).

Sturgeon, P., "Volumetric and Microscopic Pattern of Bone Marrow in Normal Infants and Children, Part I. Volumetric Pattern," Pediatrics 1, pp. 577-588 (1951).

Tanner, J. M., R. H. Whitehouse, and M. Takaishi, "Standards from Birth to Maturity for Height, Weight, Height Velocity and Weight Velocity: British Children, 1965, Part I," Arch. Dis. Childhood 41, pp. 454471 (1966).

Tanner, J. M., R. H. Whitehouse, and M. Takaishi, "Standards from Birth to Maturity for Height, Weight, Height Velocity and Weight Velocity: British Children, 1965, Part II," Arch. Dis. Childhood 41, pp. 613635 (1966).

Tipton, I. H., W. S. Snyder, and M. J. Cook, Oak Ridge National Laboratory Report ORNL-4007, 241 (1966).

Trotter, M. and R. R. Peterson, Am. J. Physiol. Anthropol. 33, pp. 313$324(1970)$.

Warner, G. G., Oak Ridge National Laboratory Report ORNL-TM-4383 (1973).

Warner, G. G, and A. M. Craig, Jr., Oak Ridge National Laboratory Report ORNL-TM-2250 (1968).

Warner, G. G., W. S. Snyder, A. M. Craig, Jr., and H. L. Fisher, Oak Ridge National Laboratory Report RSIC-13, II , August (1972).

Warner, G. G., J. W. Poston, and W. S. Snyder, Health Physics 28, 599$603(1975)$.

Whyte, G. N., Principles of Radiation Dosimetry (New York, John Wiley and Sons, Inc., 1959) pp. 26-40.

Wilhoit, D. G. and T. D. Jones, Rad. Res. 44, 263-272 (1970). 
THIS PAGE

WAS INTENTIONALLY

LEFT BLANK 


\section{APPENDIXES}

\section{APPENDIX A \\ DESCRIPTION OF THE ONE-YEAR-OLD MATHEMATICAL \\ CHILD PHANTOM}

\section{Exterior of the Phantom}

The body is represented as erect with the positive Z-axis directed upward toward the head. The $X$-axis is directed to the phantom's left (the reader's right in Figure $A-I$ ), and the $Y$-axis is directed toward the posterior side of the phantom. The origin is taken at the center of the base of the "trunk" section of the phantom. The axes are calibrated in centimeters.

The "trunk" is a solid elliptical cylinder specified by

$$
\left(\frac{X}{8.6}\right)^{2}+\left(\frac{Y}{7}\right)^{2} \leq 1
$$

and

$$
0 \leq z \leq 32
$$

so that the "trunk" includes the arms as well as the pelvic and hip bones from the point where the separation of the Tegs begins. The volume of the trunk section is $6,052 \mathrm{~cm}^{3}$, and the mass is $5,875 \mathrm{~g}$.

The head. section is a right elliptical cylinder topped by half an ellipsoid. The locus is specified by

$$
\left(\frac{X}{6.8}\right)^{2}+\left(\frac{Y}{8}\right)^{2} \leq 1
$$

and

$$
32 \leq Z \leq 42.6
$$

or 


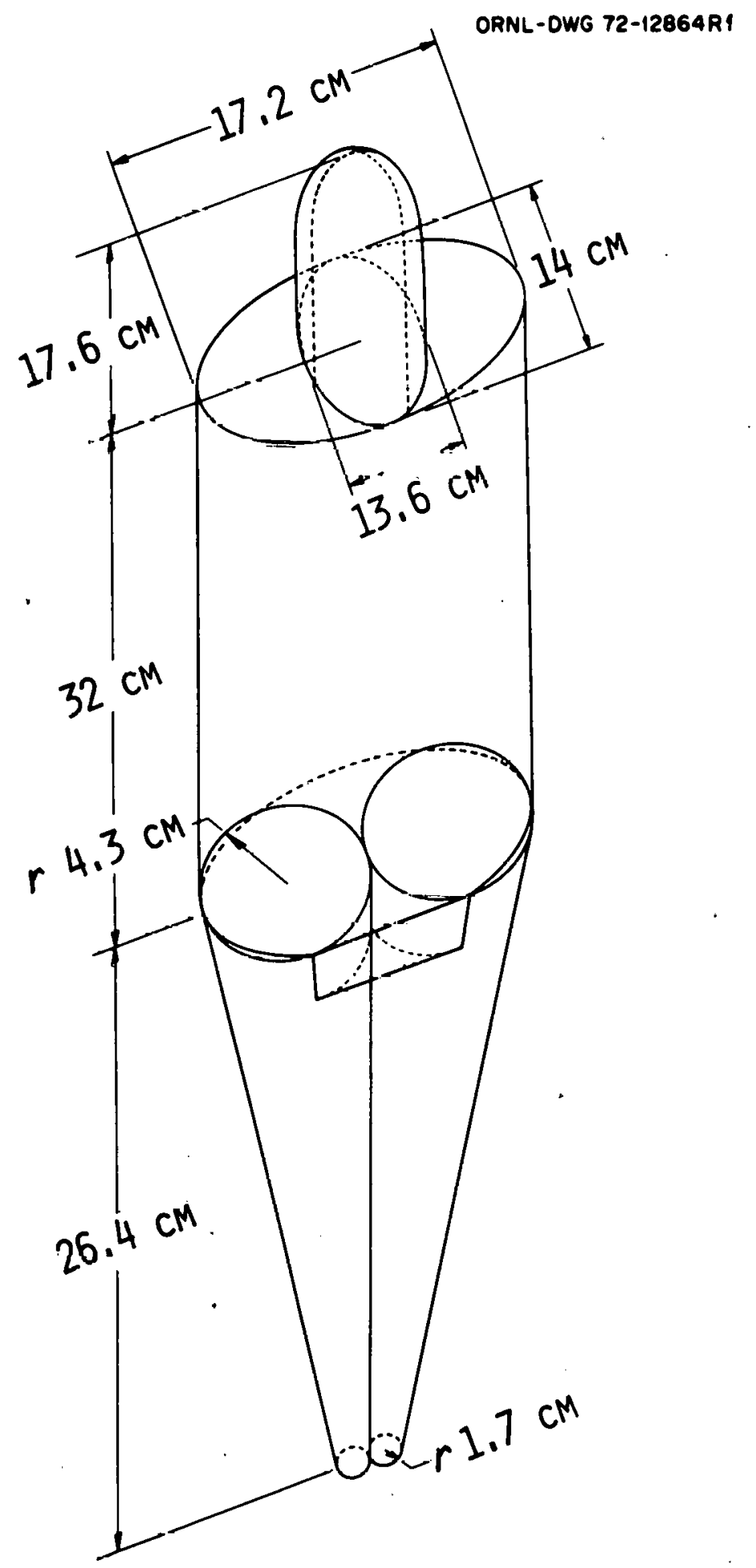

FIGURE A-I. THE ONE-YEAR OLD PHANTOM. 


$$
\left(\frac{X}{6.8}\right)^{2}+\left(\frac{Y}{8}\right)^{2}+\left(\frac{Z-42.6}{7}\right) \leq 1,
$$

and

$$
42.6 \leq Z \leq 49.6 .
$$

The total volume is $2,609 \mathrm{~cm}^{3}$, and the mass is $2,849 \mathrm{~g}$.

The leg region of the phantom consists of the frustums of two circular cones specified by

$$
X^{2}+y^{2} \leq \pm X\left(8.6+\frac{Z}{5.075}\right)
$$

and

$$
-26.4 \leq z \leq 0,
$$

where the plus sign defines the left leg and the minus sign the right. The total volume of both legs is $1,586 \mathrm{~cm}^{3}$, and the mass is $1,672 \mathrm{~g}$. It is apparent that the the leg region does not join smoothly the trunk region, because the legs protrude slightly beyond the ellipse defining the trunk in the plane $Z=0$.

The genitalia region (male) of the phantom consists of the region specified by

$$
\begin{gathered}
-1.58 \leq Z \leq 0, \\
-\left(4.3+\frac{Z}{10.15}\right) \leq X \leq\left(4.3+\frac{Z}{10.15}\right), \\
-\left(4.3+\frac{Z}{10.15}\right) \leq Y \leq 0,
\end{gathered}
$$

and 


$$
\left(x \pm\left(4.3+\frac{z}{10.15}\right)\right)^{2}+y^{2} \geq\left(4.3+\frac{z}{10.15}\right)^{2}
$$

and this last inequality must hold for either choice of sign, i.e., the genitalia region lies outside both legs. The genitalia region has a volume of $12 \mathrm{~cm}^{3}$ and a mass of $11.9 \mathrm{~g}$.

\section{Organs}

Skeletal System. The skeletal system consists of the twelve parts described below, and the dose and absorbed fraction are recorded separately for each part as well as for the total skeleton.

Leg Bones. Each leg bone is the frustum of an elliptical cone. The expression for the left leg bone is

$$
\left(x-4.3-\frac{2.6}{26.2} z\right)^{2}+y^{2} \leq\left(1.7+\frac{1.2}{26.2} z\right)^{2},
$$

and

$$
-26.2 \leq Z \leq 0 .
$$

The volume of both bones is $219 \mathrm{~cm}^{3}$ and the mass is $306.6 \mathrm{~g}$.

Arm Bones. Each arm bone is the frustum of an elliptical cone.

The left one is defined by

$$
\left[\frac{(0.7 / 62.4)(Z-31.2)+(X-7.7)}{0.7}\right]^{2}+\left(\frac{Y}{1.3}\right)^{2} \leq\left[\frac{62.4+(Z-31.2)}{62.4}\right]^{2}
$$

and

$$
0 \leq z \leq 31.2 \text {. }
$$

The volume of both arm bones is $104 \mathrm{~cm}^{3}$ and the mass is $145.6 \mathrm{~g}$. 
Pelvis. The pelvis is a portion of the volume between two nonconcentric circular cylinders described by

$$
\begin{gathered}
X^{2}+(Y+1.5)^{2} \leq(6)^{2} \\
X^{2}+(Y+2)^{2} \geq(5.5)^{2} \\
Y+1.5 \geq 0 \\
0 \leq Z \leq 9.6 \\
Y \leq 2.5 \quad \text { if } \quad Z \leq 6.14 .
\end{gathered}
$$

Its volume is $89.76 \mathrm{~cm}^{3}$, and its mass is $125.66 \mathrm{~g}$.

Spine. The spine is an elliptical cylinder given by

$$
\left(\frac{X}{1.1}\right)^{2}+\left(\frac{Y-3.8}{1.4}\right)^{2} \leq 1,
$$

and

$$
9.6 \leq z \leq 36.5,
$$

and has a volume of $130 \mathrm{~cm}^{3}$ and a mass of $182.2 \mathrm{~g}$. It is divided into three portions--an upper, middle and lower third--and dose and AF are estimated separately for each portion. These divisions are formed by the $p l$ anes $Z=32$ and $Z=16.1$.

Sku11. The skull is the volume between two nonconcentric ellipsoids defined by

$$
\begin{aligned}
& \left(\frac{X}{6}\right)^{2}+\left(\frac{Y}{7.2}\right)^{2}+\left(\frac{Z-43.4}{5.4}\right)^{2} \geq 1 \\
& \left(\frac{X}{6.6}\right)^{2}+\left(\frac{Y}{7.8}\right)^{2}+\left(\frac{Z-42.6}{6.8}\right)^{2} \leq 1
\end{aligned}
$$

and has a volume of $489 \mathrm{~cm}^{3}$ and a mass of $684.8 \mathrm{~g}$. 
Rib Cage. The rib volume is a series of bands between two concentric, right-vertical, elliptical cylinders. This region is sliced by a series of equispaced horizontal plans into slabs, every other slice being a rib. The statements that must be satisfied are

$$
\begin{gathered}
\left(\frac{X}{7}\right)^{2}+\left(\frac{Y}{6.8}\right)^{2} \leq 1 \\
\left(\frac{X}{6.7}\right)^{2}+\left(\frac{Y}{6.5}\right)^{2} \geq 1 \\
16.1 \leq z \leq 30.82 \\
\text { Integer }\left(\frac{Z-16.1}{0.64}\right) \text { is even. }
\end{gathered}
$$

The total rib volume is $97.7 \mathrm{~cm}^{3}$ and the mass is $136.7 \mathrm{~g}$.

Clavicles. The clavicles are represented as two portions of a torus which lie along the circular $\operatorname{arc} X^{2}+(Y-1)^{2}=(6.8)^{2}, Z=$ 31.4 , and has a smaller radius of $0.3831 \mathrm{~cm}$. The clavicles include only the portion of the torus between the planes $1-Y=|X| \cot \theta$ with $\theta=4^{\circ} 30.24^{\prime}$ and $\theta=76^{\circ} 30.24^{\prime}$. The absolute value sign on $X$ allows for both a right and a left clavicle. The volume of both clavicles is $7.88 \mathrm{~cm}^{3}$, and the mass is about $11 \mathrm{~g}$. The equations can be reduced to the form

$$
(Z-31.4)^{2}+\left(6.8-\sqrt{X^{2}+(Y-1)^{2}}\right)^{2} \leq(0.3831)^{2}
$$

and

$$
0.2400049 \leq \frac{1-Y}{|X|} \leq 12.694873, \quad Y \leq 0
$$


The clavicles lie slightly inside the cylinder defining the rib cage and just above the top rib. They are shown schematically in Figure AII.

Scapulae. The scapulae extend from $Z=30.82 \mathrm{~cm}$ (the top of the twelfth rib) to $Z=23.32 \mathrm{~cm}$ and 1 ie between two elliptical cylinders.

$$
\left(\frac{X}{7}\right)^{2}+\left(\frac{y}{6.0}\right)^{2}=1 \quad \text { (outer surface of ribs) }
$$

and

$$
\left(\frac{X}{7.8}\right)^{2}+\left(\frac{Y}{6.8}\right)^{2}=1 \text { (a somewhat larger cylinder) }
$$

Although the lower portion of the scapula is somewhat smaller than the upper, this distinction is ignored here, and the left scapula will occupy all the above space between the planes $Y=0.25 X$ and $Y=0.80 X$. Thus the test for point $(X, Y, Z)$ to be in the left scapula is the following:

$$
\begin{gathered}
23.32 \leq Z \leq 30.82, \\
\left(\frac{X}{7.8}\right)^{2}+\left(\frac{Y}{6.8}\right)^{2} \leq 1, \\
\left(\frac{X}{7}\right)^{2}+\left(\frac{Y}{6.8}\right)^{2}>1, \\
Y>0, \quad 0.25<Y / X<0.80 .
\end{gathered}
$$

For the right scapula, only the last inequality needs to be replaced by

$$
0.25<Y /-X<0.80 \text {. }
$$

For both scapulae, one uses 


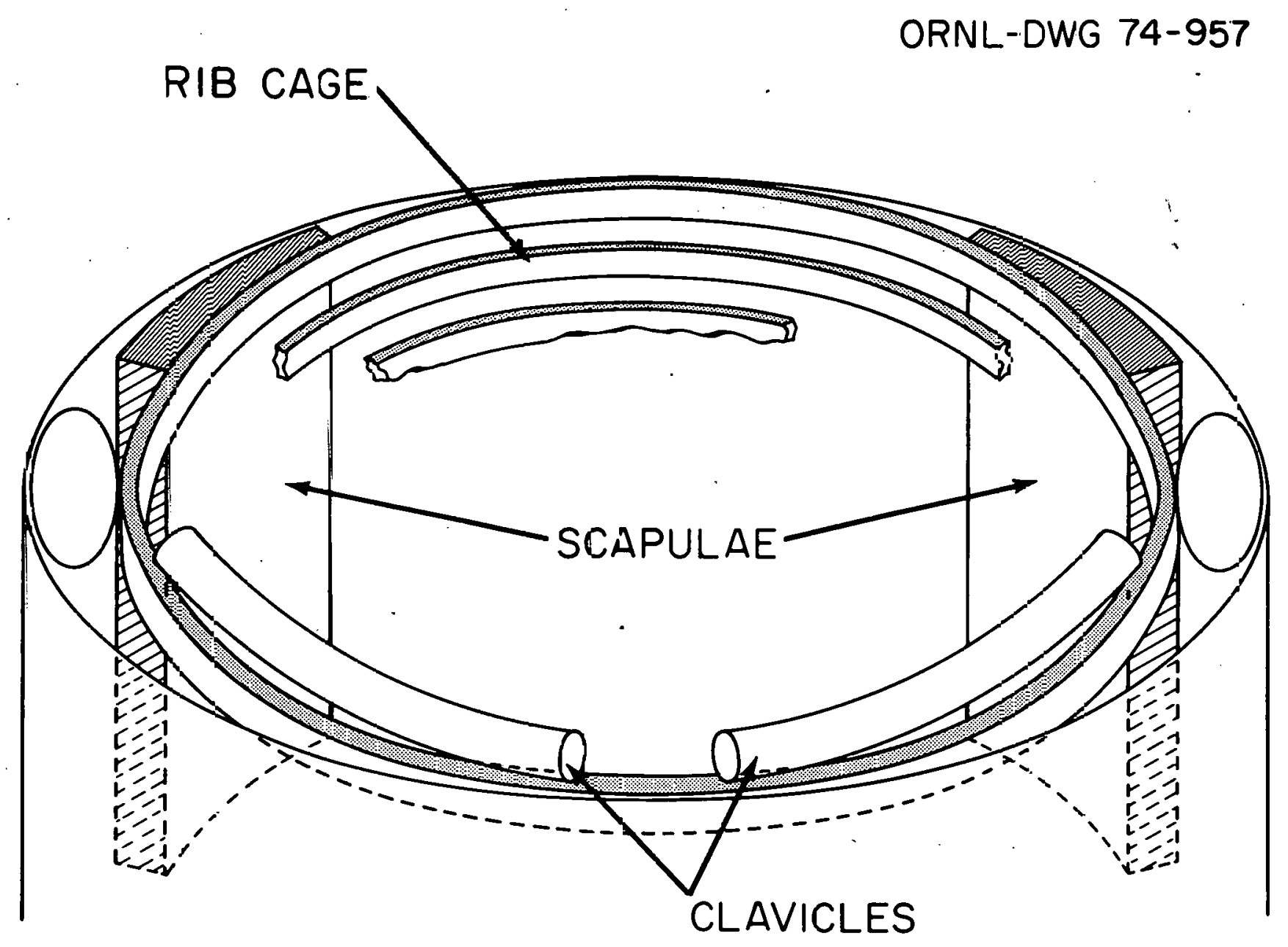

FIGURE A-II. DETAILED VIEW OF SCAPULAE AND CLAVICLES. 


$$
0.25<Y /|X|<0.80 \text {, }
$$

the other four inequalities being unaltered.

Consider the ellipse $\left(\frac{x}{a}\right)^{2}+\left(\frac{y}{b}\right)^{2}=1$. The point $(\rho, \theta)$ lies on this ellipse if

$$
\frac{\rho^{2} \cos ^{2} \theta}{a^{2}}+\frac{\rho^{2} \sin ^{2} \cdot \theta}{b^{2}}=1 \text {, }
$$

or, equivalently, if

$$
\rho=\frac{a b}{\sqrt{a^{2} \sin ^{2} \theta+b^{2} \cos ^{2} \theta}} .
$$

The area of a sector of the ellipse is given by

$$
\begin{gathered}
A\left(\theta_{1}, \theta_{2}\right)=\int_{\theta_{1}}^{\theta_{2}} \frac{\rho^{2}}{2} d \theta=\int_{\theta_{1}}^{\theta_{2}} \frac{a^{2} b^{2} d \theta}{2\left(a^{2} \sin ^{2} \theta+b^{2} \cos ^{2} \theta\right)} \\
=\frac{a b}{2}\left[\arctan \frac{a \tan \theta_{2}}{b}-\arctan \frac{a \tan \theta_{1}}{b}\right] .
\end{gathered}
$$

The volume of a "wedge" of height $h$ with the base is then

$$
V=\frac{a b h}{2}\left[\arctan \frac{a \tan \theta_{2}}{b}-\arctan \frac{a \tan \theta_{1}}{b}\right] \text {. }
$$

The volume of one scapula is then

$$
V(\text { scaputa })=V_{2}-V_{1}
$$

where $V_{2}$ is obtained from the above formula by substituting $a=7.8$, $b=6.8, h=7.5, \tan \theta_{2}=0.8$, and $\tan \theta_{1}=0.25$, and for $v_{1}$ one uses the same values except that $a=7$. One finds

$$
V(\text { scapula })=V_{2}-V_{1}=92.132-78.011=14.121 \mathrm{~cm}^{3} \text {. }
$$

For density of $1.4 \mathrm{~g} / \mathrm{cm}^{3}$, one has a mass of $19.77 . \mathrm{g}$ for one scapula. The scapulae, as so defined, do not intersect the arm bones or the ribs or other designated organs of the phantom. The scapulae are included in Figure A-II. 
Adrenals. Each adrenal is half an ellipsoid atop a kidney. The left adrenal is given by

$$
\left(\frac{x-2.15}{0.95}\right)^{2}+\left(\frac{y-4.53}{0.33}\right)^{2}+\left(\frac{z-16}{3}\right)^{2} \leq 1,
$$

and

$$
z \geq 16
$$

the volume of both adrenals is $3.94 \mathrm{~cm}^{3}$ (Figure A-III), and the mass is $4.04 \mathrm{~g}$.

Urinary Bladder and Contents. The bladder is regarded as an ellipsoid, and the defining inequalities are

$$
\begin{aligned}
& \left(\frac{X}{2.53}\right)^{2}+\left(\frac{Y+2.4}{1.76}\right)^{2}+\left(\frac{Z-3.6}{1.76}\right)^{2} \leq 1 \\
& \left(\frac{X}{2.37}\right)^{2}+\left(\frac{Y+2.4}{1.6}\right)^{2}+\left(\frac{Z-3.6}{1.6}\right)^{2} \geq 1 .
\end{aligned}
$$

The volume is $7.41 \mathrm{~cm}^{3}$, and the mass is $7.31 \mathrm{~g}$. The contents have a volume of $25.41 \mathrm{~cm}^{3}$ and a mass of $25.08 \mathrm{~g}$. This represents a moderately full bladder.

Dose to the bladder wall from a photon emitter present in the urine will vary greatly, depending on the degree of filling even for the same concentration or amount of activity present. The specific absorbed fraction, $\Phi$ (bladder wall \& content), will vary by approximately an order of magnitude (Snyder, Ford and Warner, 1970). Thus the user of these data should be aware that the values tabulated here are only appropriate for one size of bladder. The difference in $\Phi$, or dose rate, to the bladder walls of different sizes from other 


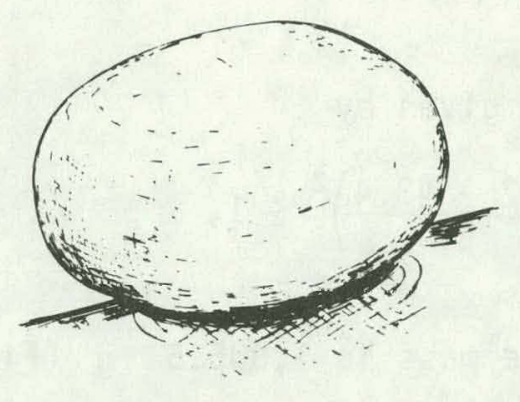

BLADDLR

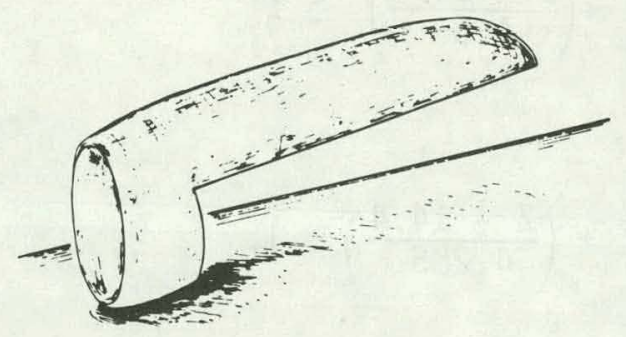

PANCREAS

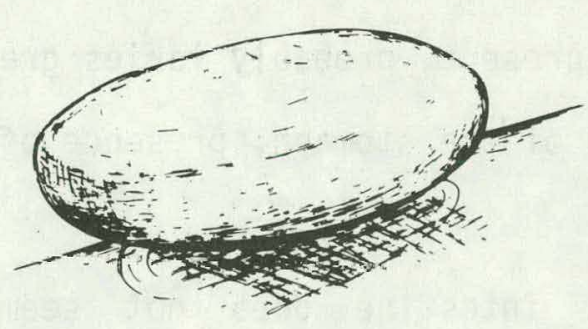

SPLEEN

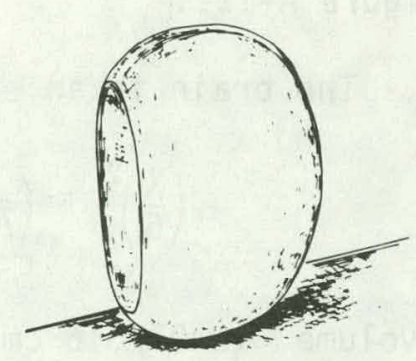

KIDNEY

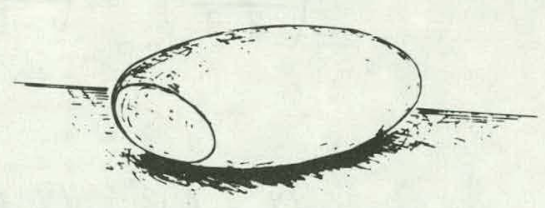

UTERUS

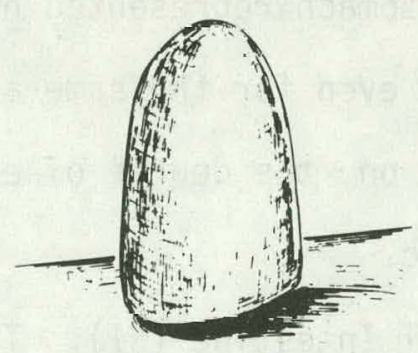

ADRENAL

FIGURE A-III. MATHEMATICAL MODELS FOR THE BLADDER, KIDNEYS, PANCREAS, UTERUS, SPLEEN AND ADRENALS. 
source organs outside the bladder is generally smal1. The bladder is shown in Figure A-III.

Brain. The brain is an ellipsoid given by

$$
\left(\frac{X}{6}\right)^{2}+\left(\frac{Y}{7.2}\right)^{2}+\left(\frac{Z-43.4}{5.4}\right)^{2} \leq 1
$$

and the volume is $977.16 \mathrm{~cm}^{3}$ and the mass is $1,005.5 \mathrm{~g}$ (Figure AIV).

Gastruintestinal Iract and Contents-Stomach (S). The stomach is represented as the mass between two ellipsoids

$$
\left(\frac{X-4}{2.3}\right)^{2}+\left(\frac{Y+2.2}{1.7}\right)^{2}+\left(\frac{Z-14.4}{4.6}\right)^{2} \leq 1
$$

and

$$
\left(\frac{X-4}{1.985}\right)^{2}+\left(\frac{\dot{Y}+2.2}{1.385}\right)^{2}+\left(\frac{Z-14.4}{4.285}\right)^{2} \geq 1
$$

The volume is $25.99 \mathrm{~cm}^{3}$, and the mass is $27.3 \mathrm{~g}$; the contents have a volume of $49.3 \mathrm{~cm}^{3}$ and a mass of $48.69 \mathrm{~g}$. The thickness of the stomach wall is about $0.315 \mathrm{~cm}$.

The stomach represented here is a "full" stomach, and the average dose rate, even for the same activity present, probably varies greatly depending on the degree of extension of the stomach, presence of air spaces, etc.

-Small Intestine (SI). The small intestine does not seem to remain in any "standard position" except the ends which are relatively fixed. Thus the small intestine is to be regarded as occupying a volume within which it is free to move. No attempt to determine a specific configuration is made here, and thus the wall and contents 

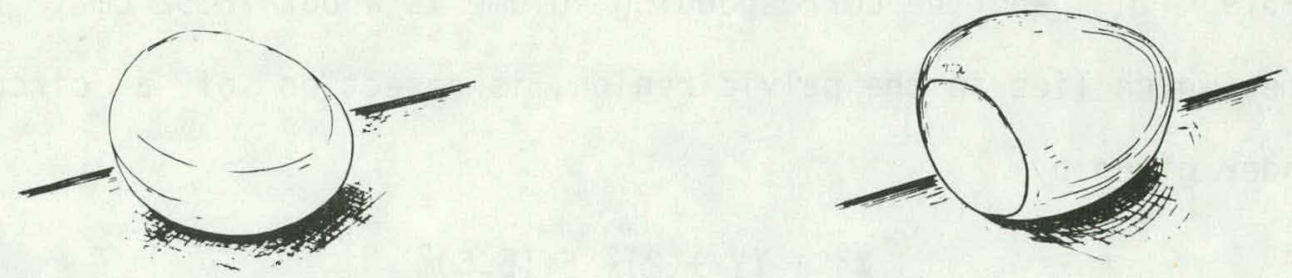

HEART
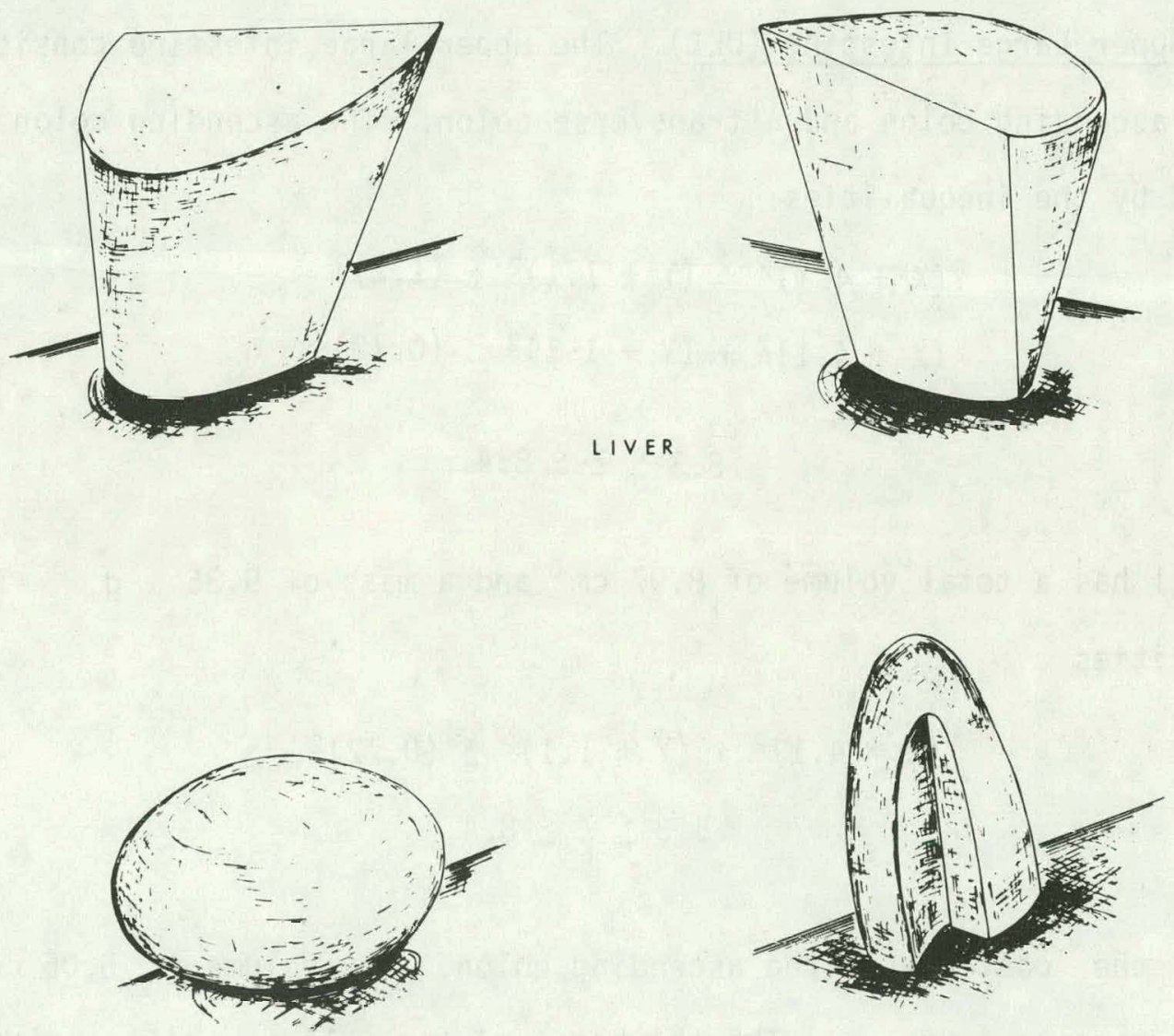

BRAIN

LIVER

IUNG

FIGURE A-IV. MATHEMATICAL MODELS FOR THE HEART, LIVER, BRAIN AND LUNGS. 
are not distinguished for estimation of photon dose. The total mass is $75.9 \mathrm{~g}$, and the corresponding volume is about $76.92 \mathrm{~cm}^{3}$. This volume, which lies in the pelvic region, is a section of a circular cylinder given by

$$
\begin{gathered}
X^{2}+(Y+2)^{2} \leq(5.5)^{2} \\
-2.3 \leq Y \leq 1.9 \\
7.24 \leq Z \leq 9.8
\end{gathered}
$$

but the portion of the large intestine within this region is excluded. -Upper Large Intestine (ULI). The upper large intestine consists of an ascending colon and a transverse colon. The ascending colon is defined by the inequalities

$$
\begin{aligned}
& (X+4.1)^{2}+(Y+1.1)^{2} \leq(1.2)^{2} \\
& (X+4.1)^{2}+(Y+1.1)^{2} \geq(0.72)^{2}
\end{aligned}
$$

$$
5.3 \leq z \leq 8.4 \text {. }
$$

The wall has a total volume of $8.97 \mathrm{~cm}^{3}$ and a mass of $9.36 \mathrm{~g}$. The inequalities

$$
\begin{gathered}
(X+4.1)^{2}+(Y+1.1)^{2} \leq(0.72)^{2} \\
5.3 \leq Z \leq 8.4
\end{gathered}
$$

define the contents of the ascending colon. The volume is $5.05 \mathrm{~cm}^{3}$, and the mass is $4.98 \mathrm{~g}$. The thickness of the wall according to this model is $0.48 \mathrm{~cm}$.

The transverse colon is an elliptical cross-section and is defined by 


$$
\begin{aligned}
& \left(\frac{Y+1.1}{1.2}\right)^{2}+\left(\frac{Z-9.1}{0.7}\right)^{2} \leq 1 \\
& \left(\frac{Y+1.1}{0.9}\right)^{2}+\left(\frac{Z-9.1}{0.4}\right)^{2} \geq 1
\end{aligned}
$$

$-5.2 \leq x \leq 5.2$

The volume of the wall is $16.28 \mathrm{~cm}^{3}$, and the mass is $16.98 \mathrm{~g}$. By this model the thickness is about $0.3 \mathrm{~cm}$. The contents are specified by

$$
\begin{gathered}
\left(\frac{Y+1.1}{0.9}\right)^{2}+\left(\frac{Z-9.1}{0.4}\right)^{2} \leq 1 \\
-5.2 \leq x \leq 5.2 .
\end{gathered}
$$

The volume is $11.76 \mathrm{~cm}^{3}$, and the mass is $11.6 \mathrm{~g}$.

-Lower Large Intestine (LLI). The lower large intestine consists of a descending colon and a sigmoid colon. The descending colon is described by the inequalities

$$
\begin{gathered}
\left(\frac{X-X_{0}}{0.9}\right)^{2}+\left(\frac{Y-Y_{0}}{1}\right)^{2} \leq 1 \\
\left(\frac{X-X_{0}}{0.65}\right)^{2}+\left(\frac{Y-Y_{0}}{0.5}\right)^{2} \geq 1 \\
4.1 \leq Z \leq 8.4
\end{gathered}
$$

where

$$
\begin{aligned}
& x_{0}=4.3+\frac{0.2(z-8.4)}{4.3} \\
& y_{0}=\frac{1.2(4.1-z)}{4.3}
\end{aligned}
$$

The descending colon has a volume of $7.76 \mathrm{~cm}^{3}$ and a mass of $8.1 \mathrm{~g}$. The thickness of the wall would vary between $0.25 \mathrm{~cm}$ and $0.5 \mathrm{~cm}$ according to this model. 
The sigmoid colon consists of portions of two torii and is defined by the inequalities (upper portion)

$$
\begin{aligned}
& \left(\sqrt{(X-1.4)^{2}+(z-4.1)^{2}}-2.7\right)^{2}+y^{2} \leq(0.85)^{2} \\
& \left(\sqrt{(x-1.4)^{2}+(z-4.1)^{2}}-2.7\right)^{2}+y^{2} \geq(0.3)^{2} \\
& x \geq 1.4 \text { and } z \leq 4.1
\end{aligned}
$$

and (lower portion)

$$
\begin{gathered}
\left(\sqrt{(X-1.4)^{2}+Z^{2}}-1.4\right)^{2}+Y^{2} \leq(0.85)^{2} \\
\left(\sqrt{(X-1.4)^{2}+Z^{2}}-1.4\right)^{2}+Y^{2} \geq(0.3)^{2} \\
X \leq 1.4 \text { and } Z \geq 0 .
\end{gathered}
$$

The volume of the sigmoid colon is $12.8 \mathrm{~cm}^{3}$, and the mass is 13.34 g. The thickness of the wall would be $0.55 \mathrm{~cm}$ according to this model.

The entire gastrointestinal tract is sketched in Figure A-V .

Heart. The heart is half an ellipsoid capped by a hemisphere which is cut by a plane. A rotation and translation are then effected. The heart (Figure A-IV) is represented by

$$
\begin{aligned}
X_{1}=0.6943(X+0.5)-0.3237(Y+1.5)-0.6428(Z-22.4), \\
Y_{1}=0.4226(X+0.5)+0.9063(Y+1.5), \\
Z_{1}=0.5826(X+0.5)-0.2717(Y+1.5)+0.7660(Z-22.4), \\
\left(\frac{X_{1}}{3.4}\right)^{2}+\left(\frac{Y_{1}}{2.2}\right)^{2}+\left(\frac{Z_{1}}{2.2}\right)^{2} \leq 1,
\end{aligned}
$$


ORNL-DWG 73-12124

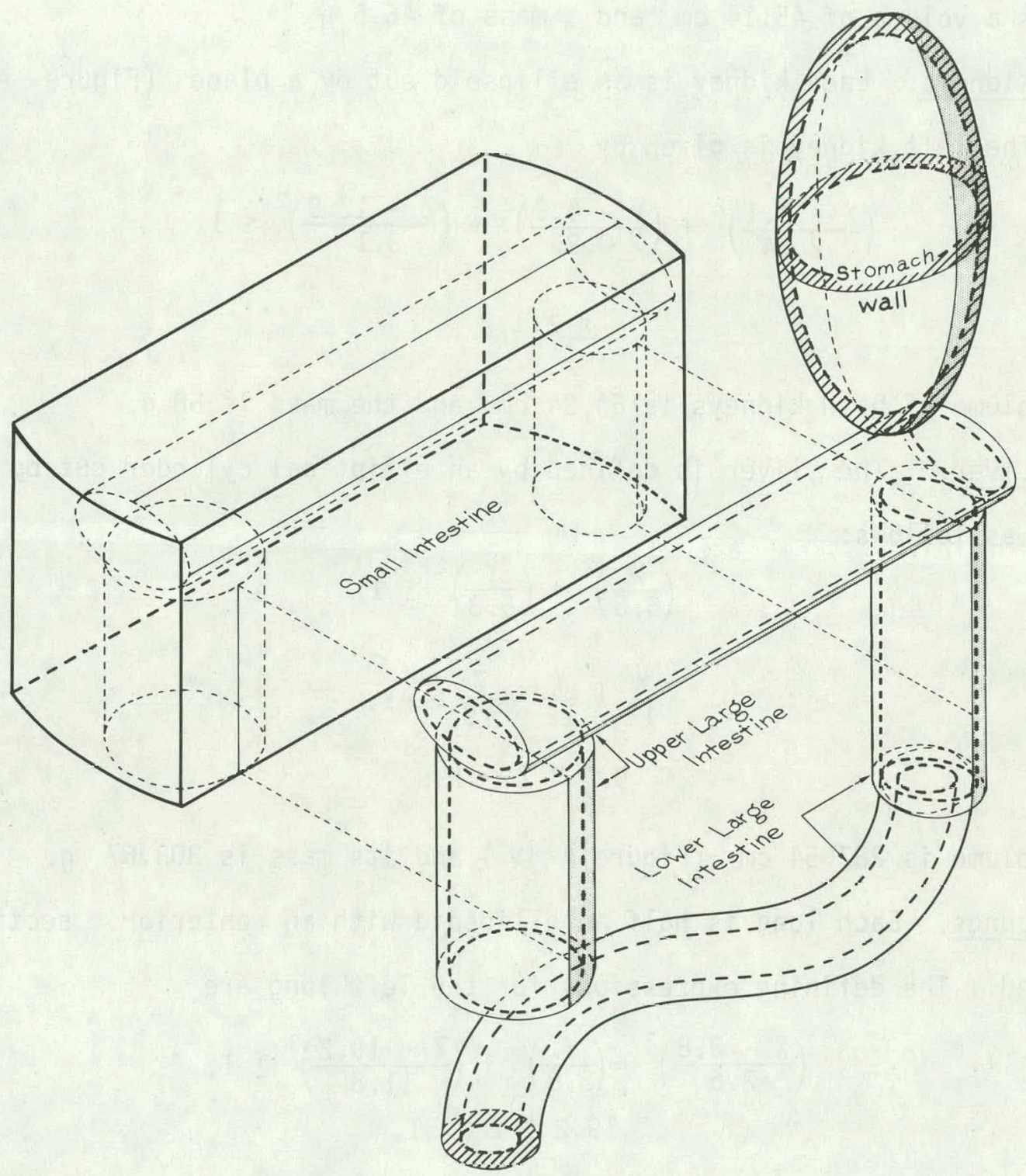

FIGURE A-V. MATHEMATICAL MODEL FOR THE GASTROINTESTINAL TRACT. 


$$
\begin{aligned}
& x_{1}^{2}+y_{1}^{2}+z_{1}^{2} \leq(2.2)^{2} \text { if } x_{1}>0 \\
& \frac{x_{1}}{1.2}+\frac{z_{1}}{2.2} \geq-1 \text { if } x_{1}<0 .
\end{aligned}
$$

It has a volume of $45.14 \mathrm{~cm}^{3}$ and a mass of $46.5 \mathrm{~g}$.

Kidneys. Each kidney is an ellipsoid cut by a plane (Figure AIII). The left kidney is given by

$$
\begin{gathered}
\left(\frac{x-3.1}{2.84}\right)^{2}+\left(\frac{Y-4.2}{0.95}\right)^{2}+\left(\frac{L-12.9}{3.1}\right)^{2} \leq 1, \\
x \geq 1.2 .
\end{gathered}
$$

The volume of both kidneys is $64.94 \mathrm{~cm}^{3}$ and the mass is $68 \mathrm{~g}$.

Liver. The liver is defined by an elliptical cylinder cut by a plane as follows:

$$
\begin{gathered}
\left(\frac{X}{6.5}\right)^{2}+\left(\frac{Y}{5.3}\right)^{2} \leq 1 \\
\frac{X}{12}+\frac{Y}{12}-\frac{Z}{19} \leq-1, \\
9.8 \leq z \leq 19 .
\end{gathered}
$$

Its volume is $287.54 \mathrm{~cm}^{3}$ (Figure A-IV) and its mass is $303.67 \mathrm{~g}$.

Lungs. Each lung is half an ellipsoid with an anterior section removed. The defining expressions for the left lung are

$$
\begin{gathered}
\left(\frac{X-3.8}{2.5}\right)^{2}+\left(\frac{Y}{3.8}\right)^{2}+\left(\frac{Z-19.2}{11.8}\right)^{2} \leq 1, \\
19.2 \leq Z \leq 31, \\
\left(\frac{X-0.6}{2.5}\right)^{2}+\left(\frac{Y}{3.8}\right)^{2}+\left(\frac{Z-19.2}{11.8}\right)^{2} \geq 1 \quad \text { if } Y<0 .
\end{gathered}
$$

The volume of both lungs is $429.4 \mathrm{~cm}^{3}$ (Figure A-IV) and the mass is $128.8 \mathrm{~g}$. 
Ovaries. Each ovary is an ellipsoid (Figure A-VI). The left ovary is given by

$$
\left(\frac{X-2.6}{0.42}\right)^{2}+\left(\frac{Y}{0.21}\right)^{2}+\left(\frac{z-6.4}{0.84}\right)^{2} \leq 1
$$

The volume of both ovaries is $0.62 \mathrm{~cm}^{3}$ and the mass is $0.65 \mathrm{~g}$.

Pancreas. The pancreas is half an ellipsoid with a section removed (Figure $A$-III). It is defined by

$$
\begin{aligned}
&\left(\frac{X+1}{7.5}\right)^{2}+\left(\frac{Y}{0.5}\right)^{2}+\left(\frac{Z-15.9}{1.6}\right)^{2} \leq 1, \\
& x \geq 1, \\
& Z \geq 15.9 \quad \text { if } \quad x \geq 0.5 .
\end{aligned}
$$

It has a volume of $8.58 \mathrm{~cm}^{3}$ and a mass of $8.99 \mathrm{~g}$.

Skin. Skin is represented as a layer of $0.2 \mathrm{~cm}$ thickness extending over the entire exterior of the phantom. Thus this corresponds to the dermis as well as the epidermis. The back is the only major body area where the thickness is larger, being about double. The volume of skin is $770 \mathrm{~cm}^{3}$ and the mass is $760 \mathrm{~g}$.

spleen. The spleen is defined by the ellipsoid

$$
\left(\frac{X-4.2}{1.8}\right)^{2}+\left(\frac{Y-2.1}{1.1}\right)^{2}+\left(\frac{Z-15.9}{3.1}\right)^{2} \leq 1
$$

and has a volume of $25.7 \mathrm{~cm}^{3}$ and a mass of $27.3 \mathrm{~g}$ (Figure A-III).

Testicles. The testicles are ellipsoid ( $\Gamma$ igure A-VI), which are represented by the inequalties

$$
\left(\frac{X \pm 0.4}{0.4}\right)^{2}+\left(\frac{Y+3.5}{0.6}\right)^{2}+\left(\frac{Z+0.7}{0.7}\right)^{2} \leq 1
$$




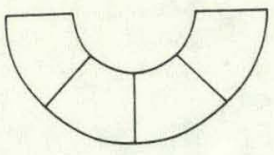

TOP VIEW

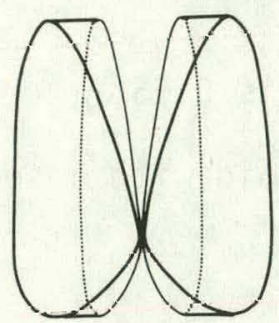

FRONT VIEW

THYROID

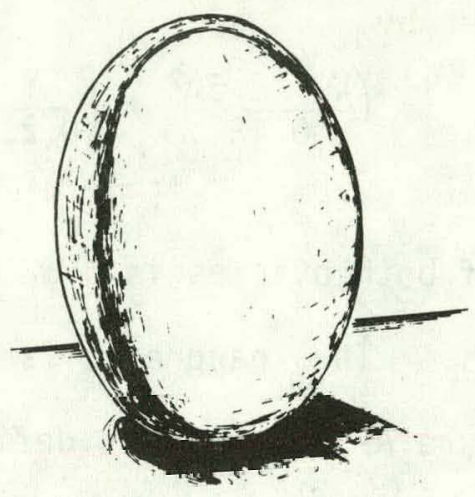

TFSTIS
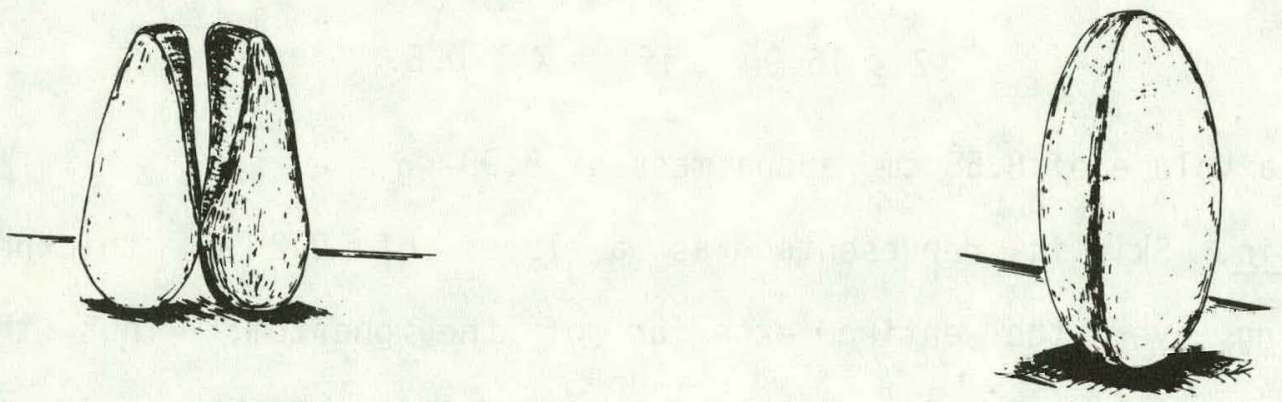

THYROID

OVARY
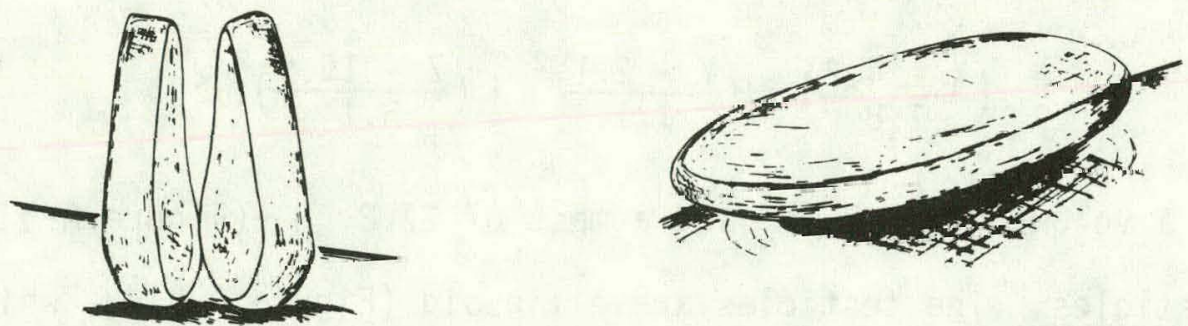

THYROID

THYMUS

FIGURE A-VI. MATHEMATICAL MODELS FOR THE THYROID, TESTES, OVARIES, AND THYMUS. 
where the plus sign is used for the right testicle and the minus sign for the left. The volume of the testicles is $1.4 \mathrm{~cm}^{3}$ and the mass of both is $1.47 \mathrm{~g}$.

Thymus. The thymus is formed by the ellipsoid

$$
\left(\frac{X+0.9}{2.85}\right)^{2}+\left(\frac{Y+4.2}{0.47}\right)^{2}+\left(\frac{Z-26.6}{3.8}\right)^{2} \leq 1,
$$

and it has a volume of $21.33 \mathrm{~cm}^{3}$ (Figure A-VI) and a mass of 21.87 g.

Thyroid. The lobes of the thyroid lie between two concentric cylinders and are formed by a cutting surface (Figure A-VI and Figure A-VII). The expressions for this organ are

$$
\begin{gathered}
X^{2}+(Y+4.8)^{2} \leq(1.6)^{2}, \\
X^{2}+(Y+4.8)^{2} \geq(1.4)^{2}, \\
Y+4.8 \leq 0, \\
32 \leq Z \leq 35.6, \\
[(Y+4.8)-|X|]]^{2} \geq 2\left[X^{2}+(Y+4.8)^{2}\right] \tau^{2},
\end{gathered}
$$

in which

$$
\tau=\frac{5}{9}(\sqrt{2}-2)(Z-32)+1 \text { for } 0 \leq Z-32 \leq \frac{9}{10}
$$

and

$$
\tau=\frac{5(2-\sqrt{2})}{27}(7-32)+\frac{2 \sqrt{2}-1}{3} \text { for } \frac{9}{10}<z-32 \leq \frac{18}{5}
$$

The volume is $2.26 \mathrm{~cm}^{3}$ and the mass is $2.38 \mathrm{~g}$.

Uterus. The uterus is an ellipsoid cut by a plane and is given by 


\section{SECTIONS BY THE PLANES:}

(a)

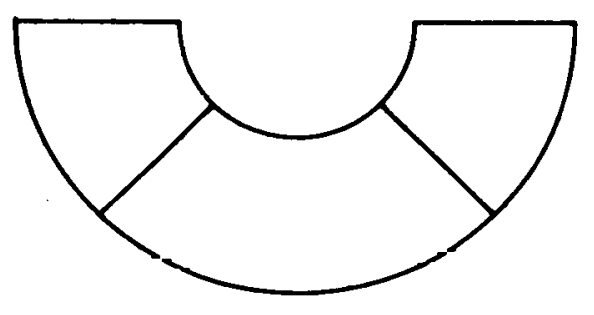

(b)

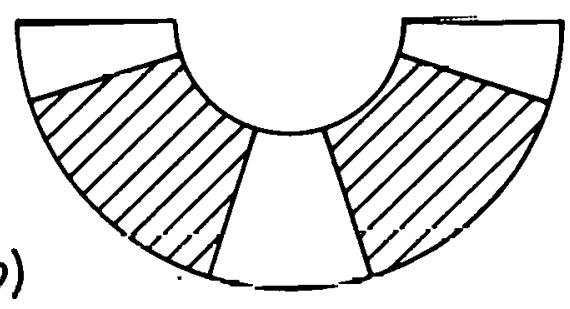

(c)

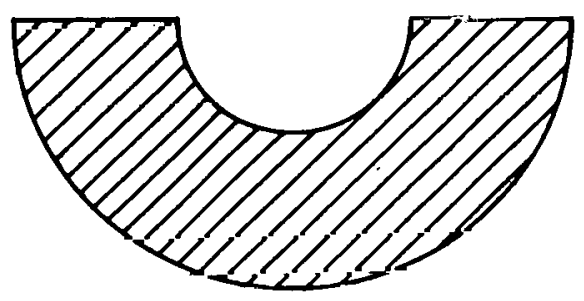

$(d)$

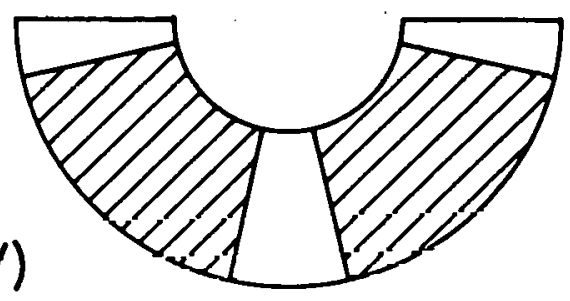

\begin{tabular}{|c|c|c|}
\hline & ONE-YEAR & FIVE-YEAR \\
\hline (A) & $Z=32, \quad Z=35.6$ & $Z=42, \quad Z=46.2$ \\
\hline (B) & $Z=32.36$ & $Z=42.42$ \\
\hline (c) & $Z=32.9$ & $Z=43.05$ \\
\hline (D) & $Z=34.16$ & $Z=44.52$ \\
\hline
\end{tabular}

FIGURE A-VII. SECTIONS OF THE MATHEMATICAL THYROID AT VARIOUS HEIGHTS FOR THE CHILDREN PHANTOMS. 


$$
\begin{gathered}
\frac{X}{0.7}^{2}+\frac{Y+0.56}{1.4}{ }^{2}+\frac{Z-5.9}{0.42}{ }^{2} \leq 1, \\
Y \geq-1.26 .
\end{gathered}
$$

It has a volume of $1.45 \mathrm{~cm}^{3}$ (Figure A-III) and a mass of $1.53 \mathrm{~g}$. 


\section{DESCRIPTION OF THE FIVE-YEAR-OLD MATHEMATICAL \\ CHILD PHANTOM}

\section{Exterior of the Phantom}

Trunk. The volume of the trunk section (shown in Figure B-I) is $11,901.6 \mathrm{~cm}^{3}$ and the mass is $11,554.1 \mathrm{~g}$. It is specified by

$$
\begin{gathered}
\left(\frac{X}{11}\right)^{2}+\left(\frac{Y}{8.2}\right)^{2} \leq 1, \\
0 \leq z \leq 42 .
\end{gathered}
$$

Head. The volume of the head section is $3,170.8 \mathrm{~cm}^{3}$ and the mass is $3,462.5 \mathrm{~g}$. It is specified by

$$
\begin{gathered}
\left(\frac{X}{6.8}\right)^{2}+\left(\frac{y}{8.8}\right)^{2} \leq 1, \\
42 \leq Z \leq 54,
\end{gathered}
$$

or

$$
\left(\frac{x}{6.8}\right)^{2}+\left(\frac{y}{8.8}\right)^{2}+\left(\frac{z-54}{7.3}\right)^{2} \leq 1
$$

$54 \leq z \leq 61.3$.

Legs. The total volume of both legs is $4,511.8 \mathrm{~cm}^{3}$ and the mass is $4,755.5 \mathrm{~g}$. The leg reginn is specified by

$$
\begin{gathered}
x^{2}+y^{2} \leq \pm x\left(11+\frac{z}{6.67}\right), \\
-50 \leq z \leq 0,
\end{gathered}
$$

where the plus sign defines the left leg and the minus sign the right.

Genitalia. The genitalia region has a volume of $37.86 \mathrm{~cm}^{3}$ and a mass of $37.36 \mathrm{~g}$. It is specified by 
89

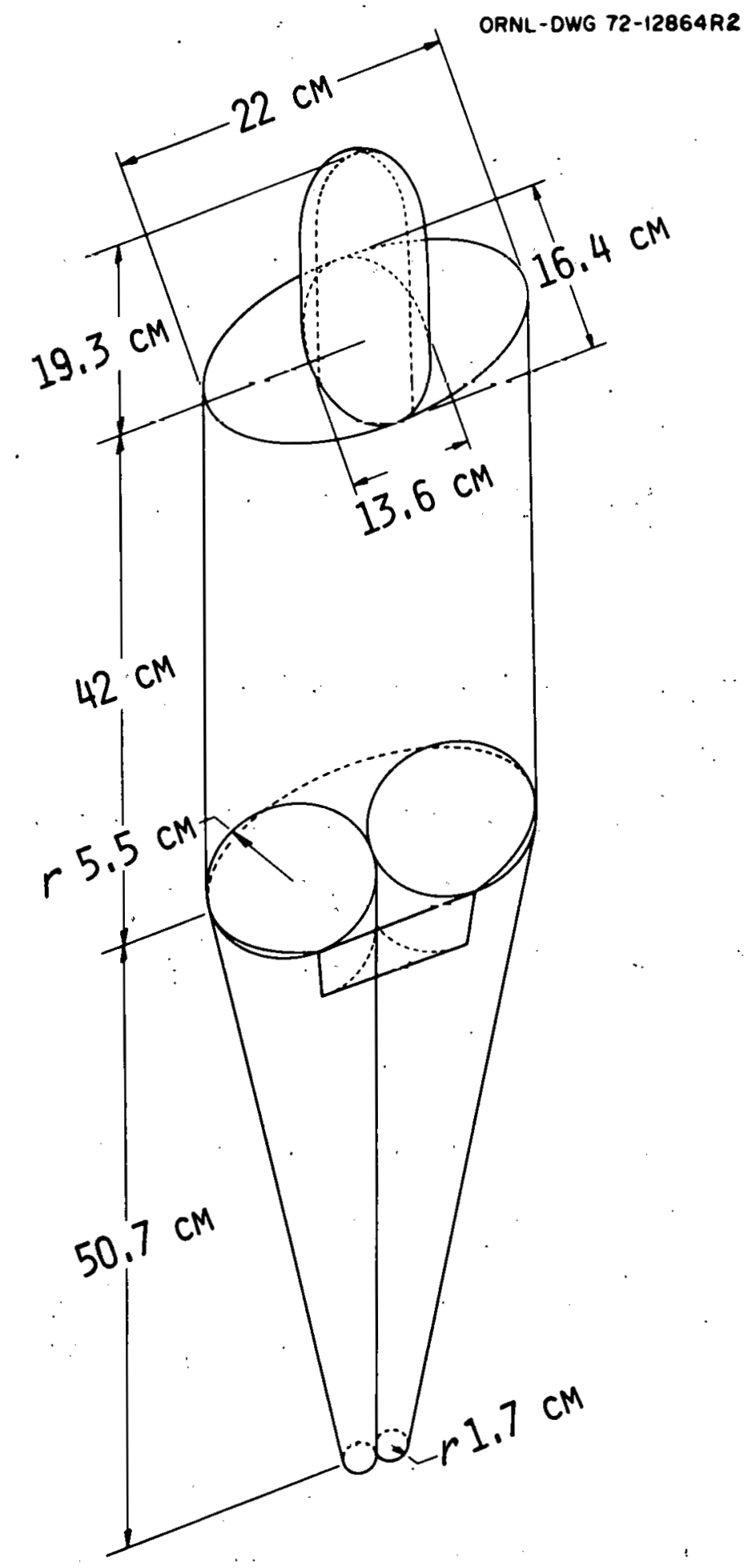

FIGURE BI. THE FIVE-YEAR OLD PHANTOM. 


$$
\begin{gathered}
-3.04 \leq z \leq 0, \\
-\left(5.5+\frac{Z}{13.34}\right) \leq X \leq\left(5.5+\frac{Z}{13.34}\right), \\
-\left(5.5+\frac{Z}{13.34}\right) \leq y \leq 0,
\end{gathered}
$$

and

$$
x \pm\left(5.5+\frac{Z}{13.34}\right)^{2}+y^{2} \geq\left(5.5+\frac{Z}{13.34}\right)^{2}
$$

Organs

Skeleton System. The skeletal system consists of the twelve parts described below.

Leg Bones. The volume of both bones is $588 \mathrm{~cm}^{3}$ and the mass is $823.2 \mathrm{~g}$. The expression for the left leg bone is

$$
x-\left(5.5-\frac{3.8}{50.5} z\right)^{2}+y^{2} \leq\left(2+\frac{1.4}{50.5} z\right)^{2} \text {, }
$$

and

$$
-50.5 \leq Z \leq 0 .
$$

Arm Bones. The volume of both arm bones is $181.2 \mathrm{~cm}^{3}$ and the mass is $253.7 \mathrm{~g}$. The left one is defined by

$$
\left[\frac{(0.8 / 82.4)(Z-41.2)+(X-10)}{0.8}\right]^{2}+\left(\frac{Y}{1.5}\right)^{2} \leq\left[\frac{82.4+(Z-41.2)}{82.4}\right]^{2},
$$

and

$$
0 \leq Z \leq 41.2 .
$$

Pelvis. The volume of the pelvis is $174.43 \mathrm{~cm}^{3}$ and the mass is 244.2 g. It is described by 


$$
\begin{gathered}
X^{2}+(Y+1.9)^{2} \leq 7.6^{2} \\
X^{2}+(Y+2.4)^{2} \geq 7^{2} \\
Y+1.9 \geq 0 \\
0 \leq Z \leq 13 \\
Y \leq 3.2 \quad \text { if } Z \leq 8.3 .
\end{gathered}
$$

Spine. The spine has a volumie of $258 \mathrm{~cm}^{3}$ and a mass of $361 \mathrm{~g}$. It is defined by

$$
\left(\frac{X}{1.4}\right)^{2}+\left(\frac{Y-4.5}{1.7}\right)^{2} \leq 1
$$

and

$$
13 \leq Z \leq 47.5 \text {. }
$$

Skull. The skull has a volume of $542 \mathrm{~cm}^{3}$ and a mass of 758.8 g. It is defined by

$$
\begin{aligned}
& \left(\frac{X}{6}\right)^{2}+\left(\frac{Y}{8}\right)^{2}+\left(\frac{Z-54.8}{5.7}\right)^{2} \geq 1, \\
& \left(\frac{X}{6.6}\right)^{2}+\left(\frac{Y}{8.6}\right)^{2}+\left(\frac{Z-54}{7.1}\right)^{2} \leq 1 .
\end{aligned}
$$

Rib Cage. The total rib volume is $212.8 \mathrm{~cm}^{3}$ and the mass is 298

g. The statements that must be satisfied are

$$
\begin{aligned}
& \left(\frac{X}{9.2}\right)^{2}+\left(\frac{Y}{8}\right)^{2} \leq 1, \\
& \left(\frac{X}{8.8}\right)^{2}+\left(\frac{Y}{7.6}\right)^{2} \geq 1, \\
& 21.1 \leq Z \leq 40.42 ;
\end{aligned}
$$

$$
\text { Integer }\left(\frac{z-21.1}{0.84}\right) \quad \text { is even. }
$$


Clavicles. The volume of both clavicles is $15.86 \mathrm{~cm}^{3}$, and the mass is about $22.0 \mathrm{~g}$. The clavicles include only the portion of the torus between the planes $22-Y=|X| \cot \theta$ with $=7042.59$ and $\theta=4^{0}$ $34.43^{\circ}$. The equation can be reduced to the form

$$
(Z-41.10)^{2}+\left(9.2-\sqrt{X^{2}+(Y-2.2)^{2}}\right)^{2} \leq(0.4875)^{2}
$$

and

$$
0.350002359 \leq \frac{2.2-Y}{|X|} \leq 12.5002413, \quad Y \leq 0 .
$$

They are shown schematically in Figure A-II (page 72).

Scapulae. One scapula has a volume of $27.5 \mathrm{~cm}^{3}$ and a mass of $38.5 \mathrm{~g}$. The scapulae arc included in Figure A-II (page 72). They are expressed by

and

$$
\begin{gathered}
\left(\frac{X}{9.2}\right)^{2}+\left(\frac{Y}{8}\right)^{2} \geq 1, \\
\left(\frac{X}{10.2}\right)^{2}+\left(\frac{Y}{8}\right)^{2} \leq 1, \\
Y>0 \\
0.25<\frac{Y}{T X T}<0.80,
\end{gathered}
$$

$$
30.57 \leq Z \leq 40.42 \text {. }
$$

Adrenals. The volume of both adrenals is $5.97 \mathrm{~cm}^{3}$ (Figure AIII, page 75), and the mass is $6.12 \mathrm{~g}$. The left adrenal is given by

$$
\left(\frac{x-2.7}{1.1}\right)^{2}+\left(\frac{Y-5.3}{0.36}\right)^{2}+\left(\frac{Z-22}{3.6}\right)^{2} \leq 1,
$$

and 
Urinary Bladder and Contents. The bladder is described by

$$
\begin{aligned}
& \left(\frac{X}{3.3}\right)^{2}+\left(\frac{Y+3.1}{2.3}\right)^{2}+\left(\frac{Z-4.9}{2.3}\right)^{2} \leq 1, \\
& \left(\frac{X}{3.12}\right)^{2}+\left(\frac{Y+3.1}{2.12}\right)^{2}+\left(\frac{Z-4.9}{2.12}\right)^{2} \geq 1,
\end{aligned}
$$

The volume is $14.38 \mathrm{~cm}^{3}$ and the mass is $14.2 \mathrm{~g}$. The contents have a volume of $58.7 \mathrm{~cm}^{3}$ and a mass of $58 \mathrm{~g}$. The bladder is shown in Figure A-III (page 75).

Brain. The brain is given by

$$
\left(\frac{X}{6}\right)^{2}+\left(\frac{Y}{8}\right)^{2}+\left(\frac{Z-54.8}{5.7}\right)^{2} \leq 1
$$

and the volume is $1,146 \mathrm{~cm}^{3}$ and the mass is $1,179 \mathrm{~g}$ (Figure A-V, page 81). Gastrointeslinal Tract and Contents-Stomach (S). The stomach is described by

$$
\left(\frac{X-4.9}{2.9}\right)^{2}+\left(\frac{Y+3}{2.2}\right)^{2}+\left(\frac{Z-19.8}{5.8}\right)^{2} \leq 1
$$

and

$$
\left(\frac{X-4.9}{2.53}\right)^{2}+\left(\frac{Y+3}{1.83}\right)^{2}+\left(\frac{Z-19.8}{5.43}\right)^{2} \geq 1
$$

The volume if $49.7 \mathrm{~cm}^{3}$, and the mass is $52.2 \mathrm{~g}$; the contents have a volume of $105.3 \mathrm{~cm}^{3}$ and a mass of $103.9 \mathrm{~g}$. The thickness of the stomach wall is about $0.37 \mathrm{~cm}$. 
-Small Intestine (SI). The total mass is $175.95 \mathrm{~g}$, and the corresponding volume is about $178.3 \mathrm{~cm}^{3}$. The small intestine lies in the pelvic region and is given by

$$
\begin{gathered}
X^{2}+(Y+2.4)^{2} \leq 7^{2} \\
-2.9 \leq Y \leq 2.0 \\
10 \leq Z \leq 14 .
\end{gathered}
$$

-Upper Large Intestine (ULI). The ascending colon is defined by

$$
\begin{gathered}
(X+5.2)^{2}+(Y+1.4)^{2} \leq(1.5)^{2} \\
(X+5.2)^{2}+(Y+1.4)^{2} \geq(0.95)^{2} \\
8 \leq Z \leq 12.2 .
\end{gathered}
$$

The wall has a total volume of $17.78 \mathrm{~cm}^{3}$ and a mass of $18.54 \mathrm{~g}$. The inequalitics

$$
\begin{gathered}
(x+5.2)^{2}+(\gamma+1.4)^{2} \leq(0.95)^{2} \\
8 \leq Z \leq 12.2 .
\end{gathered}
$$

define the contents of the ascending colnn. The volumc is $11.9 \mathrm{~cm}^{3}$, and the mass is $11.75 \mathrm{~g}$. The thickness of the wall according to this model is $0.55 \mathrm{~cm}$.

The transverse colon is defined by

$$
\begin{aligned}
& \left(\frac{Y+1.4}{1.5}\right)^{2}+\left(\frac{Z-13.1}{0.9}\right)^{2} \leq 1 \\
& \left(\frac{Y+1.4}{1.18}\right)^{2}+\left(\frac{Z-13.1}{0.58}\right)^{2} \geq 1
\end{aligned}
$$

$-6.4 \leq x \leq 6.4$. 
The volume of the wall is $26.76 \mathrm{~cm}^{3}$ and the mass is $27.9 \mathrm{~g}$. The thickness is about $0.32 \mathrm{~cm}$. The contents are specified by

$$
\begin{gathered}
\left(\frac{Y+1.4}{1.18}\right)^{2}+\left(\frac{Z-13.1}{0.58}\right)^{2} \leq 1 \\
-6.4 \leq Z \leq 6.4 .
\end{gathered}
$$

The volume is $27.5 \mathrm{~cm}^{3}$, and the mass is $27.2 \mathrm{~g}$.

-Lower Large Intestine (LLI). The descending colon is described by the inequalities

$$
\begin{aligned}
& \left(\frac{X-X_{0}}{1.1}\right)^{2}+\left(\frac{Y-Y_{0}}{1.26}\right)^{2} \leq 1 \\
& \left(\frac{X-X_{0}}{0.85}\right)^{2}+\left(\frac{Y-Y_{0}}{0.7}\right)^{2} \geq 1
\end{aligned}
$$

$$
5.1 \leq Z \leq 12.2
$$

where

$$
\begin{aligned}
& x_{0}=5.35+\frac{0.25(z-12.2)}{7.1} \\
& y_{0}=\frac{1.55(5.1-z)}{7.1}
\end{aligned}
$$

The descending colon has a voluilie of $17.64 \mathrm{~cm}^{3}$ and a mass of $18.4 \mathrm{~g}$. The thickness of the wall would vary between $0.25 \mathrm{~cm}$ and $0.56 \mathrm{~cm}$ according to this model.

The sigmoid colon is defined by the inequalities (upper portion).

$$
\begin{aligned}
& \left(\sqrt{(x-1.75)^{2}+(z-5.1)^{2}}-3.35\right)^{2}+y^{2} \leq 1^{2} \\
& \left(\sqrt{(x-1.75)^{2}+(z-5.1)^{2}}-3.35\right)^{2}+y^{2} \geq(0.42)^{2}
\end{aligned}
$$




$$
x \geq 1.75 \text { and } z \leq 5.1
$$

and (lower portion)

$$
\begin{gathered}
\left(\sqrt{(x-1.75)^{2}+Z^{2}}-1.75\right)^{2}+y^{2} \leq 12 \\
\left(\sqrt{(x-1.75)^{2}+Z^{2}}-1.75\right)^{2}+y^{2} \geq(0.42)^{2} \\
x \leq 1.75 \text { and } z \geq 0 .
\end{gathered}
$$

The volume of the sigmoid colon is $20.73 \mathrm{~cm}^{3}$, and the mass is 21.62 g. The thickness of the wall would be $0.58 \mathrm{~cm}$ according to this model.

The entire gastrointestinal tract is sketched in Figure $A-V$ (page 81 ).

Heart. The heart (Figure A-IV, page 77.) is represented by

$$
\begin{aligned}
& X_{1}=0.6634(X+0.5)-0.3830(Y+2.1)-0.6428(Z-29.4) \text {, } \\
& Y_{1}=0.5(X+0.5)+0.8660(Y+2.1) \text {, } \\
& Z_{1}=0.5567(X+0.5)-0.3214(Y+2.1)+0.7660(Z-29.4) \text {, } \\
& \left(\frac{X_{1}}{4.3}\right)^{2}+\left(\frac{Y_{1}}{2.7}\right)^{2}+\left(\frac{Z_{1}}{2.7}\right)^{2} \leq 1 \\
& x_{1}^{2}+y_{1}^{2}+z_{1}^{2} \leq(2 . \overline{7})^{2} \text { if } x_{1}<0 \text {, } \\
& \frac{x_{1}}{1.8}+\frac{z_{1}}{2.7} \geq-1 \text { if } x_{1}<0 \text {. }
\end{aligned}
$$

It has a volume of $88.5 \mathrm{~cm}^{3}$ and a mass of $91.15 \mathrm{~g}$.

Kidneys. The volume of both kidneys is $110.2 \mathrm{~cm}^{3}$ and the mass is $115.5 \mathrm{~g}$. The left kidney (Figure A-III, page 75) is given by

$$
\begin{gathered}
\left(\frac{X-3.8}{3.2}\right)^{2}+\left(\frac{Y-4.9}{1.1}\right)^{2}+\left(\frac{Z-18}{4}\right)^{2} \leq 1, \\
x \geq 1.6 .
\end{gathered}
$$


Liver. The liver (Figure A-IV, page 77) is defined by

$$
\begin{gathered}
\left(\frac{X}{8.5}\right)^{2}+\left(\frac{Y}{6.8}\right)^{2} \leq 1, \\
\frac{X}{18}+\frac{Y}{18}-\frac{Z}{25.6} \leq-1, \\
14 \leq z \leq 25.6 .
\end{gathered}
$$

Its volume is $575.89 \mathrm{~cm}^{3}$ and its mass is $608 \mathrm{~g}$.

Lungs. The defining expressions for the left lung are

$$
\begin{gathered}
\left(\frac{X-4.8}{3.2}\right)^{2}+\left(\frac{Y}{4.8}\right)^{2}+\left(\frac{Z-26}{14.8}\right)^{2} \leq 1 \\
\left(\frac{X-1.0}{3.2}\right)^{2}+\left(\frac{Y}{4.8}\right)^{2}+\left(\frac{Z-26}{14.8}\right)^{2} \geq 1 \text { if } Y<0 .
\end{gathered}
$$

The volume of both lungs is $850 \mathrm{~cm}^{3}$ (Figure A-IV, page 77) and the mass is $255 \mathrm{~g}$.

Ovaries. The volume of both ovaries (Figure A-VI, page 84 ) is 1.81 $\mathrm{cm}^{3}$ and the mass is $1.89 \mathrm{~g}$. The left ovary is given by

$$
\left(\frac{X-3.3}{0.6}\right)^{2}+\left(\frac{Y}{0.3}\right)^{2}+\left(\frac{Z-8.8}{1.2}\right)^{2} \leq 1
$$

Pancreas. The pancreas (Figure A-III, nage 77) which has a volume of $18 \mathrm{~cm}^{3}$ and a mass of $18.9 \mathrm{~g}$. is defined by

$$
\begin{gathered}
\left(\frac{X+0.7}{9.2}\right)^{2}+\left(\frac{Y}{0.66}\right)^{2}+\left(\frac{Z-21.7}{2.1}\right)^{2} \leq 1, \\
x \geq-0.7, \\
Z \geq 21.7 \quad \text { if } \quad x \geq 1.1 .
\end{gathered}
$$

Skin. The volume of skin is $1286 \mathrm{~cm}^{3}$ and has a mass of $1269 \mathrm{~g}$.

Spleen. The spleen (Figure A-III, page 77 ) which has a volume of $46.72 \mathrm{~cm}^{3}$ and a mass of $49.6 \mathrm{~g}$ is defined by 


$$
\left(\frac{X-5.5}{2.2}\right)^{2}+\left(\frac{Y-2.5}{1.3}\right)^{2}+\left(\frac{Z-21.7}{3.9}\right)^{2} \leq 1 .
$$

Testicles. The testicles (Figure A-VI, page 84 ) with a total volume of $1.53 \mathrm{~cm}^{3}$ and a total mass of $1.6 \mathrm{~g}$ are defined by the inequalities

$$
\left(\frac{X \pm 0.41}{0.41}\right)^{2}+\left(\frac{Y+4.68}{0.62}\right)^{2}+\left(\frac{Z+0.72}{0.72}\right)^{2} \leq 1
$$

where the plus sign is used for the right testicle and the minus sign fur the left.

Thymus. The thymus. (Figure A-VI, page 84.) with a volume of $28.9 \mathrm{~cm}^{3}$ and a mass of $30.6 \mathrm{~g}$ is defined by

$$
\left(\frac{X+1.1}{3.2}\right)^{2}+\left(\frac{Y+4.9}{0.53}\right)^{2}+\left(\frac{Z-36}{4.2}\right)^{2} \leq 1 .
$$

Thyroid. The expression for the thyroid (Figure A-VI and A-VII, pages

84 and 86$)$ are

$$
\begin{gathered}
X^{2}+(Y+5.3)^{2} \leq(1.9)^{2}, \\
X^{2}+(Y+5.3)^{2} \geq(1.6)^{2}, \\
Y+5.3 \leq 0 \\
42 \leq Z \leq 46.2, \\
{[(Y+5.3)-|X|]^{2}-2\left[X^{2}+(Y+5.3)^{2}\right] \mathrm{i}^{2},}
\end{gathered}
$$

in which

$$
\tau=\frac{10}{21}(\sqrt{2}-2)(Z-42)+1 \text { for } 0 \leq Z-42 \leq 1.05
$$

and

$$
\tau=\frac{10(2-\sqrt{2})}{63}(Z-42)+\frac{2 \sqrt{2}-1}{3} \text { for } 1.05 \leq Z-42 \leq 4.2 \text {. }
$$

The volume is $4.62 \mathrm{~cm}^{3}$ and the mass is $4.85 \mathrm{~g}$. 
Uterus. The uterus (Figure A-III, page 75) with a volume of 2.47 $\mathrm{cm}^{3}$ and a mass of $2.6 \mathrm{~g}$ is defined by

$$
\begin{gathered}
\left(\frac{X}{0.84}\right)^{2}+\left(\frac{Y+0.67}{1.67}\right)^{2}+\left(\frac{Z-8.6}{0.5}\right)^{2} \leq 1, \\
Y \geq-1.5 .
\end{gathered}
$$




\section{THIS PAGE}

\section{WAS INTENTIONALLY LEFT BLANK}


INTERNAL DISTRIBUTION

1-2. Central Research Library

3. Document Reference Section

4-6. Laboratory Records Department

7. Laboratory Records, ORNL R.C.

8. ORNL Patent Office

9. Research and Technical Support Div.

10-36. Technical Information Center.

37. J. A. Auxier

38. S. R. Bernard

39: M. F. Fair

40. M. R. Ford

41. F. F. Haywood

42. J. L. Hwang
43. D. G: Jacobs
44. T. D. Jones
45. G. D. Kerr
46. S. K. Penny
47-71. J. W. Poston
72. C. R. Richmond
73-87. R. L. Shoup
88. W. S. Snyder
89. P. S. Stansbury
90. S. B. Watson
91. G. G. Warner
92. H. A. Wright

\section{EXTERNAL DISTRIBUTION}

93. S. James Adelstein, Shields Warren Radiology Lab., 50 Binney St. , Boston, Mass. 02115.

94. Monte Blau, Roswell Park Memorial Institute, Dept. of Nuclear Medicine, 666 Elm Street, Buffalo, NY 14203.

95. Mones Berman, National Cancer Institute of Health, Building 10, Room 4B-56, Bethesda, MD 20014.

96. C. E. Carter, Division of Biomedical and Environmental Research, ERDA, Washington, D.C. 20545.

97. R. J. Cloutier, ORAU, Oak Ridge, Tennessee 37830

98. R. D. Cooper, Division of Biomedical and Environmental Research, ERDA, Washington, D.C. 20545.

99. Dr. George Cowper, Atomic Energy of Canada, Ltd., Chalk River, Ontario, Canada.

100. L. J. Deal, Asst. Director of Safety Protection, Division of Operational Safety, ERDA, Washington, D.C. 20545.

101. L. T. Dillman, Department of Physics, Ohio Wesleyan University, Delaware, Ohio 43015.

102. Mrs. Judy Glos, The Society of Nuclear Medicine, 475 Park Avenue South, New York, NY 10016.

103. Al exander Gottschalk, Department of Radiology, Yale University School of Medicine, 333 Cedar Street, New Haven, CT 06510.

104. R. J. Hart, Manager, Oak Ridge Operations.

105. Dr. Marguerite T. Hays, 151, Director of Medical Research Services, Veterans Administration, Department of Medicine and Surgery, Washington, D.C. 20420. 


\section{EXTERNAL DISTRIBUTION (CONT'D)}

106. R. Eugene Johnston, Dept. of Radiology, N.C.M.H., Division of Nuclear Medicine, University of North Carolina, Chapel Hill, N.C. 27514.

107. Dr. James Kereiakes, E555 Medical Sciences Building, University of Cincinnati, Cincinnati, Ohio 45267.

108. Katherine A. Lathrop, Frankl in McLean Memorial Research Institute, The Univ. of Chicago, 950 East 59th St., Box 420, Chicago, Ill. 60637.

109. Robert Loevinger, Radiation Physics Bldg., Room C210, National Bureau of Standards, Washington, D.C. 20234.

110. John G. McAfee, Division of Nuclear Medirine, Upstate Mcdical Center, 750 East Adams Street, Syracuse, NY 13210.

111. R. E. McLaughl in, Director, Radiation Physics Division, Health and Safety Laboratory, ERDA, New York Operations Office, 376 Hudson Street, New York, NY 10014.

112. K. Z. Morgan, School of Nuclear Engineering, Georgia Institute of Technology, Atlanta, Georgia 30332.

113. Dr. Peter Paras, Bureau of Radiological Health, Food and Drug Administration, 12720 Twinbrook Parkway, Rockville, MD 20852.

114. E. James Potchen, Office of the Dean, John Hopkins Medical School, $725 \mathrm{~N}$. Wolfe Street, Baltimore, MD 21205.

115. Robert H. Rohrer, Ph.D., Dept. of Physics, Emory University, Atlanta, Georgia 30322.

116. Dr. Marvin Rosenstein, Bureau of Radiological Health, Food and Drug Administration, 12720 Twinbrook Parkway, Rorkville, MD 20852.

117. W. W. Schroebel, Division of Biomedical and Environmental Research, ERDA, Washington, D.C. 20545.

118. Dr. Edward M. Smith, Execuitive Dir., MIRD Committee, 404 Church Ave, , Suite 15, Maryville, TN 37801.

119. Dr. L. V. Spencer, Center on Radiation Research, National Bureau Standards, Washington, D.C. 20234.

120. Dr. Betsy J. Stover, Division of Health Affairs, Department of Pharmacology, Swing Building, University of North Car.olina, Chapel Hill, North Carol ina 27514.

121. Dr. Roy L. Thumpson, B10logy Uept., Pacific Northwest Laboratories, Battelle, Richland, Washington 99352.

122. Jhhn C. Villforth, Bureau or Radlological Health, Food and Drug Administration, 12720 Twinbrook Parkway, Rockv1lie, MD 21205.

123. Robert W. Wood, Division of Biomedical and Environmental Research, Radiological Physics and Instrumentation Branch, ERDA, Washington, D.C. 20545. 